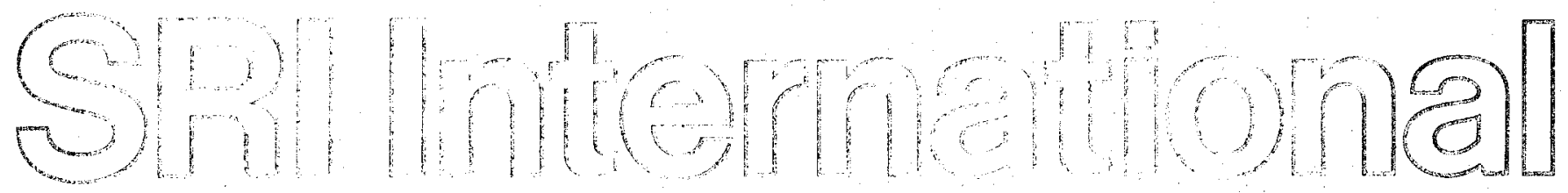

\title{
EVALUATION OF A DIFFUSION/TRAPPING MODEL FOR HYDROGEN INGRESS IN HIGH-STRENGTH ALLOYS
}

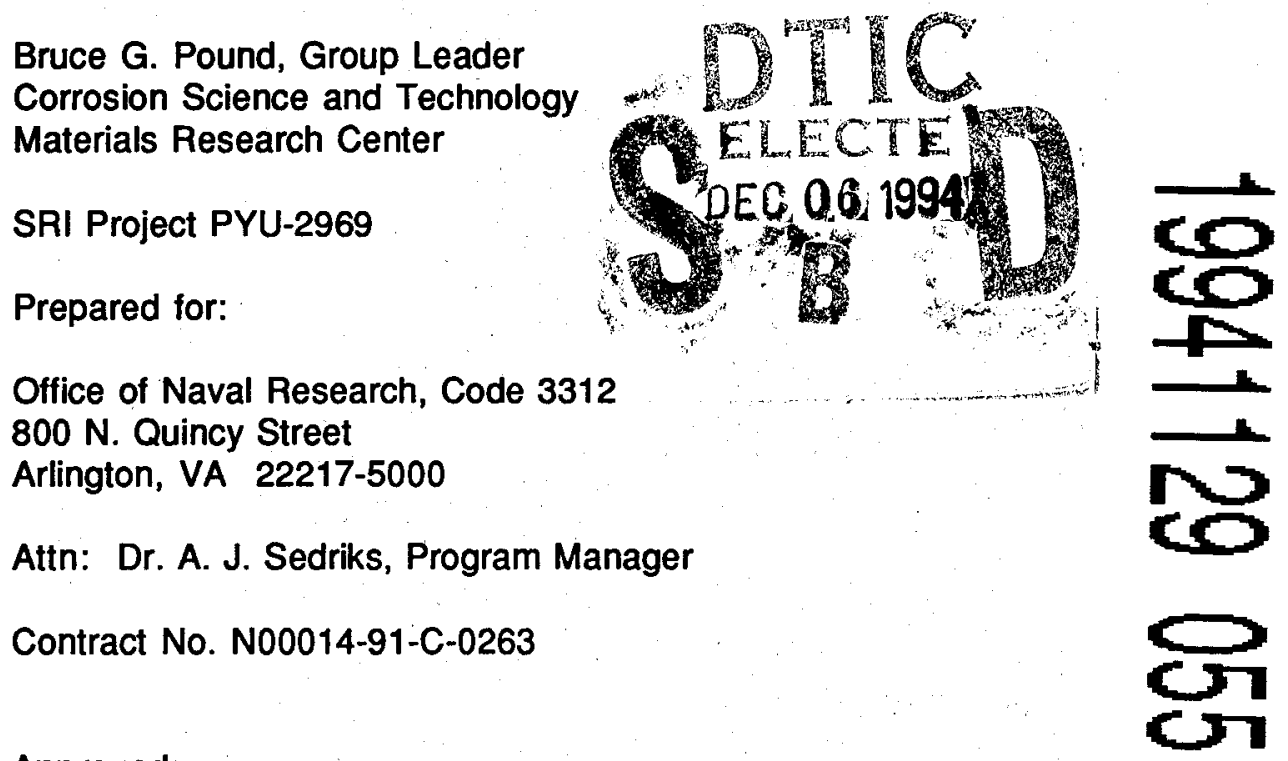

Approved:

R. Thomas Podoll

Laboratory Director

Materials and Chemical Engineering Laboratory

David M. Golden

Vice President

Physical Sciences Division

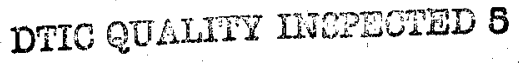

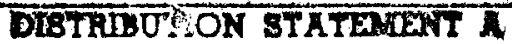

Approred for priblie relecres Dimirtbation Unlimited 


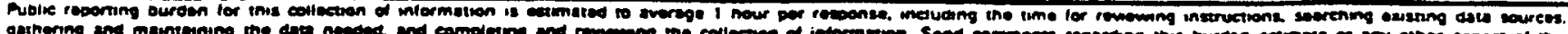

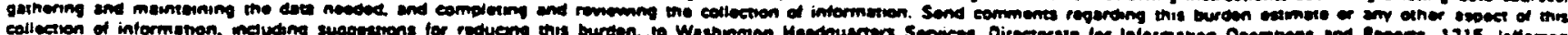

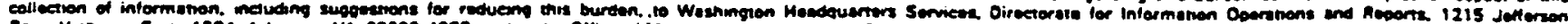

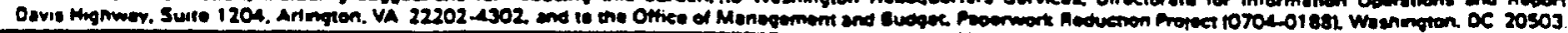

\begin{tabular}{l|l|l} 
1. AGENCY USE ONLY (Leave blank) & 2 REPORT DATE & 3. REPORT TYPE AND DATES COVERED
\end{tabular}

4. TRLEANO SUBRTLE in High-Strength Alloys.

6. AUTHOR(S)

Bruce G. Pound

7. PERFORMING ORGANIZATION NAME(S) AND AODAESS(ES)

SRI International

333 Ravenswood Ave.

15 Sept 93-14 Sept 94

Menlo Park, CA 94025

N00014-91-C-0263

\begin{tabular}{|c|c|}
\hline (2) & \\
\hline 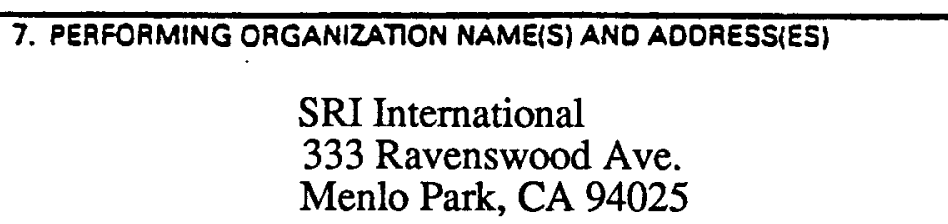 & $\begin{array}{l}\text { 8. PERFORMING ORGANIZATION } \\
\text { REPOAT NUMBER } \\
\text { PYU-2969 }\end{array}$ \\
\hline $\begin{array}{l}\text { 9. SPONSORING/MONITORING AGENCY NAMEIS) AND AODRESS(ES) } \\
\text { Office of Naval Research, Code } 3312 \\
\text { 800 N. Quincy St. } \\
\text { Arlington, VA 22217-5000 }\end{array}$ & $\begin{array}{l}\text { 10. SPONSORING/MONITORING } \\
\text { AGENCY REPORT NUMBER }\end{array}$ \\
\hline
\end{tabular}

11. SUPPLEMENTARY NOTES

12a. DISTRIBUTION/AVAILABIUTY STATEMENT

12b. DISTRIBUTION CODE

Approved for public release - distribution unlimited

13. ABSTRACT (Meximum 200 wards)

The ingress of hydrogen in various high-strength alloys was investigated with a view to characterizing their susceptibility to hydrogen embrittlement (HE). A potentiostatic pulse technique was applied to two precipitation-hardened iron-base alloys (AerMet 100 and alloy A-286), two Cu-containing alloys (Be-Cu and alloy K-500), and a superferritic stainless steel (UNS S44660) in $1 \mathrm{~mol} / \mathrm{L}$ acetic acid-1 mol/L sodium acetate. The data were analyzed using a diffusion/trapping model to obtain the irreversible trapping constant $(\mathrm{k})$ and hydrogen entry flux for each alloy. Irreversible trapping was negligible in overaged AerMet 100 but pronounced in the aged alloy. The order of the $\mathrm{k}$ values for AerMet 100 and two steels (4340 and 18Ni) previously studied inversely parallels their threshold stress intensities for stress corrosion cracking. Likewise, the $\mathrm{k}$ values of alloy A-286, $18 \mathrm{Ni}$ steel, and also alloy 718 from earlier work are consistent with test data for their relative resistance to HE. The results for AerMet 100 and alloy A-286 extend the previously reported correlation between $\mathrm{k}$ and $\mathrm{HE}$ resistance. Unaged $\mathrm{Be}-\mathrm{Cu}$ is intrinsically more susceptible to HE than unaged alloy K-500. The type of heat treatment has a marked effect on the trapping behavior of alloy K-500. The intrinsic susceptibility of the annealed and aged alloy is twice that for the direct-aged alloy. The propensity of the $\$ 44660$ alloy to undergo $\mathrm{HE}$ at cathodic protection potentials can be attributed to the absence of an oxide and hence the relatively unrestricted entry of $H$.

14. SUQUECT TERMS

Iron-Base Alloys, AerMet 100, Sea-Cure, Alloy A-286, Alloy K-500, Be-Cu Potentiostatic Pulse, Hydrogen Trapping, Trapping Model, Hydrogen Ingress
15. NUMBER OF PAGES 68

16. PRICE CODE
17. SECURITY CLASSIFICATION OF REPORT

UNCLASSIFIED
18. SECUAITY CLASSIFICATION OF THIS PAGE

UNCLASSIFIED
19. SECURITY CLASSIFICATION OF ABSTRACT

UNCLASSIFIED
20. UIMITATION OF ABSTRACT

UL 


\section{CONTENTS}

PREFACE.

EXECUTIVE SUMMARY.

1. HYDROGEN TRAPPING IN PRECIPITATION-HARDENED IRON-

BASE ALLOYS

Abstract.

Introduction

Experimental Procedure.

Results.

Discussion.

Irreversible Trapping Constants.

$1-4$

Comparison of Trapping Parameters

$1-8$

Summary

Identification of Irreversible Traps.

Acknowledgements

References.

1-12

Tables.

2. THE EFFECT OF AGING ON HYDROGEN TRAPPING IN COPPERCONTAINING ALLOYS

Abstract.....

Introduction

Experimental Procedure.

Results

Discussion.

Irreversible Trapping Constants.

Comparison of Ingress Characteristics

Identification of Irreversible Traps...

Summary

Acknowledgements

References.

Tables.

3. THE INGRESS OF HYDROGEN INTO A SUPERFERRITIC STAINLESS

STEEL

Abstract.

Introduction

Experimental Procedure.

Results

Discussion

Summary

Acknowledgements

References.

Tables. 
4. THE RESISTANCE OF HIGH-STRENGTH ALLOYS TO HYDROGEN EMBRITTLEMENT

Abstract.

Introduction

Experimental Procedure

Analysis

Results.

Discussion

Summary

Acknowledgements

References.

5. THE ROLE OF TRAPS IN DETERMINING THE RESISTANCE TO HYDROGEN EMBRITTLEMENT

Abstract.....

Introduction

Experimental Procedure.

Analysis

Susceptibility to HE

Identification of Traps

Precipitates/Inclusions

Segregants.

Interstitials

Hydrides.

Discussion

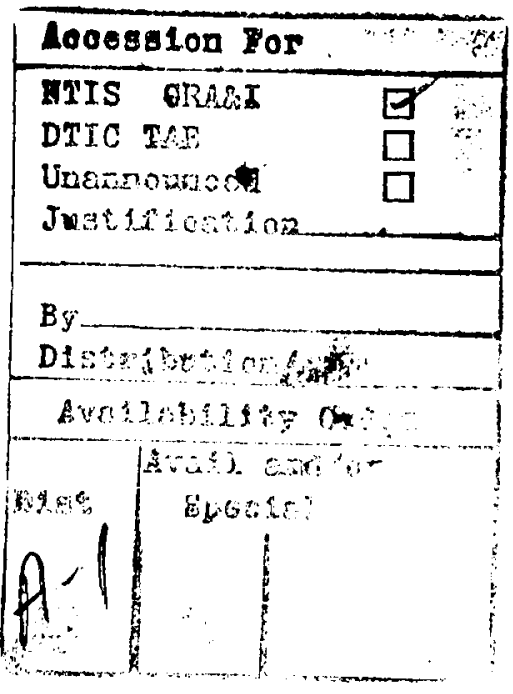




\section{PREFACE}

This final report describes work performed under Office of Naval Research (ONR) Contract No. N00014-91-C-0263 in a continuation of our program to investigate hydrogen ingress into various high-strength alloys, particularly in terms of irreversible trapping, with a view to characterizing the susceptibility of the alloys to hydrogen embrittlement (HE). A technique called hydrogen ingress analysis by potentiostatic pulsing (HIAPP) was used to obtain anodic current transients for the alloys in $1 \mathrm{~mol} \mathrm{~L}^{-1}$ acetic acid/1 mol L-1 sodium acetate, and the transients were analyzed using a diffusion/trapping model under interface control conditions to evaluate the trapping constant and hydrogen entry flux in each case.

The report is presented as an Executive Summary followed by five sections that will eventually form papers for publication in journals or in conference proceedings:

1. "Hydrogen Trapping in Precipitation-Hardened Iron-Base Alloys."

2. "The Effect of Aging on Hydrogen Trapping in Copper-Containing Alloys."

3. "The Ingress of Hydrogen into a Superferritic Stainless Steel."

4. "The Resistance of High-Strength Alloys to Hydrogen Embrittlement," in Proceedings of the Tri-Service Conference on Corrosion (Wright-Patterson Air Force Base, Dayton, $\mathrm{OH}, 1994)$, in press.

5. "The Role of Traps in Determining the Resistance to Hydrogen Embrittlement," in Proceedings of the 5th International Conference on Hydrogen Effects on Material Behavior, N. R. Moody and A. W. Thompson, Eds. (The Minerals, Metals \& Materials Society, Warrendale, PA, 1994), in press.

The first paper covers a high-strength steel (AerMet 100) and a stainless steel (A-286) and the next two concern $\mathrm{Cu}$-containing alloys (Be-Cu and two heats of alloy $\mathrm{K}-500$ ) and a superferritic stainless steel (Sea-Cure) in its standard, hydrogen-resistant, and intermediate grades. The final two papers review the progress made in characterizing hydrogen trapping in highstrength alloys studied during our program with ONR; some of the work reported there was supported by our earlier ONR contract, No. N00014-86-C-0233.

The principal investigator would like to acknowledge Mr. J. Eckenrod of Crucible Research for supplying samples of the three grades of Sea-Cure and Dr. M. Natishan, then at the David Taylor Research Center, Department of the Navy but now at the University of Maryland, for providing samples of the two heats of alloy K-500. 


\section{EXECUTIVE SUMMARY}

High performance alloys are often required to possess a combination of properties such as strength, toughness, and corrosion resistance. However, their resistance to hydrogen embrittlement (HE) remains a concern in many situations. Microstructural defects in these and other alloys provide potential trapping sites for hydrogen and so can play a crucial role in determining an alloy's intrinsic susceptibility to HE. However, whether embrittlement will actually occur is also affected by the amount of hydrogen entering the alloy. Consequently, alloys need to be characterized in terms of both trapping capability and the rate of hydrogen entry to assess their likelihood of embrittlement.

This report describes work performed during a continuation of our program with the Office of Naval Research to investigate hydrogen ingress in various alloys, particularly in terms of irreversible trapping, with a view to characterizing the susceptibility of the alloys to $\mathrm{HE}$. A technique referred to as hydrogen ingress analysis by potentiostatic pulsing (HIAPP) was used to obtain anodic current transients for the alloys in $1 \mathrm{~mol} \mathrm{~L}^{-1}$ acetic acid/1 mol L-1 sodium acetate containing $15 \mathrm{ppm} \mathrm{As}{ }_{2} \mathrm{O}_{3}$. The transients were analyzed using a diffusion/trapping model under interface control conditions to evaluate the apparent trapping constant $\left(k_{\mathrm{a}}\right)$ and hydrogen entry flux in each case. Where possible, $k_{\mathrm{a}}$ was then used to determine the irreversible trapping constant $(k)$ and the density of irreversible traps.

The first part of this work focused on investigating the trapping behavior of two precipitation-hardened iron-base alloys (AerMet 100 and alloy A-286). Overaged/annealed and aged specimens of AerMet 100 exhibited a marked difference in trapping. Irreversible trapping in the overaged specimen was negligible, which is consistent with its lack of particles such as carbides that are responsible for irreversible trapping in many high-strength alloys. The aged specimen, however, displayed a relatively high value of $k$, which is quite possibly associated with $\mathrm{Mo}_{2} \mathrm{C}$ and $\mathrm{Cr}_{2} \mathrm{C}$ particles precipitated during aging. The order of the $k$ values for AerMet 100 and two high-strength steels (4340 and $18 \mathrm{Ni}$ ) previously studied inversely parallels their threshold stress intensities for stress corrosion cracking ( $\mathrm{K}_{\mathrm{ISCC}}$ ); that is, the lower the value of $k$, the higher the value of $\mathrm{K}_{\mathrm{ISCC}}$.

The value of $k$ for alloy A-286 is lower than that for AerMet 100 and is intermediate between those for two Ni-base alloys (718 and 925$)$ examined previously. Thus, alloy A-286 is intrinsically less susceptible than the three steels and alloy 718 but more so than alloy 925 . The $k$ values of the precipitation-hardened alloys, $718, \mathrm{~A}-286$, and $18 \mathrm{Ni}$ steel, are consistent with test 
data for their relative resistance to HE. The results for AerMet 100 and alloy A-286 appear to extend the previously reported correlation between $k$ and HE resistance.

The second part of the study involved two $\mathrm{Cu}$-containing alloys, $\mathrm{Be}-\mathrm{Cu}$ and alloy $\mathrm{K}-500$. The results were compared with those for a $77 \mathrm{Cu}-15 \mathrm{Ni}$ alloy (Marinel) and another heat of alloy $\mathrm{K}-500$ studied in earlier work. The Be-Cu alloy (1.8-2.0Be) in the unaged condition has a higher $k$ than that for unaged alloy $\mathrm{K}-500$ (nominally $65 \mathrm{Ni}-30 \mathrm{Cu}$ ) and therefore is intrinsically more susceptible to $\mathrm{HE}$. The type of heat treatment was found to have a marked effect on the trapping behavior of alloy $\mathrm{K}-500$. The value of $k$ for alloy $\mathrm{K}-500$ annealed and aged to a yield strength of 689-724 $\mathrm{MPa}$ is more than twice as large as that for a specimen cold-drawn and direct-aged to a yield strength of $1096 \mathrm{MPa}$. The value of $k$ for the $77 \mathrm{Cu}-15 \mathrm{Ni}$ alloy aged to a yield strength of $793 \mathrm{MPa}$ is similar to that of direct-aged alloy $\mathrm{K}-500$.

The final part of the work addressed a superferritic stainless steel - Sea-Cure (UNS S44660) - in its standard grade, its hydrogen-resistant grade and an intermediate grade. The three grades proved difficult to investigate in terms of trapping. In all cases, hydrogen entry was still low when reduction of the surface oxide occurred at a charging potential of -0.6 V (SCE). As a result, negligible hydrogen entered the alloys, and so their trapping characteristics could not be determined. On the other hand, it was clear that the surface oxides were effective barriers to hydrogen entry and therefore that these superferritics should be resistant to HE in mildly acidic or near-neutral solutions, provided that the potential is less cathodic than $-0.6 \mathrm{~V}$ (SCE). The propensity of superferritics to undergo $\mathrm{HE}$ in seawater when they are cathodically polarized to potentials in the range -0.9 to $-1.4 \mathrm{~V}$ (SCE) can be attributed to the absence of an oxide and hence to the relatively unrestricted entry of hydrogen into the alloy. An effective way of rendering SeaCure more resistant to $\mathrm{HE}$ under these circumstances is to reduce the intrinsic susceptibility by controlling the number and type of carbide particles, as is apparently done for the hydrogenresistant grade. 


\section{Section 1}

\section{HYDROGEN TRAPPING IN PRECIPITATION-HARDENED IRON-BASE ALLOYS}

\section{ABSTRACT}

The ingress of hydrogen into two precipitation-hardened alloys - AerMet 100 (Overaged and aged) and alloy A-286 (UNS K66286) - was studied using a technique referred to as hydrogen ingress analysis by potentiostatic pulsing (HIAPP). Values of the irreversible trapping constant $(\mathrm{k})$ and the hydrogen entry flux were determined for these alloys in $1 \mathrm{~mol} \mathrm{~L}^{-1}$ acetic acidl 1 mol $L^{-1}$ sodium acetate. Overaged/annealed and aged specimens of AerMet 100 exhibited a marked difference in trapping. Irreversible trapping in the overaged specimen was negligible, which is consistent with its lack of particles such as carbides that are known to be responsible for irreversible trapping in many high-strength alloys. The aged specimen, however, displayed a relatively high value of $\mathrm{k}$, which is quite possibly associated with $\mathrm{Mo}_{2} \mathrm{C}$ and $\mathrm{Cr}_{2} \mathrm{C}$ particles precipitated during aging. The order of the $\mathrm{k}$ values for AerMet 100 and two high-strength steels (4340 and 18Ni) previously studied inversely parallels their threshold stress intensities for stress corrosion cracking (KISCC); that is, the lower the value of $\mathrm{k}$, the higher the value of $K_{I S C C}$. The value of $\mathrm{k}$ for alloy A-286 is lower than that for AerMet 100 and is intermediate between those for two Ni-base alloys (718 and 925) examined previously. Thus, alloy A-286 is intrinsically less susceptible than the three steels and alloy 718 but more so than alloy 925 . The $\mathrm{k}$ values of the precipitation-hardened alloys, 718, A-286, and 18Ni steel, are consistent with test data for their relative resistance to $H E$. The results for AerMet 100 and alloy A-286 appear to extend the previously reported correlation between $\mathrm{k}$ and $H E$ resistance.

\section{INTRODUCTION}

Various steels are used for aircraft components such as landing gear and arresting hooks, because of their high-strength characteristics. However, these steels must meet stringent requirements with respect not only to strength but also to fracture toughness and resistance to environmentally assisted cracking. One of the alloys that have been developed for aerospace applications is a martensitic steel -AerMet 100-that is strengthened by precipitation of $\mathrm{Mo}_{2} \mathrm{C}$ and $\mathrm{Cr}_{2} \mathrm{C}$. This steel is reported to possess a balanced combination of the required properties, including a higher resistance to hydrogen-assisted cracking in $3.5 \% \mathrm{NaCl}$ than 4340 steel and $18 \mathrm{Ni}$ 
steel. ${ }^{1}$ However, precipitation-hardened martensitic iron-base alloys as a group tend to be rather prone to hydrogen embrittlement $(\mathrm{HE}) .^{2-4}$ Austenitic iron-base alloys such as A-286, in which the strength is imparted by precipitation of $\gamma^{\prime}$ phase composed of $\mathrm{Ni}_{3}(\mathrm{Al}, \mathrm{Ti})$, have also been found to undergo HE. -7 $^{-7}$ Thus, the possibility of HE remains a major concern in the use of high-strength iron-base alloys, irrespective of the type of matrix and strengthening precipitates.

The resistance of an alloy to $\mathrm{HE}$ is strongly affected by the interaction of hydrogen with microstructural defects that act as hydrogen traps. ${ }^{8}$ The type of defect plays a crucial role in determining an alloy's intrinsic susceptibility to $\mathrm{HE}$, with large irreversible (high binding energy) traps typically imparting a high susceptibility. 9,10 Hence, characterization of alloys in terms of irreversible trapping can allow their intrinsic $\mathrm{HE}$ susceptibility to be assessed and provide a basis for examining the effect of traps on the observed resistance to HE.

The entry and trapping of hydrogen in a wide range of high-strength alloys have been investigated in previous work using an electrochemical technique referred to as hydrogen ingress analysis by potentiostatic pulsing (HIAPP). ${ }^{11-14}$ The rates of $\mathrm{H}$ entry and rate constants for irreversible trapping were determined, and it appeared that, for most of these alloys, there was a correlation between the intrinsic susceptibility, as represented by $k$, and the actual resistance to $\mathrm{HE}$ observed in mechanical tests.

In the present work, HIAPP was used to obtain the rates of $\mathrm{H}$ entry and irreversible trapping constants for AerMet 100 in the overaged and aged conditions and aged alloy A-286 (UNS S66286). AerMet 100 extends the range of high-strength steels (4340 and 18Ni) examined previously, ${ }^{11,12}$ while alloy A-286 provides a comparison with two precipitation-hardened nickelbase superalloys ( 718 and 925 ) that had already been studied. ${ }^{12}$ The research was aimed in part at characterizing the intrinsic susceptibility of each alloy to HE in terms of its irreversible trapping constant. The intrinsic susceptibilities for AerMet 100 and alloy A-286 were then compared with those for the previous two steels and Ni-base alloys, respectively, and with results for the actual resistance to HE observed in tests by other workers. A further goal was to determine the trap density where possible and thereby identify the principal irreversible trap in each alloy.

\section{EXPERIMENTAL PROCEDURE}

The composition of each alloy is given in Table 1-1. The AerMet 100 and alloy A-286 were supplied in the form of rods with a diameter of $1.36 \mathrm{~cm}$ and $1.27 \mathrm{~cm}$, respectively. The AerMet 100 was received in an overaged/annealed $\left(677^{\circ} \mathrm{C} / 16 \mathrm{~h}\right)$ condition. It was subsequently solution treated at $885^{\circ} \mathrm{C}$ for $1 \mathrm{~h}$, air cooled to $66^{\circ} \mathrm{C}$ over $1-2 \mathrm{~h}$, then further cooled to $-73^{\circ} \mathrm{C}$ for 1 
$\mathrm{h}$, and finally aged at $482^{\circ} \mathrm{C}$ for $5 \mathrm{~h}$ to give a yield strength of about $1834 \mathrm{MPa}$. As noted above, $\mathrm{Mo}_{2} \mathrm{C}$ and $\mathrm{Cr}_{2} \mathrm{C}$ are precipitated within the martensite during aging.

The alloy A-286 was used as-received in the solution-annealed $\left(900^{\circ} \mathrm{C} / 2 \mathrm{~h}\right)$ and aged $\left(720^{\circ} \mathrm{C} / 16 \mathrm{~h}\right)$ condition. The yield strength of the aged alloy was $848 \mathrm{MPa}$. In addition to the $\gamma^{\prime}$ phase precipitated during aging, alloy A-286 also exhibited Ti-rich particles that appeared to becarbides. The characteristic dimension of the particles was determined to be $3 \mu \mathrm{m}$ and the particle concentration was $6.6 \times 10^{13} \mathrm{~m}^{-3}$.

Details of the electrochemical cell and instrumentation have been given previously. ${ }^{11}$ The test electrodes of each alloy consisted of a 1.27 -cm length of rod press-fitted into a polytetrafluoroethylene sheath so that only the planar end surface was exposed to the electrolyte. The surface was polished before each experiment with $\mathrm{SiC}$ paper followed by $0.05-\mu \mathrm{m}$ alumina powder. The electrolyte contained $1 \mathrm{~mol} \mathrm{~L}^{-1}$ acetic acid and $1 \mathrm{~mol} \mathrm{~L}^{-1}$ sodium acetate (pH 4.8) with 15 ppm $\mathrm{As}_{2} \mathrm{O}_{3}$ and was deaerated continuously with argon before and throughout data acquisition. The potentials were measured with respect to a saturated calomel electrode (SCE). All tests were performed at $22 \pm 1^{\circ} \mathrm{C}$.

The test electrode was cathodically charged with hydrogen at a constant potential $\mathrm{E}_{\mathrm{c}}$ for a time $t_{c}$, after which the potential was stepped in the positive direction to a value $10 \mathrm{mV}$ negative of the open-circuit potential $\mathrm{E}_{\mathrm{oc}}$. Anodic current transients were obtained over a range of charging times, typically from 5 to $60 \mathrm{~s}$, at different overpotentials $\left(\eta=E_{c}-E_{o c}\right)$. The open-circuit potential of the test electrode was measured immediately before each charging time and was also used to monitor the stability of the alloy surface.

\section{RESULTS}

The current transients were analyzed using a diffusion/trapping model based on a constant entry flux at the surface. ${ }^{11,15}$ According to the model, the total anodic charge $\left(\mathrm{C} \mathrm{m}^{-2}\right)$ is given by

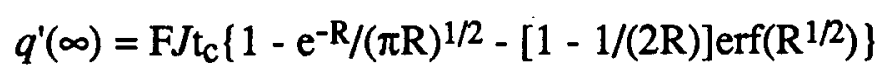

where $\mathrm{F}$ is the Faraday constant, $J$ is the ingress flux in mol m-2 $\mathrm{s}^{-1}$, and $\mathrm{R}=k_{\mathrm{a}} \mathrm{t}_{\mathrm{c}}$. The charge $q^{\prime}(\infty)$ is equated to the charge $\left(q_{\mathrm{a}}\right)$ passed during the experimental anodic transients. The adsorbed charge is almost invariably negligible, so $q_{\mathrm{a}}$ can be associated entirely with absorbed $\mathrm{H}$. $k_{\mathrm{a}}$ is an apparent trapping constant measured for irreversible traps in the presence of reversible traps. It is related to the irreversible trapping constant $(k)$ by $k \mathrm{D}_{\mathrm{a}} / \mathrm{D}_{\mathrm{L}}$ where $\mathrm{D}_{\mathrm{a}}$ is the apparent diffusivity and $\mathrm{D}_{\mathrm{L}}$ is the lattice diffusivity of $\mathrm{H}$. The use of $k$ as an index of the intrinsic susceptibility has been discussed elsewhere. ${ }^{14}$ 
For aged AerMet 100 and alloy A-286, Eq. [1-1] could be fitted to the experimental data for $q_{\mathrm{a}}$ to obtain values of $k_{\mathrm{a}}$ and $J$, where $J$ was independent of charging time at each potential. In the case of overaged AerMet 100, $q_{\mathrm{a}}$ increased linearly with $t_{\mathrm{c}}$ (Fig. 1-1), indicating that $k_{\mathrm{a}}=0$ and therefore that irreversible trapping was negligible. In contrast, the aged alloy exhibited moderately high values of $k_{\mathrm{a}}$, which were indicative of pronounced irreversible trapping. Values of $k_{\mathrm{a}}$ and $J$ for two tests with aged AerMet 100 are given in Table 1-2. In both tests, $k_{\mathrm{a}}$ was independent of charging potential, which is to be expected since the trapping characteristics should be unaffected by electrochemical conditions unless the traps become filled to a significant extent. The overall mean value of $k_{\mathrm{a}}$ was $0.069 \pm 0.004 \mathrm{~s}^{-1}$. The flux in general did not change significantly with overpotential.

Alloy A-286 also displayed irreversible trapping; data for $k_{\mathrm{a}}$ and $J$ obtained from three tests are given in Table 1-3. In all three tests, $k_{\mathrm{a}}$ is independent of overpotential, the mean value of $k_{\mathrm{a}}$ for the three tests being $0.073 \pm 0.005 \mathrm{~s}^{-1}$. The flux, however, in contrast to that for aged AerMet 100 , showed a marked increase with potential. The dependence of $J$ on $E_{\mathcal{c}}$ was shown to be logarithmic (Fig. 1-2), which is characteristic of Nernstian-type behavior and implies that the surface coverage of adsorbed hydrogen responds rapidly to changes in potential.

\section{DISCUSSION}

\section{Irreversible Trapping Constants}

Evaluation of $k$ from $k_{\mathrm{a}}$ requires that the effect of reversible trapping be taken into account. The minor alloying elements, either in their atomic form or as intermetallics that are precipitated during aging, are assumed to be largely responsible for reversible trapping in AerMet 100 and alloy A-286, though for different reasons. In the case of body-centered cubic (bcc) $\mathrm{Fe}$, elements such as $\mathrm{Cr}$ are known to have a marked effect on the diffusivity. ${ }^{16}$ For example, the addition of 5 at.\% $\mathrm{Cr}$ to Fe decreases the diffusivity by two orders of magnitude at $27^{\circ} \mathrm{C}$. Significant effects could therefore be expected with minor elements that act as reversible traps in alloys such as AerMet 100 with a martensite lattice. Moreover, based on the case of $\mathrm{Cr}$, these effects are likely to dominate those from microstructural defects such as dislocations.

For face-centered cubic (fcc) alloys, defects such as vacancies or edge dislocations are unlikely to contribute significantly to reversible trapping, since the binding energy of hydrogen to defects such as vacancies or edge dislocations in an fcc lattice is somewhat (a factor of 4) smaller than the activation energy for diffusion. ${ }^{17}$ Thus, reversible trapping in alloy A-286, which has an austenitic lattice, should be influenced more by composition than by microstructural defects. 


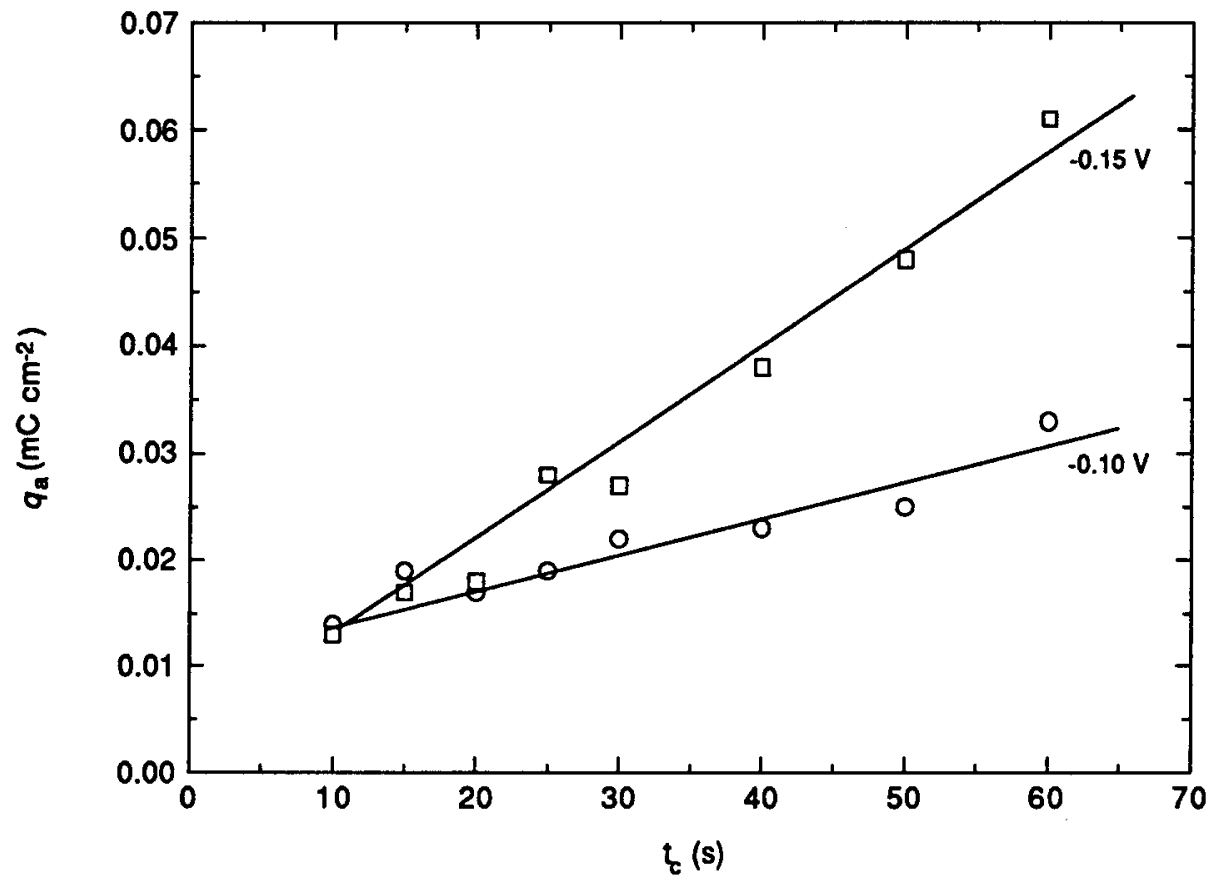

Figure 1-1. Dependence of anodic charge on charging time for overaged AerMet 100 at two charging potentials. 


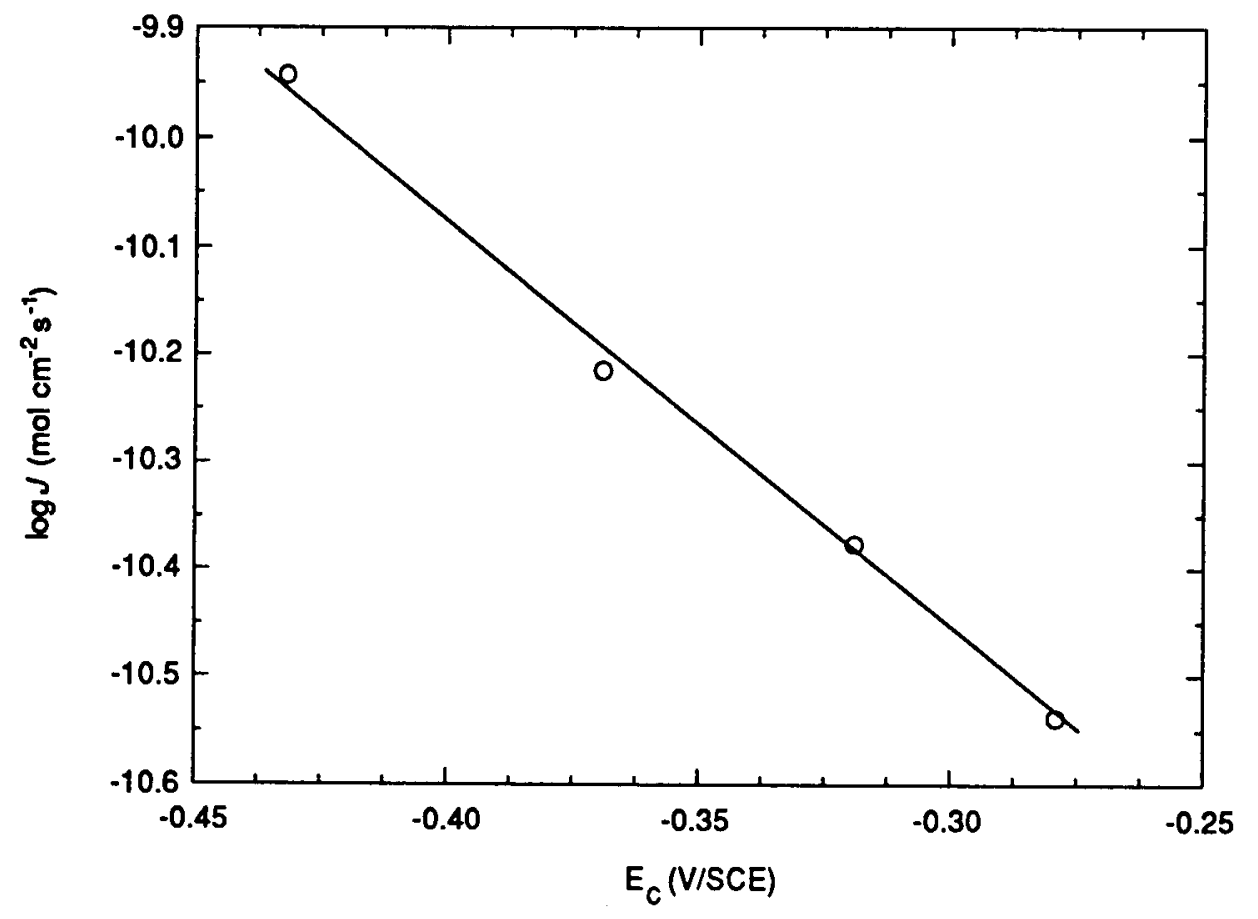

Figure 1-2. Dependence of entry flux on charging potential for alloy A-286. 
The effect of reversible trapping is determined using the values of $D_{L}$ and $D_{a}$, corresponding to the diffusivity for the "pure" alloy and for the actual alloy, respectively. Although Co is a prominent alloying element in AerMet 100, it is regarded as an anti-trap in $\mathrm{Fe}^{8}$ and has been shown to have little effect on the diffusivity. ${ }^{18}$ Thus, the pure alloys were assumed to be Fe-11Ni-3Cr for AerMet 100 and Fe-24Ni-14Cr for alloy A-286. Diffusivity data were not available for these alloys, so values were obtained for $\mathrm{D}_{\mathrm{L}}$ by comparing data for annealed $\mathrm{Fe}-\mathrm{Cr}$ and $\mathrm{Fe}-\mathrm{Ni}$ alloys. It should be noted that, with the annealed alloys, the difference between $\mathrm{D}_{\mathrm{a}}$ and $\mathrm{D}_{\mathrm{L}}$ should reflect the contribution of dislocations as well as that of minor alloying elements to reversible trapping.

AerMet 100 contains $3 \% \mathrm{Cr}$, and, as noted above, $\mathrm{Cr}$ has a marked effect on the diffusivity, which can be attributed to its role as a trap. ${ }^{8}$ The value of $\mathrm{D}_{\mathrm{L}}$ for $\mathrm{Fe}-3 \mathrm{Cr}$ is $(5 \pm 1) \times$ $10^{-11} \mathrm{~m}^{2} \mathrm{~s}^{-1}$ at $27^{\circ} \mathrm{C} .{ }^{16}$ It is uncertain whether Ni acts as a trap or an anti-trap. ${ }^{8}$ Nevertheless, adding $11 \% \mathrm{Ni}$ to Fe decreases the diffusivity by a factor of $23 \pm 1$, to $\sim 3 \times 10^{-10} \mathrm{~m}^{2} \mathrm{~s}^{-1}$, though this decrease may be associated more with the presence of an austenitic phase than with the composition directly. ${ }^{19}$ Interestingly, the trapping energy $(0.08 \mathrm{eV})$ for $\mathrm{Ni}$, assuming it to be a trap, is believed to be slightly smaller than that for $\mathrm{Cr}(0.10 \mathrm{eV}) .20$ By assuming that the addition of $11 \% \mathrm{Ni}$ causes a comparable decrease in the diffusivity for $\mathrm{Fe}-3 \mathrm{Cr}$, whether by trapping or by affecting the type of lattice, $D_{L}$ was estimated to be $(2.2 \pm 0.5) \times 10^{-12} \mathrm{~m}^{2} \mathrm{~s}^{-1}$ for $\mathrm{Fe}-11 \mathrm{Ni}-3 \mathrm{Cr}$.

Diffusivity data were not available for AerMet 100. However, the diffusivity for another precipitation-hardened steel - 18Ni maraging steel with a yield strength of $1723 \mathrm{MPa}(250 \mathrm{ksi})$ has been studied as a function of aging temperature ${ }^{21}$ and was considered to provide the most appropriate value of $\mathrm{D}_{\mathrm{a}}$. $18 \mathrm{Ni}$ maraging steel has a nominal basic composition of Fe-18Ni-9Co and, after aging at $482^{\circ} \mathrm{C}$, has a Rockwell $\mathrm{C}$ hardness (HRC) of 52, compared with a value of 55 for AerMet 100 . The diffusivity for $18 \mathrm{Ni}(1723 \mathrm{MPa})$ maraging steel aged at $482^{\circ} \mathrm{C}$ is $(3.7 \pm 0.2)$ $\times 10^{-13} \mathrm{~m}^{2} \mathrm{~s}^{-1}$. By using these values of $\mathrm{D}_{\mathrm{a}}$ and $\mathrm{D}_{\mathrm{L}}, k$ was calculated to be $0.41 \pm 0.15 \mathrm{~s}^{-1}$. In the case of overaged AerMet 100, $k_{\mathrm{a}}$ was roughly zero, which implies that $k=0$.

For alloy A-286, the value of $D_{L}$ for Fe-14Cr is $(1.2 \pm 0.2) \times 10^{-12} \mathrm{~m}^{2} \mathrm{~s}^{-1} .16$ The addition of $24 \% \mathrm{Ni}$ to Fe decreases the diffusivity ${ }^{19}$ by a factor of $3500 \pm 150$ to $2 \times 10^{-12} \mathrm{~m}^{2} \mathrm{~s}^{-1}$. Such a large decrease is to be expected in view of the presence of a large volume fraction of austenite phase. Again, it was assumed that a comparable decrease would occur in $\mathrm{Fe}-24 \mathrm{Ni}-14 \mathrm{Cr}$, and so the value of $D_{L}$ for Fe-24Ni-14Cr was taken as $(3.4 \pm 0.7) \times 10^{-16} \mathrm{~m}^{2} \mathrm{~s}^{-1}$.

$D_{a}$ for alloy A-286 was estimated from data for other austentic stainless steels. Diffusivities for alloys 301,304 , and 310 at $25^{\circ} \mathrm{C}$ were estimated by extrapolation from data ${ }^{22}$ at temperatures from $100^{\circ}$ to $350^{\circ} \mathrm{C}$ and are given in Table 1-4. $\mathrm{H}$ transport in austenitic stainless 
steels is reported to be essentially independent of the austenite composition, ${ }^{23}$ which is consistent with the values shown for these three alloys. The $24 \mathrm{Ni}$ and $14 \mathrm{Cr}$ in alloy A-286 are at the upper and lower ends of their respective ranges, so $\mathrm{D}_{\mathrm{a}}$ was taken to have an intermediate value of $(3.5 \pm$ $0.5) \times 10^{-16} \mathrm{~m}^{2} \mathrm{~s}^{-1}$. The ratio of $D_{L}$ to $D_{a}$ is $\sim 1$, which might be expected for an alloy with such a low diffusivity; that is, reversible trapping should have a negligible effect when the activation energy for diffusion is large, as implied by the low values of $D_{a}$ and $D_{L}$. Hence, for alloy A-286, $k$ was approximately equal to $k_{\mathrm{a}}$ and so was taken as $0.073 \pm 0.0 .031 \mathrm{~s}^{-1}$.

\section{Comparison of Trapping Parameters}

The trapping constants for AerMet 100 and alloy A-286 are compared with those for other steels and precipitation-hardened alloys, respectively, in Table 1-5. AerMet 100 has a lower $k$ value than 4340 and $18 \mathrm{Ni}$ maraging steel and therefore has the lowest intrinsic susceptibility to $\mathrm{HE}$ of the three steels. The order of the $k$ values for these three steels inversely parallels their threshold stress intensities for stress corrosion cracking ( $\mathrm{K}_{\mathrm{ISCC}}$ ) in $3.5 \% \mathrm{NaCl}^{1}$ (Fig. 1-3); that is, a lower value of $k$ corresponds to a higher value of $\mathrm{K}_{I S C C}$. The parallel between the trapping constant and KISCC supports the general view that hydrogen plays the dominant role in SCC of martensitic steels. ${ }^{24}$ Thus, for these three steels, the observed resistance to HE, as represented by $\mathrm{K}_{\mathrm{ISCC}}$, appears to correlate with the intrinsic susceptibility, as represented by $k$. In other words, the observed resistance to $\mathrm{HE}$ appears to be determined primarily by the intrinsic susceptibility, with the entry flux having only a secondary effect.

Alloy A-286 is intermediate in its $k$ value between alloys 718 and 925 . Hence, it is intrinsically less susceptible than alloy 718 but more so than alloy 925 . Measurements of the reduction in notch tensile strength and ductility in gas-phase charging tests have shown that alloy 718 undergoes extreme HE whereas alloy A-286 exhibits negligible embrittlement. 25 Corresponding measurements have also been made in cathodic charging tests on alloys 718 and A286 aged to strengths that, relative to each other, were similar to those used in the present work. As in the gas-phase tests, it was found that alloy 718 undergoes a greater decrease in notch tensile strength and ductility than alloy A-286. ${ }^{26}$ Thus, irrespective of the type of charging, the intrinsic susceptibility seems to parallel the relative resistance to $\mathrm{HE}$ for alloys 718 and A-286. The cathodic charging tests indicated that, the stronger the alloy, the greater the decrease in strength and ductility with increasing $\mathrm{H}$ concentration. However, in general, the observed resistance to $\mathrm{HE}$ is considered to be more directly an effect of microstructure than of strength. 24,27 In the case of alloys 718 and A-286, the trapping constants parallel the mechanical properties, so it is quite possible that the microstructure through its traps could be the key factor for these alloys too. 


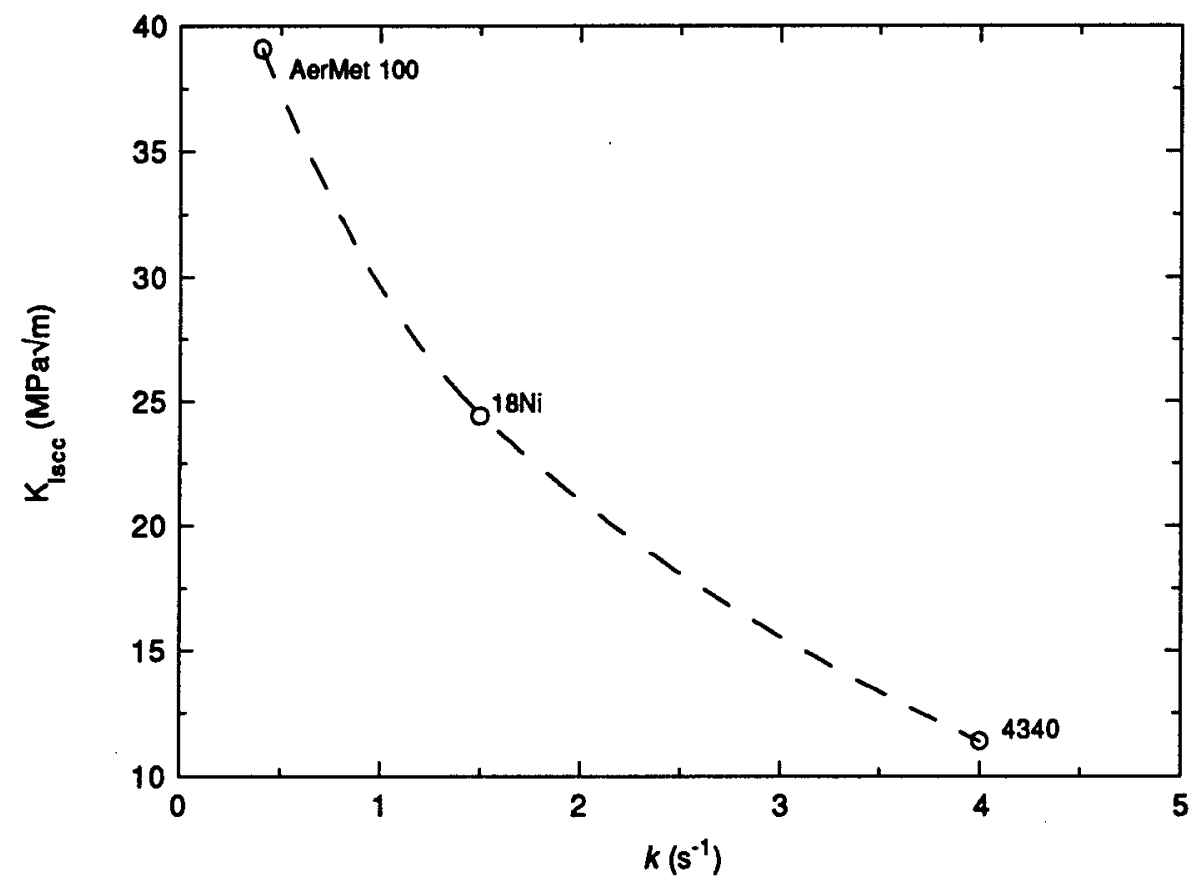

Figure 1-3. Variation of $K_{I S C C}$ with $k$ for high-strength steels. 
The irreversible trapping constants for AerMet 100 and alloy A-286 are compared with the values for other alloys in Table 1-6. The value of $k$ for alloy A-286 is lower than those for AerMet 100 and several Ni-base alloys, so alloy A-286 has a lower intrinsic susceptibility than the three steels and these Ni-base alloys. It has been found that alloy 718, like alloy A-286, is more resistant to $\mathrm{HE}$ than $18 \mathrm{Ni}\left(1723 \mathrm{MPa}\right.$ ) maraging steel, ${ }^{25}$ so the values of $k$ for these three precipitation-hardened alloys are consistent with their relative resistances to $\mathrm{HE}$ observed in tests. The results for AerMet 100 and alloy A-286 therefore appear to extend the previously reported correlation between $k$ and $\mathrm{HE}$ resistance to include these alloys.

A lack of appropriate mechanical test data in the literature makes it difficult to determine whether the position of alloy A-286 is justified with respect to that of alloy C-276 and the other precipitation-hardened alloy, 925; alloy 716 was found to be an exception to the correlation because its $\mathrm{HE}$ resistance appears to be determined by the $\mathrm{H}$ entry flux. ${ }^{28}$ The difficulty in evaluating the relative position of A-286 is compounded by some uncertainty in the values of $k$, particularly for C-276. Nevertheless, on the basis of these values, it would be predicted that, in practice, the resistance of alloy A-286 to HE would be higher than that of alloy C-276 but less than that of alloy 925 .

\section{Identification of Irreversible Traps}

The density of particles or defects $\left(\mathrm{N}_{\mathrm{i}}\right)$ providing irreversible traps can be obtained from $k_{\mathrm{a}}$ according to Eq. $[1-2]^{12,29}$ :

$$
\mathrm{N}_{\mathrm{i}}=k_{\mathrm{a}} a /\left(4 \pi d^{2} \mathrm{D}_{\mathrm{a}}\right)
$$

where $a$ is the diameter of the metal atom and $d$ is the trap radius. The value of $a$ for an alloy is taken as the mean of the atomic diameters weighted in accordance with the atomic fraction of each element. The trap radius is estimated from the dimensions of heterogeneities that are potential irreversible traps, and trap densities are then calculated for the different values of $d$. In this way, the dominant irreversible trap can be identified by comparing the values of $\mathrm{N}_{\mathrm{i}}$ with the actual concentrations of specific heterogeneities.

In the case of AerMet 100, aging causes precipitation of $\mathrm{Mo}_{2} \mathrm{C}$ and $\mathrm{Cr}_{2} \mathrm{C}$ within the martensite, as indicated above. Since irreversible trapping was negligible in the overaged/annealed alloy but pronounced in the aged alloy, it seems reasonable to assume that the carbides are the principal irreversible traps in the aged alloy. This assumption is consistent with our previous studies ${ }^{11-14}$ showing that carbide and carbonitride precipitates are the predominant irreversible traps in many alloys. 
For alloy $\mathrm{A}-286$, the presence of the $\mathrm{Ni}_{3}(\mathrm{Al}, \mathrm{Ti}) \gamma^{\prime}$ phase precipitated during aging appears to be critical to the hydrogen-induced losses in ductility. ${ }^{30}$ In particular, the misfit between $\gamma^{\prime}$ and the austenitic matrix is important with regard to planar slip and affects $\mathrm{H}$ accumulation at the particles. ${ }^{31}$ Thus, $\gamma$ appears to provide irreversible traps in alloy A-286, though intermetallic precipitates in alloys such as maraging steels tend to be reversible traps. ${ }^{12,32}$ Accordingly, the $\gamma^{\prime}$ precipitates are assumed to act as the principal irreversible traps in alloy A-286. For both alloys, however, the role of the $\mathrm{Mo} / \mathrm{Cr}$ carbides and $\gamma^{\prime}$ as irreversible traps is speculative and has not been verified yet.

Although $\gamma^{\prime}$ has been implicated in the $\mathrm{HE}$ of alloy A-286, a value of $\mathrm{N}_{\mathrm{i}}$ was calculated on the basis of the Ti-rich particles observed in this alloy, since Ti-carbide and carbonitride particles have often been identified as the principal irreversible traps in other alloys. ${ }^{14}$ By using $\mathrm{D}_{\mathrm{a}}=(3.5 \pm$ $0.5) \times 10^{-16} \mathrm{~m}^{2} \mathrm{~s}^{-1}, d=1.5 \times 10^{-6} \mathrm{~m}$, and $a=250 \times 10^{-12} \mathrm{~m}, \mathrm{~N}_{\mathrm{i}}$ was found to be $(1.8 \pm 0.4) \times$ $10^{15} \mathrm{~m}^{-3}$, whereas the actual concentration of Ti-rich particles was $6.6 \times 10^{13} \mathrm{~m}^{-3}$. The factor of 27 difference in the two values probably means that these particles are not the principal traps. This finding is consistent with the results of other work, in which it was found that the TiC phase could not be correlated with the overall hydrogen-induced ductility loss of alloy A-286.31

\section{SUMMARY}

- AerMet 100 exhibited a marked difference in trapping between overaged/annealed and aged specimens. The negligible irreversible trapping in the overaged specimen is consistent with its lack of particles such as carbides. The aged specimen, however, displayed a relatively high irreversible trapping constant, which is quite possibly associated with $\mathrm{Mo}_{2} \mathrm{C}$ and $\mathrm{Cr}_{2} \mathrm{C}$ particles precipitated during aging.

- AerMet 100 has a lower value of $k$ than two other high-strength steels, 4340 and $18 \mathrm{Ni}$ maraging steel, and therefore has the lowest intrinsic susceptibility to HE of the three steels. For these steels, the observed resistance to HE, as represented by $\mathrm{K}_{\mathrm{ISCC}}$, appears to correlate with the intrinsic susceptibility, as represented by $k$.

- The value of $k$ for alloy A-286 is lower than that for AerMet 100 and intermediate between those for the two Ni-base alloys, 718 and 925 . Thus, alloy A-286 is intrinsically less susceptible than the three steels and alloy 718 but more so than alloy 925 . The intrinsic susceptibilities (defined by $k$ ) of the three precipitation-hardened alloys (718, A-286, and $18 \mathrm{Ni}$ ) are consistent with their observed resistances to HE. The results for AerMet 100 and alloy A-286 therefore appear to extend the previously reported correlation between $k$ and HE resistance to include these alloys. 
- The principal irreversible traps were assumed to be $\mathrm{Mo}_{2} \mathrm{C}$ and $\mathrm{Cr}_{2} \mathrm{C}$ in aged AerMet 100 and the $\mathrm{Ni}_{3}(\mathrm{Al}, \mathrm{Ti}) \gamma^{\prime}$ phase in alloy A-286. However, the role of both the carbides and $\gamma^{\prime}$ as irreversible traps has not been verified yet.

\section{ACKNOWLEDGEMENTS}

Financial support of this work by the U.S. Office of Naval Research under Contract N00014-91-C-0263 is gratefully acknowledged.

\section{REFERENCES}

1 T. J. McCaffrey, Advanced Maters. Processes 9, 47 (1992).

2. A. W. Thompson, Metall. Trans. 4, 2819 (1973).

3. A. W. Thompson, in Fracture 1977: Proceedings of the Fourth International Conference on Fracture, D.M.R. Taplin, Ed., Vol. 2 (University of Waterloo Press, Waterloo, Ontario, Canada, 1977), p. 237.

4. D. P. Dautovich and S. Floreen, in Proceedings of the Conference on Stress Corrosion Cracking and Hydrogen Embrittlement of Iron-Base Alloys, R. W. Staehle, J. Hochman, R. D. McCright, and J. E. Slater, Eds. (National Association of Corrosion Engineers, Houston, TX, 1977), p. 798.

5. J. Papp, R. F. Hehemann, and A. R. Troiano, in Hydrogen in Metals, I. M. Bernstein and A. W. Thompson, Eds. (American Society for Metals, Metals Park, OH, 1974), p. 657.

6. J. LeGrand, M. Caput, C. Couderc, R. Broudeur, and J.-P. Fidelle, Mem. Sci. Rev. Met. 68, 861 (1971).

7. A. W. Thompson, in Hydrogen in Metals, I. M. Bernstein and A. W. Thompson, Eds. (American Society for Metals, Metals Park, OH, 1974), p. 91.

8. I. M. Bernstein and G. M. Pressouyre, in Hydrogen Degradation of Ferrous Alloys, R. A. Oriani, J. P. Hirth, and M. Smialowski, Eds. (Noyes Publications, Park Ridge, NJ, 1985), p. 641.

9. G. M. Pressouyre and I. M. Bernstein, Metall. Trans. 9A, 1571 (1978).

10. G. M. Pressouyre and I. M. Bernstein, Acta Metall. 27, 89 (1979).

11. B. G. Pound, Corrosion 45, 18 (1989).

12 B. G. Pound, Acta Metall. 38, 2373 (1990).

13. B. G. Pound, Acta Metall. 39, 2099 (1991).

14. B. G. Pound, in Proceedings of the Fifth International Conference on Hydrogen Effects on Material Behavior, N. R. Moody and A. W. Thompson, Eds. (The Minerals, Metals \& Materials Society, Warrendale, PA, 1994), in press. 
15. R. McKibbin, D. A. Harrington, B. G. Pound, R. M. Sharp, and G. A. Wright, Acta Metall. 35, 253 (1987).

16. J. O'M. Bockris, M. A. Genshaw, and M. Fullenwider, Electrochim. Acta 15, 47 (1970).

17. W. D. Wilson and S. C. Keeton, in Advanced Techniques for Characterizing Hydrogen in Metals, N. F. Fiore and B. J. Berkowitz, Eds. (The Metallurgical Society of AIME, Warrendale, PA, 1981), p. 3.

18. K. W. Lange and H. J. Koning, in Proceedings of the Second International Conference on Hydrogen in Metals, P. Azou, Ed., paper 1A5 (Paris, 1973).

19. W. Beck, J. O'M. Bockris, M. A. Genshaw, and P. K. Subramanyan, Metall. Trans. 2, 883 (1971).

20. G. M. Pressouyre, Metall. Trans. 10A, 1571 (1979).

21. M. T. Wang, Technical Report AFML-72-102, Part I (1972); Ref. 105 in "The Stress Corrosion and Hydrogen Embrittlement Behavior of Maraging Steels," in Proceedings of the Conference on Stress Corrosion Cracking and Hydrogen Embrittlement of Iron-Base Alloys, Unieux-Firminy, France (National Association of Corrosion Engineers, Houston, TX, 1973), p. 798.

22. T.-P. Perng and C. J. Altstetter, Acta Metall. 34, 1771 (1986).

23. M. R. Louthan, Jr., and R. G. Derrick, Corrosion Sci. 15, 565 (1975).

24. A. W. Thompson and I. M. Bernstein, in Advances in Corrosion Science and Technology, R. W. Staehle and M. Fontana, Eds. (Plenum Press, New York, 1979), p. 53.

25. R. J. Walter, R. P. Jewett, and W. T. Chandler, Mater. Sci. Eng. 5, 98 (1969/70).

26. P. D. Hicks and C. J. Alstetter, in Proceedings of the Fourth International Conference on Hydrogen Effects on Material Behavior, N. R. Moody and A. W. Thompson, Eds. (The Minerals, Metals \& Materials Society, Warrendale, PA, 1990), p. 613.

27. I. M. Bernstein and A. W. Thompson, Int. Met. Rev. 21, 269 (1976).

28. B. G. Pound, Scripta Metall. 29, 1433 (1993).

29. B. G. Pound, R. M. Sharp, and G. A. Wright, Acta Metall. 35, 263 (1987).

30. A. W. Thompson, in Hydrogen in Metals, I. M. Bernstein and A. W. Thompson, Eds., (American Society for Metals, Metals Park, OH, 1974), p. 91.

31. A. W. Thompson and J. A. Brooks, Metall. Trans 6A, 1431 (1975).

32. V. I. Sarrak, G. A. Filippov, and G. G. Kush, Phys. Met. Metall. 55, 94 (1983). 
ALLOY COMPOSITION (wt\%)

\begin{tabular}{lcc}
\hline Element & AerMet 100 & A-286 \\
\hline Al & 0.005 & 0.13 \\
$\mathrm{~B}$ & & 0.0046 \\
$\mathrm{C}$ & 0.24 & 0.024 \\
$\mathrm{Co}$ & 13.47 & 0.08 \\
$\mathrm{Cr}$ & 3.00 & 14.02 \\
$\mathrm{Cu}$ & & 0.10 \\
$\mathrm{Fe}$ & 71.00 & 57.08 \\
$\mathrm{Mg}$ & & - \\
$\mathrm{Mn}$ & 0.01 & 0.28 \\
$\mathrm{Mo}$ & 1.19 & 1.37 \\
$\mathrm{~N}$ & $<0.0010$ & \\
$\mathrm{Nb}+\mathrm{Ta}$ & & 5.30 \\
$\mathrm{Ni}$ & 11.07 & 24.38 \\
$\mathrm{O}$ & $<0.0010$ & \\
$\mathrm{P}$ & 0.002 & 0.019 \\
$\mathrm{~S}$ & $<0.0005$ & 0.001 \\
$\mathrm{Si}$ & $<0.01$ & 0.22 \\
$\mathrm{Ti}$ & 0.009 & 2.09 \\
$\mathrm{~V}$ & & 0.20 \\
\hline
\end{tabular}

Table 1-2

VALUES OF $k_{a}$ AND $J$ FOR AERMET 100

\begin{tabular}{cccccc}
\hline Test & $\eta(\mathrm{V})$ & $E_{\mathrm{c}}(\mathrm{V} / \mathrm{SCE})$ & $k_{\mathrm{a}}\left(\mathrm{s}^{-1}\right)$ & $J\left(\mathrm{nmol} \mathrm{cm} \mathrm{cm}^{-1}\right)$ & Mean $k_{\mathrm{a}}$ \\
\hline 1 & -0.10 & -0.561 & 0.059 & 0.058 & \\
& -0.15 & -0.613 & 0.079 & 0.054 & \\
& -0.20 & -0.670 & 0.066 & 0.046 & $0.069 \pm 0.006$ \\
& -0.25 & -0.727 & 0.070 & 0.046 & \\
2 & -0.20 & -0.666 & 0.068 & 0.059 & $0.069 \pm 0.001$ \\
& -0.25 & -0.722 & 0.069 & 0.061 & \\
\hline
\end{tabular}


Table 1-3

VALUES OF $k_{\mathrm{a}}$ AND $J$ FOR ALLOY A-286

\begin{tabular}{cccccc}
\hline Test & $\eta(\mathrm{V})$ & $\mathrm{E}_{\mathrm{c}}(\mathrm{V} / \mathrm{SCE})$ & $k_{\mathrm{a}}\left(\mathrm{s}^{-1}\right)$ & $J\left(\mathrm{nmol} \mathrm{cm} \mathrm{cm}^{-1}\right)$ & Mean $k_{\mathrm{a}}$ \\
\hline 1 & -0.15 & -0.279 & 0.075 & 0.029 & \\
& -0.20 & -0.319 & 0.070 & 0.042 & $0.077 \pm 0.005$ \\
& -0.25 & -0.369 & 0.075 & 0.061 & \\
& -0.30 & -0.432 & 0.086 & 0.114 & \\
2 & -0.15 & -0.268 & 0.072 & 0.023 & \\
& -0.20 & -0.313 & 0.080 & 0.037 & $0.071 \pm 0.006$ \\
& -0.30 & -0.428 & 0.062 & 0.087 & \\
3 & -0.15 & -0.258 & 0.074 & 0.026 & \\
& -0.20 & -0.296 & 0.064 & 0.041 & $0.071 \pm 0.004$ \\
& -0.25 & -0.346 & 0.074 & 0.059 & \\
\hline
\end{tabular}

Table 1-4

DIFFUSIVITIES FOR AUSTENITIC STAINLESS STEELS

\begin{tabular}{cccc}
\hline Alloy & $\mathrm{Ni}$ & $\mathrm{Cr}$ & $\mathrm{D}_{\mathrm{a}}\left(\mathrm{m}^{2} \mathrm{~s}^{-1}\right)$ \\
\hline 301 & 7 & 17 & $3.09 \times 10^{-16}$ \\
304 & 9 & 18 & $3.49 \times 10^{-16}$ \\
310 & 20 & 25 & $3.67 \times 10^{-16}$ \\
\hline
\end{tabular}


Table 1.5

TRAPPING PARAMETERS

\begin{tabular}{lcccc}
\hline Alloy & $\begin{array}{c}\text { Yield Strength } \\
\text { (MPa) }\end{array}$ & $k_{\mathrm{a}}\left(\mathrm{s}^{-1}\right)$ & $\mathrm{D}_{\mathrm{L}} / \mathrm{D}_{\mathrm{a}}$ & $k\left(\mathrm{~s}^{-1}\right)$ \\
\hline $\begin{array}{l}\text { Steels } \\
4340\end{array}$ & 1792 & $0.008 \pm 0.001$ & 500 & $4.0 \pm 0.5$ \\
$18 \mathrm{Ni}$ & 1954 & $0.005 \pm 0.002$ & $300 \pm 90$ & $1.50 \pm 1.05$ \\
AerMet 100 & 1834 & $0.069 \pm 0.004$ & $5.9 \pm 1.8$ & $0.41 \pm 0.15$ \\
Precipitation-hardened alloys & & & \\
718 & 1238 & $0.031 \pm 0.002$ & $4.0 \pm 0.5$ & $0.124 \pm 0.024$ \\
A-286 & 848 & $0.073 \pm 0.005$ & $1.0 \pm 0.4$ & $0.073 \pm 0.031$ \\
925 & 758 & $0.006 \pm 0.003$ & $5.6 \pm 0.6$ & $0.034 \pm 0.004$ \\
\hline
\end{tabular}

Table 1-6

IRREVERSIBLE TRAPPING CONSTANTS FOR RANGE OF ALLOYS

\begin{tabular}{llc}
\hline Alloy & Test Condition & $k\left(\mathrm{~s}^{-1}\right)$ \\
\hline 4340 & HRC 53 & $4.0 \pm 0.5$ \\
$18 \mathrm{Ni}(300)$ & Aged & $1.50 \pm 1.05$ \\
AerMet 100 & Overaged/annealed, aged & $0.41 \pm 0.15$ \\
716 & Annealed, aged, 4\% cold work & $0.20 \pm 0.06$ \\
718 & Solution treated & $0.124 \pm 0.024$ \\
C-276 & Hot rolled, 27\% cold work & $0.090 \pm 0.030$ \\
A-286 & Annealed, aged & $0.073 \pm 0.031$ \\
K-500 & Cold drawn, aged & $0.042 \pm 0.006$ \\
Ti grade 2 (high H) & Annealed & $0.040 \pm 0.008$ \\
925 & Annealed, aged & $0.034 \pm 0.004$ \\
Tigrade 2(low H) & Annealed & $0.028 \pm 0.002$ \\
$35 \mathrm{~N}$ & Cold drawn, aged & $0.026 \pm 0.002$ \\
625 & Annealed, 17\% cold work & $0.014 \pm 0.010$ \\
\hline
\end{tabular}




\title{
Section 2 \\ THE EFFECT OF AGING ON HYDROGEN TRAPPING IN COPPER-CONTAINING ALLOYS
}

\begin{abstract}
The irreversible trapping constants $(\mathrm{k})$ and hydrogen entry fluxes were determined for two copper-containing alloys - alloy $\mathrm{Cl} 7200$ (Be-Cu) and alloy $\mathrm{K}-500$ in two heats. A potentiostatic pulse technique was used to charge the alloys with hydrogen at various potentials in $1 \mathrm{~mol} \mathrm{~L}^{-1}$

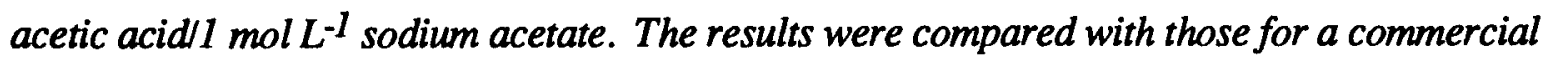
$77 \mathrm{Cu}-15 \mathrm{Ni}$ alloy and another heat of alloy $\mathrm{K}-500$ studied in earlier work. The Be-Cu alloy (1.8 to $2.0 B e$ ) in the unaged condition has a higher $\mathrm{k}$ than that for unaged alloy $K-500$ (unannealed colddrawn) and therefore is intrinsically more susceptible to $H E$. The type of heat treatment was found to have a marked effect on the trapping behavior of alloy $K-500$. The value of $\mathrm{k}$ for alloy $K-500$ annealed and aged to a yield strength of 689-724 MPa is more than twice as large as that for $a$ specimen cold-drawn and direct-aged to a yield strength of $1096 \mathrm{MPa}$. The $\mathrm{k}$ value of $77 \mathrm{Cu}-15 \mathrm{Ni}$ alloy aged to a yield strength of $793 \mathrm{MPa}$ is similar to that of direct-aged alloy $\mathrm{K}-500$.
\end{abstract}

\section{INTRODUCTION}

Various copper-containing alloys can be precipitation-hardened to high yield strengths. Be$\mathrm{Cu}$ alloys, for example, are strengthened by precipitation of $(\mathrm{Cu}, \mathrm{Co}) \mathrm{Be}$ in a matrix of $\alpha-\mathrm{Cu}, 1$ while in Ni-Cu alloys such as $\mathrm{K}-500$, the strength is imparted by precipitation of $\gamma$ phase composed of $\mathrm{Ni}_{3}(\mathrm{Al}, \mathrm{Ti}){ }^{2}$ The capability of these alloys to be aged allows them to be used in a wide range of applications but does tend to make them more vulnerable to hydrogen embrittlement (HE), as observed for alloy K-500.3

$\mathrm{HE}$ in Ni-Cu base alloys is known to be assisted by $\mathrm{S}$ segregated at grain boundaries. ${ }^{4}$ In Ni-base alloys, the presence of sulfide-formers such as Ti can often limit the grain boundary segregation of $S, 5$ but it is TiN particles that are usually present in alloy K-500.6 The HE resistance of two Ni-base alloys - C-276 and 35N, which contained $0.8 \% \mathrm{Ti}-$ was found to correlate with aging treatment, which in turn could be correlated with the concentration of grain boundary $\mathrm{S}$ and $\mathrm{P} .7,8$ The segregation of impurities in Cu-containing alloys may likewise be affected by aging and therefore affect the resistance to HE. 
Microstructural defects in alloys provide potential trapping sites for hydrogen and so can play a crucial role in determining an alloy's resistance to hydrogen embrittlement (HE). ${ }^{9}$ The local concentration of hydrogen trapped at a defect must reach some critical level $\left(C_{k}\right)$ for cracks to be initiated.9,10 Large irreversible (high binding energy) traps typically impart a high intrinsic susceptibility to an alloy because they have a relatively high probability of being located in a cracksensitive region and therefore are associated with low values of $\mathrm{C}_{\mathrm{k}}{ }^{9}$ However, small irreversible traps may also be detrimental - that is, have a low $C_{k}$ - if they lie in a vulnerable region such as a grain boundary. For example, in the case of alloy C-276, it has been suggested that an increased level of grain boundary $\mathrm{P}$ could reduce the critical concentration of $\mathrm{H}$ required for fracture. ${ }^{7}$ Thus, the intrinsic susceptibility of an alloy to $\mathrm{HE}$ is highly dependent on the type of microstructural defect and could be increased considerably by segregation of impurities to grain boundaries.

The entry and trapping of hydrogen in a wide range of high-strength alloys have been investigated in previous work using an electrochemical technique referred to as hydrogen ingress analysis by potentiostatic pulsing (HIAPP). ${ }^{11}$ The rates of $\mathrm{H}$ entry and rate constants for irreversible trapping were determined, and it was found that, for most of these alloys, there appears to be a correlation between the intrinsic susceptibility, as represented by $k$, and the actual resistance to $\mathrm{HE}$ observed in mechanical tests. These alloys included alloy $\mathrm{K}-500(65 \mathrm{Ni}-30 \mathrm{Cu})$ and Marinel ${ }^{*}(77 \mathrm{Cu}-15 \mathrm{Ni}){ }^{12}$ From an analysis of these alloys' trapping characteristics, it was concluded that the sulfur and phosphorus segregated at grain boundaries were probably the principal irreversible traps.

In the present work, the rates of $\mathrm{H}$ entry and trapping constants were obtained for three copper-containing alloys - alloy $17200(\mathrm{Cu}-2 \% \mathrm{Be})$ and two heats of alloy $\mathrm{K}-500$ - by using HIAPP. The research was aimed at characterizing the intrinsic susceptibility of each alloy to HE in terms of its irreversible trapping constant. The hydrogen entry and trapping constants for these alloys were compared with those for the $77 \mathrm{Cu}-15 \mathrm{Ni}$ alloy and alloy $\mathrm{K}-500$ studied previously, with the objective of relating these characteristics to the HE susceptibilities of the alloys.

\section{EXPERIMENTAL PROCEDURE}

The composition of each heat of alloy $\mathrm{K}-500$ and, for comparison, the $77 \mathrm{Cu}-15 \mathrm{Ni}$ alloy is given in Table 2-1. The $\mathrm{Be}-\mathrm{Cu}$ alloy contained 1.8/2.0 Be and was supplied as rod with a diameter of $6.35 \mathrm{~mm}$. The alloy was received in an unaged condition with a Rockwell B hardness (HRB) of 93-95 (17-18 HRC), which corresponds to a yield strength of 585-613 MPa.

\footnotetext{
* Trade name of Langley Alloys, Ltd. (Berkshire, England).
} 
The two heats of alloy K-500 were supplied as sections of bar that had been solutionannealed and aged (AA) at $607^{\circ} \mathrm{C}$ for $16 \mathrm{~h}$ to give a yield strength in the range 689-724 MPa. The two heats are denoted as AA-1 and AA-2. Cylindrical specimens were machined from the sections of bar. In contrast to the present specimens, the alloy K-500 studied previously was supplied as cold-drawn (CD) rod that was direct-aged (DA) to give a yield strength of about $1096 \mathrm{MPa}$.

Details of the electrochemical cell and instrumentation have been given previously. ${ }^{13}$ The test electrodes of each alloy consisted of a 3.8-cm length of rod (1.27 cm in diameter) press-fitted into a polytetrafluoroethylene sheath so that only the planar end surface was exposed to the electrolyte. The surface was polished before each experiment with $\mathrm{SiC}$ paper followed by 0.05 $\mu \mathrm{m}$ alumina powder. The electrolyte contained $1 \mathrm{~mol} \mathrm{~L}^{-1}$ acetic acid and $1 \mathrm{~mol} \mathrm{~L}^{-1}$ sodium acetate with $15 \mathrm{ppm} \mathrm{As}_{2} \mathrm{O}_{3}$ and was deaerated continuously with argon before and throughout data acquisition. The potentials were measured with respect to a saturated calomel electrode (SCE). All tests were performed at $22 \pm 1^{\circ} \mathrm{C}$.

The test electrode was cathodically charged with hydrogen at a constant potential $\mathrm{E}_{\mathrm{c}}$ for a time $t_{c}$, after which the potential was stepped in the positive direction to a value $10 \mathrm{mV}$ negative of the open-circuit potential $E_{o c}$. Anodic current transients were obtained over a range of charging times, typically from 5 to $60 \mathrm{~s}$, at different overpotentials $\left(\eta=E_{c}-E_{o c}\right)$. The open-circuit potential of the test electrode was measured immediately before each charging time and was also used to monitor the stability of the alloy surface.

\section{RESULTS}

The current transients were analyzed using a diffusion/trapping model that was based on a constant entry flux at the surface. ${ }^{13,14}$ According to the model, the total anodic charge $\left(\mathrm{C} \mathrm{m}^{-2}\right)$ is given by

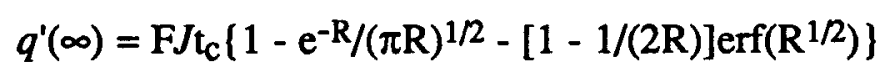

where $\mathrm{F}$ is the Faraday constant, $J$ is the ingress flux in $\mathrm{mol} \mathrm{m}^{-2} \mathrm{~s}^{-1}$, and $\mathrm{R}=k_{\mathrm{a}} \mathrm{t}_{\mathrm{c}}$. The charge $q^{\prime}(\infty)$ is equated to the charge $\left(q_{\mathrm{a}}\right)$ passed during the experimental anodic transients. $q_{\mathrm{a}}$ can be associated entirely with absorbed $\mathrm{H}$, since the adsorbed charge is almost invariably negligible. $k_{\mathrm{a}}$ is an apparent trapping constant measured for irreversible traps in the presence of reversible traps. It is related to the irreversible trapping constant $(k)$ by $k \mathrm{D}_{\mathrm{a}} / \mathrm{D}_{\mathrm{L}}$ where $\mathrm{D}_{\mathrm{a}}$ is the apparent diffusivity and $D_{L}$ is the lattice diffusivity of $H$. 
For the constant flux model to be applicable, it must be possible to determine a trapping constant for which $J$ is independent of charging time. Eq. [2-1] could in fact be fitted to the experimental data for $q_{\mathrm{a}}$ to obtain values of $k_{\mathrm{a}}$ and $J$ that satisfy this requirement at each potential. Values of $k_{\mathrm{a}}$ and $J$ for two tests on unaged Be-Cu are given in Table 2-2. In both cases, $k_{\mathrm{a}}$ is independent of charging potential, as is required for the model to be valid, since the trapping characteristics should be unaffected by electrochemical conditions at the metal surface. The overall mean value of $k_{\mathrm{a}}$ was $0.045 \pm 0.006 \mathrm{~s}^{-1}$. The flux was constant over the range of charging times for each overpotential and, as expected, increased with overpotential because of the dependence of $J$ on the surface coverage of adsorbed hydrogen. The surface coverage is assumed to respond rapidly to changes in potential, so the flux should exhibit an exponential dependence on potential. $\log J$ is indeed observed to vary linearly with $\eta$ (Fig. 2-1), indicating that the coverage response is very fast.

The AA-2 specimen of alloy K-500 has not been tested yet and only a limited number of tests have been performed on the AA-1 specimen. Values of $k_{\mathrm{a}}$ and $J$ for two tests on the AA-1 K500 are given in Table 2-3. Based on the tests to date, $k_{\mathrm{a}}$ appears to be independent of charging potential and has a mean value of $0.060 \pm 0.006 \mathrm{~s}^{-1}$. In this case, the flux showed only a slight dependence on overpotential.

\section{DISCUSSION}

\section{Irreversible Trapping Constants}

The irreversible trapping constants $(k)$ were derived from $k_{\mathrm{a}}$ by using diffusivity data for the "pure" alloy to obtain the lattice diffusivity $\left(D_{\mathfrak{L}}\right)$ and for the actual alloy to obtain the apparent diffusivity $\left(D_{\mathrm{a}}\right)$, so that the effect of reversible traps could be taken into account. The "pure" alloy is considered to be $\mathrm{Cu}$ for $\mathrm{Be}-\mathrm{Cu}$ and $\mathrm{Cu}-\mathrm{Ni}$ for alloy $\mathrm{K}-500$, so the minor alloying elements, either in their atomic form or as intermetallics that are precipitated during aging, are assumed to be largely responsible for reversible trapping in the actual alloys; for fcc alloys, defects such as vacancies or edge dislocations are unlikely to contribute significantly to reversible trapping, since the binding energy of hydrogen to defects such as vacancies or edge dislocations in an fcc lattice is somewhat (a factor of 4) smaller than the activation energy for diffusion. 15

Be-Cu. The diffusivity of hydrogen in $\alpha$-Cu over the temperature range $47^{\circ}-657^{\circ} \mathrm{C}$ is given by ${ }^{16}$

$$
\mathrm{D}=9.0 \times 10^{-7} \exp [-43.5(\mathrm{~kJ} / \mathrm{mol}) / \mathrm{RT}] \mathrm{m}^{2} \mathrm{~s}^{-1}
$$




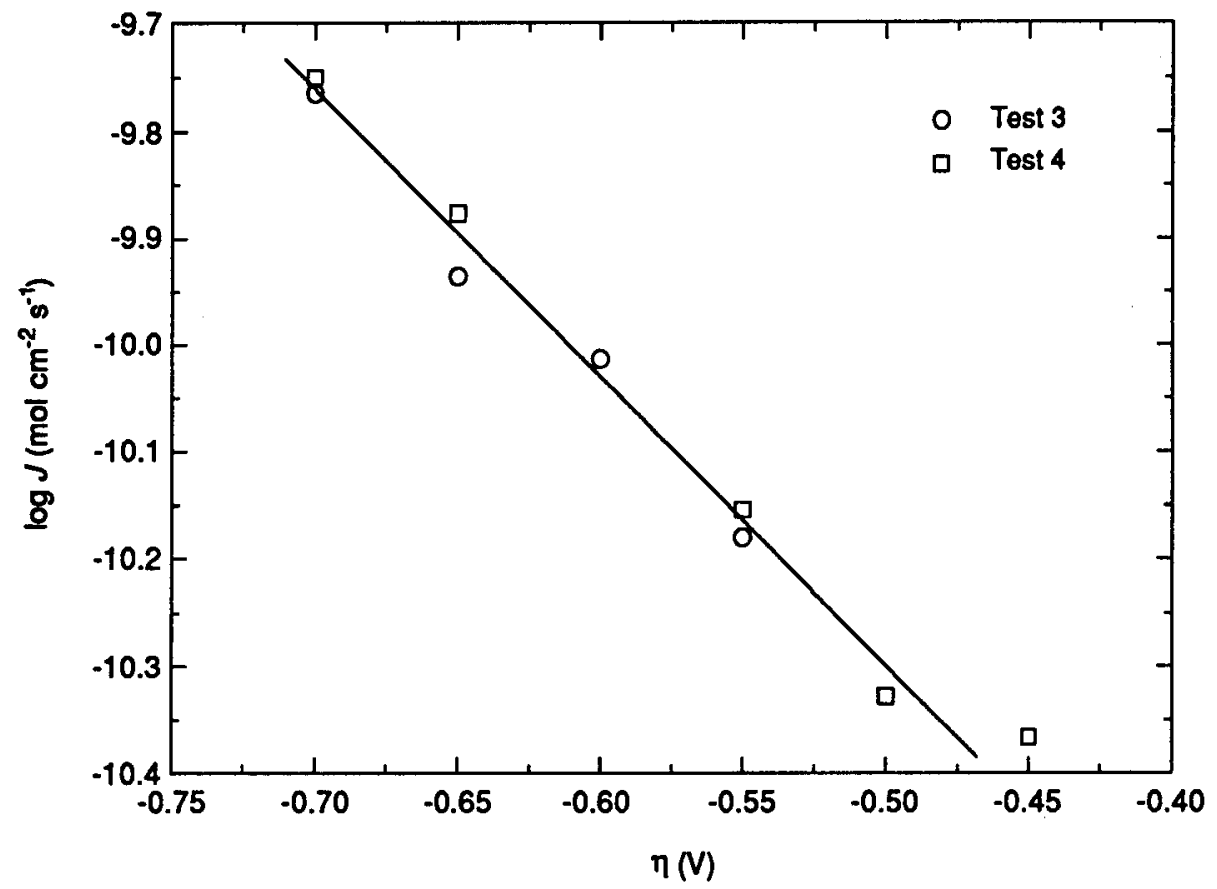

Figure 2-1. Dependence of entry flux on overpotential for Be-Cu in two identical tests. 
Extrapolation to $25^{\circ} \mathrm{C}$ gives a value of $2.1 \times 10^{-14} \mathrm{~m}^{2} \mathrm{~s}^{-1}$ at $25^{\circ} \mathrm{C}$. The addition of $2 \% \mathrm{Be}$ is unlikely to significantly affect the low diffusivity for copper. Hence, $\mathrm{D}_{\mathrm{a}}$ for unaged $\mathrm{Be}-\mathrm{Cu}$ is assumed to be similar in value to $\mathrm{D}_{\mathrm{L}}$, and so in this case, $k \sim k_{\mathrm{a}}$.

No data were available for the diffusivity in the aged alloy. However, in the case of alloy $\mathrm{K}-500$, the intermetallic particles appear to have little effect on $\mathrm{D}_{\mathrm{a}}$ compared with that of the minor alloying elements in solid solution. ${ }^{12}$ Hence, it was assumed that the intermetallic particles in Be$\mathrm{Cu}$ also have little effect on $\mathrm{D}_{\mathrm{a}}$ and $k$ was taken to have the value of $k_{\mathrm{a}}$.

Alloy K-500. The lattice diffusivity was determined by interpolation of data for a range of binary $\mathrm{Cu}-\mathrm{Ni}$ alloys and was found to be $(3.0 \pm 0.1) \times 10^{-14} \mathrm{~m}^{2} \mathrm{~s}^{-1}$ for $35 \mathrm{wt} \% \mathrm{Cu}-65 \% \mathrm{Ni}$ at $25^{\circ} \mathrm{C}$. 16 The level of $\mathrm{Cu}$ differs a little between the $35 \mathrm{Cu}-65 \mathrm{Ni}$ alloy and alloy $\mathrm{K}-500(30 \% \mathrm{Cu})$, but the error in using the diffusivity of the $35 \mathrm{Cu}$ alloy for $\mathrm{D}_{\mathrm{L}}$ is considered to be negligible. The diffusivity for annealed and aged alloy K-500 (assumed to be at ambient temperature) is $1.90 \times$ $10^{-14} \mathrm{~m}^{2} \mathrm{~s}^{-1}$, which is slightly higher than the value of $1.48 \times 10^{-14} \mathrm{~m}^{2} \mathrm{~s}^{-1}$ for the direct-aged alloy. ${ }^{3}$ By using these data for $\mathrm{D}_{\mathrm{L}}$ and $\mathrm{D}_{\mathrm{a}}, k$ was found to be $0.0 .096 \pm 0.013 \mathrm{~s}^{-1}$ for AA-1 alloy K-500.

\section{Comparison of Ingress Characteristics}

The irreversible trapping constants for the range of $\mathrm{Cu}$-containing alloys are listed in Table 2-4. They are also presented graphically in Fig. 2-2 to highlight differences between them. The $\mathrm{Be}-\mathrm{Cu}$ alloy $(1.8$ to $2.0 \mathrm{Be})$ in the unaged condition has a higher $k$ than that for unaged alloy $\mathrm{K}-500$ (unannealed CD) and therefore is intrinsically more susceptible to HE. The type of heat treatment has a marked effect on the trapping behavior of alloy K-500. The value of $k$ for annealed and aged alloy K-500 (AA-1) with a yield strength of $689-724 \mathrm{MPa}$ is more than twice as large as that for the direct-aged specimen with a yield strength of $1096 \mathrm{MPa}$. The $k$ value for the aged $77 \mathrm{Cu}-15 \mathrm{Ni}$ alloy with a yield strength of $793 \mathrm{MPa}$ is similar to that of direct-aged alloy K-500.

Mechanical tests have shown that the decrease in elongation was the same (71\%) for directaged and annealed-aged alloy K-500 after cathodic charging for $16 \mathrm{~h} .{ }^{3}$ The loss in ductility can be defined in terms of the percent decrease in elongation, anal0gously to the reduction of area used by other workers, ${ }^{17,18}$ and it is apparent that the observed resistance to HE is similar for the two types of aged alloy K-500 despite a difference in their intrinsic susceptibility. However, the entry flux was considerably higher (by up to a factor of 4 ) for the direct-aged specimen over the same range of overpotentials. ${ }^{12}$ Thus, the similarity in HE resistance may result from the lower intrinsic susceptibility being largely balanced by a higher entry flux. 


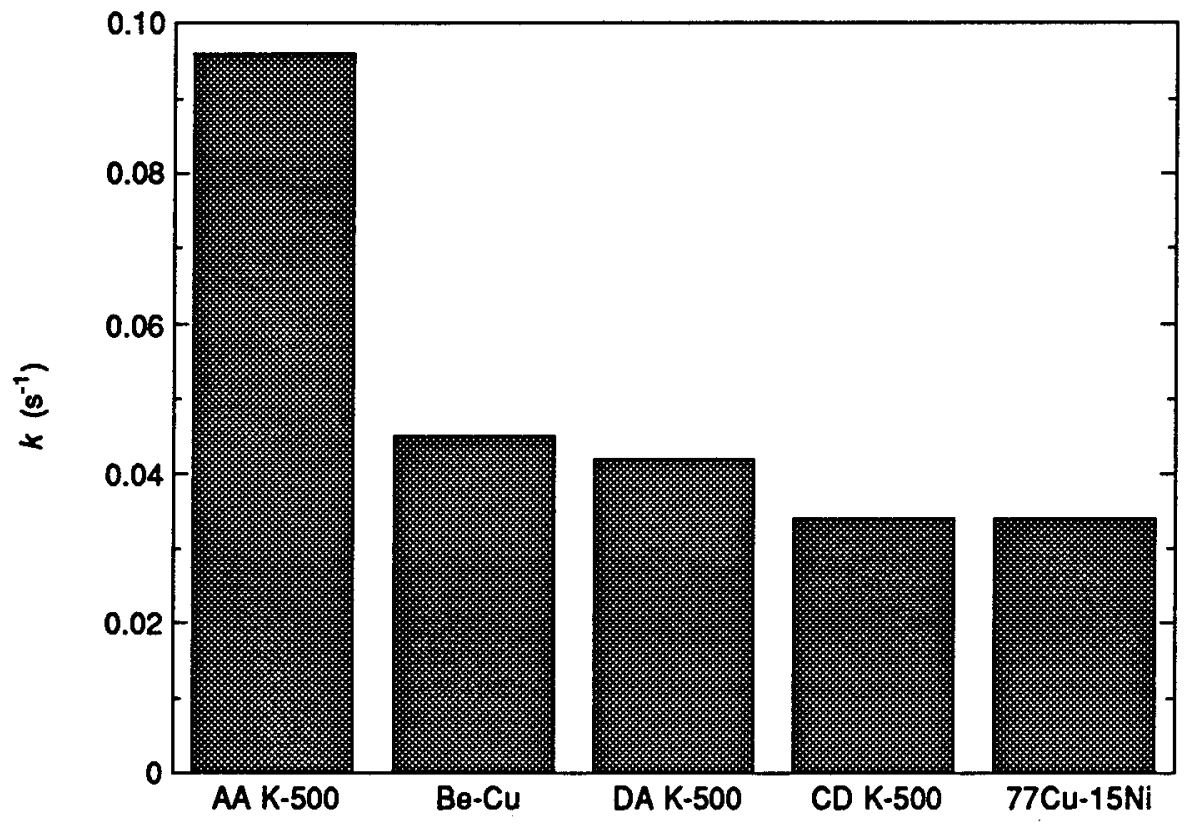

Figure 2-2. Variation in $k$ for $\mathrm{Be}-\mathrm{Cu}$, the $77 \mathrm{Cu}-15 \mathrm{Ni}$ alloy, and alloy $\mathrm{K}-500$ in annealed and aged (AA), direct-aged (DA), and cold-drawn (CD) unannealed/unaged conditions. 


\section{Identification of Irreversible Traps}

The density of particles or defects $\left(\mathrm{N}_{\mathrm{i}}\right)$ providing irreversible traps can be obtained from $k_{\mathrm{a}}$, according to Eq. [2-3]:

$$
\mathrm{N}_{\mathrm{i}}=k_{\mathrm{a}} a /\left(4 \pi d^{2} \mathrm{D}_{\mathrm{a}}\right)
$$

where $a$ is the diameter of the metal atom and $d$ is the trap radius. ${ }^{19,20}$ The value of $a$ for an alloy is taken as the mean of the atomic diameters weighted in accordance with the atomic fraction of each element. The trap radius is estimated from the dimensions of heterogeneities that are potential irreversible traps, and trap densities are then calculated for the different values of $d$. In this way, the dominant irreversible trap can be identified by comparing the values of $\mathrm{N}_{\mathrm{i}}$ with the actual concentrations of specific heterogeneities.

In the previous work on direct-aged alloy K-500, the irreversible traps predominantly encountered by hydrogen in alloy K-500 were assumed to be provided by sulfur segregated at grain boundaries. ${ }^{12}$ This assumption was based on two factors: First, $\mathrm{HE}$ in Ni-Cu base alloys, as noted above, is assisted by sulfur segregated at grain boundaries ${ }^{4}$ and hydrogen also probably segregates to the grain boundaries as in nickel. ${ }^{21}$ Second, in the case of alloys C-276 and 35N, the calculated trap densities were in close agreement with the amount of grain boundary $S$ and $P$ distributed per unit volume $\left(\mathrm{C}_{\mathrm{gb}}\right)$ of the alloy, whereas there were large differences between $\mathrm{N}_{\mathrm{i}}$ and the bulk S-P content in these alloys. ${ }^{11}$

The absence of data for $S$ segregation in alloy K-500 meant that the identity of the principal irreversible traps could not be verified by comparing $\mathrm{N}_{\mathrm{i}}$ with the grain boundary concentration in this case. On the other hand, it was apparent that the principal traps were not associated with matrix $S$, since $N_{i}$ was about 3 orders of magnitude less than the $S$ content $\left(1.6 \times 10^{24}\right.$ atoms m $\left.{ }^{-3}\right)$ of the alloy. TiN particles present in alloy K-500 were likewise ruled out as the principal traps because of a large ( 2 orders of magnitude) difference between the corresponding value of $\mathrm{N}_{\mathrm{i}}$ and the particle concentration. Further support was provided by results for the $77 \mathrm{Cu}-15 \mathrm{Ni}$ alloy, which was found to have a higher trap density than the $65 \mathrm{Ni}-30 \mathrm{Cu}$ alloy K-500.12 Even allowing for some difference in the degree of segregation between the two alloys, the higher trap density was consistent with a higher level of grain boundary segregants, based on the higher S-P content $(0.015 \mathrm{wt} \%)$ of the $77 \mathrm{Cu}-15 \mathrm{Ni}$ alloy.

A recent study, however, has suggested that intergranular cracking of AA alloy K-500 may be due to grain boundary carbon. ${ }^{22}$ The two AA heats used in that study were the same as those in the present work. A bulk chemical analysis of AA specimens did not detect known embrittling elements such as $\mathrm{P}$ and $\mathrm{S}$, nor did an energy dispersive spectroscopic analysis did not detect 
embrittling elements on the fracture surfaces. However, high-resolution scanning Auger electron spectroscopy showed graphitic carbon to be located on the intergranular facets and within grain boundaries. The only significant compositional difference between the annealed-aged and directaged specimens is that their levels of $\mathrm{Si}$ are $<0.05$ and $0.15 \mathrm{wt} \%$, respectively. However, there are clearly microstructural differences between them, as indicated by differences in hardness and yield strength.

\section{SUMMARY}

- $\mathrm{Be}-\mathrm{Cu}(1.8$ to $2.0 \mathrm{Be}$ ) in the unaged condition has a higher $k$ than that for unaged alloy $\mathrm{K}-500$ (unannealed CD) and therefore is intrinsically more susceptible to $\mathrm{HE}$.

- The type of heat treatment has a marked effect on the trapping behavior of alloy K-500. The value of $k$ for the annealed and aged alloy (AA-1) is more than twice as large as that for a direct-aged specimen. However, the direct-aged alloy has a value of $k$ similar to that of the aged $77 \mathrm{Cu}-15 \mathrm{Ni}$ alloy.

- The intrinsic susceptibility, as defined by $k$, of annealed-aged and direct-aged alloy K500 differs markedly, yet other work has shown from the decrease in elongation that their HE resistance was similar. However, it is possible that the the difference in intrinsic susceptibility is compensated for by the considerable difference observed between the entry flux for these alloys.

- The primary irreversible traps in direct-aged alloy K-500 are believed to involve sulfur and phosphorus segregated at grain boundaries, but in the case of annealed and aged alloy $\mathrm{K}-500$, there is evidence that graphitic carbon—not sulfur-is associated with HE.

\section{ACKNOWLEDGEMENTS}

Financial support of this work by the U.S. Office of Naval Research under Contract N00014-91-C-0263 is gratefully acknowledged. The author is also grateful to Dr. M Natishan, then at the David Taylor Research Center, Department of the Navy but now at the University of Maryland, for providing samples of the two heats of alloy K-500. 


\section{REFERENCES}

1 Metals Handbook, 9th ed., Vol. 2 (American Society for Metals, Metals Park, OH, 1979), p. 303.

2. Monel Nickel-Copper Alloys, 4th ed., Huntington Alloys (Huntington, WV, 1981), p. 31.

3. J. A. Harris, R. C. Scarberry, and C. D. Stephens, Corrosion 28, 57 (1972).

4. J. D. Frandsen and H. L. Marcus, in Effect of Hydrogen on Behavior of Materials, A. W. Thompson and I. M. Bernstein, Eds. (The Metallurgical Society of AIME, Warrendale, PA, 1976), p. 233.

5. W. C. Johnson, J. E. Doherty, B. H. Kear, and A. F. Giamei, Scripta Metall. 8, 971 (1974).

6. Metals Handbook, 9th ed., Vol. 9 (American Society for Metals, Metals Park, OH, 1985), p. 436.

7. B. J. Berkowitz and R. D. Kane, Corrosion 36, 24 (1980).

8. R. D. Kane and B. J. Berkowitz, Corrosion 36, 29 (1980).

9. I. M. Bernstein and G. M. Pressouyre, in Hydrogen Degradation of Ferrous Alloys, R. A. Oriani, J. P. Hirth, and M. Smialowski, Eds. (Noyes Publications, Park Ridge, NJ, 1985), p. 641.

10. G. M. Pressouyre and I. M. Bernstein, Acta Metall. 27, 89 (1979).

11. B. G. Pound, in Proceedings of the Fifth International Conference on Hydrogen Effects on Material Behavior, N. R. Moody and A. W. Thompson, Eds. (The Minerals, Metals \& Materials Society, Warrendale, PA, 1994), in press.

12. B. G. Pound, Corrosion 50, 301 (1994).

13. B. G. Pound, Corrosion 45, 18 (1989).

14. R. McKibbin, D. A. Harrington, B. G. Pound, R. M. Sharp, and G. A. Wright, Acta Metall. 35, 253 (1987).

15. W. D. Wilson and S. C. Keeton, in Advanced Techniques for Characterizing Hydrogen in Metals, N. F. Fiore and B. J. Berkowitz, Eds. (The Metallurgical Society of AIME, Warrendale, PA, 1981), p. 3.

16. H. Hagi, Trans. Jpn. Inst. Metals 27, 233 (1986).

17. A. W. Thompson, Metall. Trans. 7A, 315 (1976).

18. A. W. Thompson, Metall. Trans. 6A, 1431 (1975).

19. B. G. Pound, R. M. Sharp, and G. A. Wright, Acta Metall. 35, 263 (1987).

20. B. G. Pound, Acta Metall. 38, 2373 (1990).

21. D. H. Lassila and H. K. Birnbaum, Acta Metall. 35, 1815 (1987).

22. M. E. Natishan, E. R. Sparks, and M. L. Tims, in ISTFA '90: Proceedings of the International Symposium for Testing and Failure Analysis, (American Society for Metals, Metals Park, OH, 1990), p. 385. 
Table 2-1

COMPOSITION (wt\%) OF Cu-CONTAINING ALLOYS

\begin{tabular}{|c|c|c|c|c|}
\hline Element & $\begin{array}{c}K-500 \\
D A\end{array}$ & $\begin{array}{r}K-500 \\
A A-1\end{array}$ & $\begin{array}{r}K-500 \\
A A-2\end{array}$ & Marinel \\
\hline Al & 2.92 & 2.95 & 2.95 & 1.61 \\
\hline$c$ & 0.16 & $<0.17$ & $<0.14$ & 0.010 \\
\hline $\mathrm{Cr}$ & & & & 0.40 \\
\hline $\mathrm{Cu}$ & 29.99 & 29.53 & 29.8 & 76.8 \\
\hline $\mathrm{Fe}$ & 0.64 & $<0.85$ & $<0.74$ & 0.96 \\
\hline $\mathrm{Mg}$ & & & & 0.02 \\
\hline$M n$ & 0.72 & $<0.70$ & $<0.58$ & 4.36 \\
\hline $\mathrm{Nb}$ & & & & 0.69 \\
\hline $\mathrm{Ni}$ & 64.96 & 65.29 & 65.1 & 15.00 \\
\hline $\mathbf{P}$ & & & $<0.002$ & 0.010 \\
\hline $\mathrm{Pb}$ & & & & 0.007 \\
\hline$S$ & 0.001 & $<0.001$ & $<0.001$ & 0.005 \\
\hline Si & 0.15 & $<0.05$ & $<0.15$ & 0.05 \\
\hline Sn & & & & $<0.02$ \\
\hline $\mathrm{Ti}$ & 0.46 & 0.46 & 0.44 & \\
\hline $\mathrm{Zn}$ & & & & 0.02 \\
\hline
\end{tabular}

Table 2-2

VALUES OF $k_{a}$ AND $J$ FOR UNAGED Be-Cu

\begin{tabular}{llllll}
\hline Test & $\eta(V)$ & $E_{\mathrm{c}}(\mathrm{V} / \mathrm{SCE})$ & $k_{\mathrm{a}}\left(\mathrm{s}^{-1}\right)$ & $J\left(\mathrm{nmol} \mathrm{cm}^{-2} \mathrm{~s}^{-1}\right)$ & Mean $k_{\mathrm{a}}$ \\
\hline 1 & -0.55 & -0.696 & 0.035 & 0.066 & \\
& -0.60 & -0.746 & 0.048 & 0.097 & $0.047 \pm 0.006$ \\
& -0.65 & -0.780 & 0.049 & 0.116 & \\
& -0.70 & -0.836 & 0.054 & 0.172 & \\
& & & & & \\
& -0.45 & -0.620 & 0.045 & 0.043 & $0.044 \pm 0.006$ \\
& -0.50 & -0.659 & 0.038 & 0.047 & \\
& -0.55 & -0.694 & 0.035 & 0.070 & \\
& -0.65 & -0.778 & 0.051 & 0.133 & \\
& -0.70 & -0.841 & 0.052 & 0.178 & \\
\hline
\end{tabular}


Table 2-3

VALUES OF $k_{a}$ AND $J$ FOR ALLOY K-500

\begin{tabular}{lcccccc}
\hline Heat & Test & $\eta(V)$ & $E_{c}(V / S C E)$ & $k_{\mathrm{a}}\left(\mathrm{s}^{-1}\right)$ & $J\left(\mathrm{nmol} \mathrm{cm}^{-2} \mathrm{~s}^{-1}\right)$ & Mean $k_{\mathrm{a}}$ \\
\hline AA-1 & 3 & -0.25 & -0.366 & 0.059 & 0.048 & \\
& & -0.30 & -0.411 & 0.051 & 0.046 & $0.061 \pm 0.006$ \\
& -0.35 & -0.461 & 0.062 & 0.051 & \\
& -0.40 & -0.511 & 0.070 & 0.055 & \\
& & & & & \\
& 4 & -0.25 & -0.364 & 0.058 & 0.043 & $0.059 \pm 0.006$ \\
& -0.30 & -0.411 & 0.045 & 0.040 & \\
& -0.35 & -0.460 & 0.063 & 0.059 & \\
& -0.40 & -0.509 & 0.061 & 0.052 & \\
& -0.45 & -0.558 & 0.069 & 0.053 & \\
\hline
\end{tabular}

Table 2-4

TRAPPING CONSTANTS FOR COPPER-CONTAINING ALLOYS

\begin{tabular}{llcccc}
\hline Alloy & State & $\begin{array}{c}\text { Yield Strength } \\
(\mathrm{MPa})\end{array}$ & $k_{\mathrm{a}}\left(\mathrm{s}^{-1}\right)$ & $\mathrm{D}_{\mathrm{L}} / \mathrm{D}_{\mathrm{a}}$ & $k\left(\mathrm{~s}^{-1}\right)$ \\
\hline $\mathrm{K}-500(\mathrm{AA}-1)$ & Annealed-aged & $689-724$ & $0.060 \pm 0.006$ & 1.6 & $0.096 \pm 0.013$ \\
$\mathrm{Be}-\mathrm{Cu}$ & Unaged & $585-613$ & $0.045 \pm 0.006$ & $\sim 1$ & $0.045 \pm 0.006$ \\
$\mathrm{~K}-500(\mathrm{DA})$ & Direct-aged & 1096 & $0.021 \pm 0.003$ & 2.0 & $0.042 \pm 0.007$ \\
$\mathrm{~K}-500(\mathrm{CD})$ & Unaged & 758 & $0.017 \pm 0.003$ & 2.0 & $0.034 \pm 0.007$ \\
$77 \mathrm{Cu}-15 \mathrm{Ni}$ & Aged & 793 & $0.034 \pm 0.004$ & $\sim 1$ & $0.034 \pm 0.015$ \\
\hline
\end{tabular}


THE INGRESS OF HYDROGEN INTO A SUPERFERRITIC STAINLESS STEEL

\section{ABSTRACT}

The ingress of hydrogen into a superferritic stainless steel - UNS $\$ 44660$, its hydrogenresistant grade, and an intermediate grade - was studied using a technique referred to as hydrogen ingress analysis by potentiostatic pulsing (HIAPP). Anodic current transients were obtained for these alloys in $1 \mathrm{~mol} \mathrm{~L}^{-1}$ acetic acid/1 $\mathrm{mol} \mathrm{L}^{-1}$ sodium acetate, but the three grades of UNS $\$ 44660$ proved difficult to investigate in terms of trapping. In all cases, hydrogen entry was still low when reduction of the surface oxide occurred at a charging potential of $-0.6 \mathrm{~V}(S C E)$. As a result, negligible hydrogen entered the alloys, and so their trapping characteristics could not be determined. On the other hand, it was clear that the surface oxides were effective barriers to hydrogen entry and therefore that these superferritics should be resistant to HE in mildly acidic or near-neutral solutions, provided that the potential is less cathodic than -0.6 V (SCE). The propensity of superferritics to undergo $H E$ in seawater when they are cathodically polarized to potentials in the range -0.9 to $-1.4 \mathrm{~V}$ (SCE) can be attributed to the absence of an oxide and hence to the relatively unrestricted entry of $H$ into the alloy. An effective way of rendering the UNS $\$ 44660$ alloy more resistant to $H E$ is to reduce the intrinsic susceptibility by controlling the number and type of carbide particles, as has apparently been done for the hydrogen-resistant grade.

\section{INTRODUCTION}

Superferritic stainless steels such as Sea-Cure* (UNS S44660) and 29-4C (UNS S44735) are used for tubes in power plant condensers that are seawater-cooled. In many cases, the waterboxes and tube sheets in the condensers must be cathodically protected. However, the superferritics exhibit hydrogen embrittlement (HE) when they are polarized to potentials in the range -0.9 to $-1.4 \mathrm{~V}$ (SCE). ${ }^{1}$ This problem led to the development of a grade of the UNS S44660 alloy that is reportedly resistant to HE at cathodic potentials up to $-2.0 \mathrm{~V}$ (SCE). ${ }^{2}$ The new grade, which is designated as Sea-Cure Hy-Resist*, was obtained by restricting the combined $\mathrm{C}$ and $\mathrm{N}$ content to a maximum of $0.02 \%$ and replacing $\mathrm{Ti}$ by $\mathrm{Nb}$. These compositional changes are presumed to affect the alloy's intrinsic susceptibility to HE by modifying the number and type of carbide particles, which are known to be strong hydrogen traps. ${ }^{3}$ Thus, the differences observed

\footnotetext{
* Trade names of Crucible Materials Corporation, Pittsburgh, PA.
} 
in the HE resistance for the UNS S44660 alloy and its hydrogen-resistant grade should correspond to differences in their hydrogen trapping characteristics. In other words, the improvement in the HE resistance with the changes in stabilizing elements and impurity elements suggests that hydrogen trapping plays a crucial role in determining the resistance of these alloys to $\mathrm{HE}$ at highly cathodic potentials.

The entry and trapping of hydrogen in various alloys have been investigated in recent work using an electrochemical technique referred to as hydrogen ingress analysis by potentiostatic pulsing (HIAPP). ${ }^{4}$ Values were determined for the rate of hydrogen entry and the rate constant for irreversible trapping $(k)$. In addition, the trapping constants were analyzed to determine the density of particles or defects $\left(\mathrm{N}_{\mathrm{i}}\right)$ providing irreversible traps. The objective of the present study was to determine the rate of $\mathrm{H}$ entry and trapping constants in the UNS $\$ 44660$ alloy, its hydrogenresistant grade and an intermediate grade. The research was aimed at characterizing the intrinsic susceptibility in each case to $\mathrm{HE}$ in terms of the irreversible trapping constant and then relating the intrinsic susceptibility to the observed resistance to HE.

\section{EXPERIMENTAL PROCEDURE}

The thickness and composition of each grade of the stainless steel are given in Table 3-1. The stabilizing element is $\mathrm{Ti}$ in the standard grade and $\mathrm{Nb}$ in the hydrogen-resistant grade, whereas the intermediate grade contains both elements. The other significant difference is that the hydrogen-resistant grade has much less $\mathrm{C}$ and $\mathrm{N}$ than either of the other grades. A minor change was also made in that small amounts of $\mathrm{Cu}$ and $\mathrm{Al}$ were added to the intermediate and hydrogenresistant grades.

Details of the electrochemical cell and instrumentation have been given previously. 5 The three grades of Sea-Cure were supplied as sheet. Test electrodes were fabricated by machining a disk ( $1.27 \mathrm{~cm}$ in diameter) from each sheet and press-fitting it into a polytetrafluoroethylene sheath so that only one surface was exposed. The electrode surface was polished before each experiment with $\mathrm{SiC}$ paper followed by $0.05-\mu \mathrm{m}$ alumina powder. The electrolyte contained $1 \mathrm{~mol} \mathrm{~L}^{-1}$ acetic acid and $1 \mathrm{~mol} \mathrm{~L}^{-1}$ sodium acetate with $15 \mathrm{ppm} \mathrm{As}_{2} \mathrm{O}_{3}$ and was deaerated continuously with argon before and throughout data acquisition. The potentials were measured with respect to a saturated calomel electrode (SCE). All tests were performed at $22 \pm 1^{\circ} \mathrm{C}$.

The test electrode was charged with hydrogen for times from $5 \mathrm{~s}$ to $60 \mathrm{~s}$ for each $\mathrm{E}_{\mathrm{c}}$. Anodic current transients with a charge $q_{\mathrm{a}}$ were obtained for each charging time over a range of cathodic overpotentials $\left(\eta=E_{c}-E_{o c}\right.$ ). The open-circuit potential of the test electrode was sampled immediately before each pulse. 


\section{RESULTS}

For most alloys, the charge $\left(q_{\mathrm{a}}\right)$ associated with the current transients can be analyzed using a diffusion/trapping model that has been derived for conditions imposed by the pulse technique. ${ }^{6}$ The analysis yields values of the ingress flux $(J)$ and an apparent trapping constant $\left(k_{\mathrm{a}}\right)$, which is used to determine the rate constant for irreversible trapping $(k)$. However, all three grades of the UNS $\$ 44660$ alloy showed little change in $q_{\mathrm{a}}$ with charging time at cathodic potentials up to reduction of the surface oxide at about $-0.6 \mathrm{~V}$ (SCE).

It was evident that hydrogen entry does not increase enough with overpotential to become significant before the oxide is reduced. Thus, $q_{\mathrm{a}}$ must correspond almost entirely to oxidation of the adsorbed layer of hydrogen. If the adsorbed hydrogen is assumed to respond very rapidly to a change in potential, the surface coverage might be expected to exhibit an exponential dependence on overpotential. For all three alloys, $\log q_{\mathrm{a}}$ was found to vary linearly with $\eta$ (Fig. 3-1), which suggests that Nernstian-type conditions do in fact exist at the surface of the alloys with respect to the discharge reaction.

\section{DISCUSSION}

The amount of hydrogen that entered the UNS S44660 alloy and its other two grades during cathodic charging appears to have been negligible, as implied by the lack of change in $q_{\mathrm{a}}$. As a result, the trapping constants could not be evaluated for any of the grades. On the other hand, the results did indicate that the surface oxides formed on these alloys in the acetate solution $(\mathrm{pH}$ 4.8) were effective barriers to hydrogen entry and therefore that these superferritics should be resistant to $\mathrm{HE}$ in mildly acidic or near-neutral solutions, provided that the potential was less cathodic than about $-0.6 \mathrm{~V}$ (SCE). At more cathodic potentials when the oxide was reduced, hydrogen gas was evolved rapidly enough to produce bubbles on the alloy surface in the acetate solution.

The behavior of the UNS $\$ 44660$ alloy is consistent with that observed for superferritics under cathodic protection in seawater. Although the $\mathrm{pH}$ of seawater is usually slightly alkaline ( $\mathrm{pH}$ 8), the superferritics are unlikely to possess a surface oxide at highly cathodic potentials. Thus, the propensity of superferritics to undergo $\mathrm{HE}$ in seawater when they are cathodically polarized to potentials in the range -0.9 to $-1.4 \mathrm{~V}$ (SCE) can be attributed to the absence of an oxide and hence to the relatively unrestricted entry of hydrogen into the alloy. Changes in the alloying elements that are designed to produce a modified surface oxide, and hence a modified rate of hydrogen entry, would clearly be irrelevant at highly cathodic potentials. Therefore, in the absence of coatings, the 


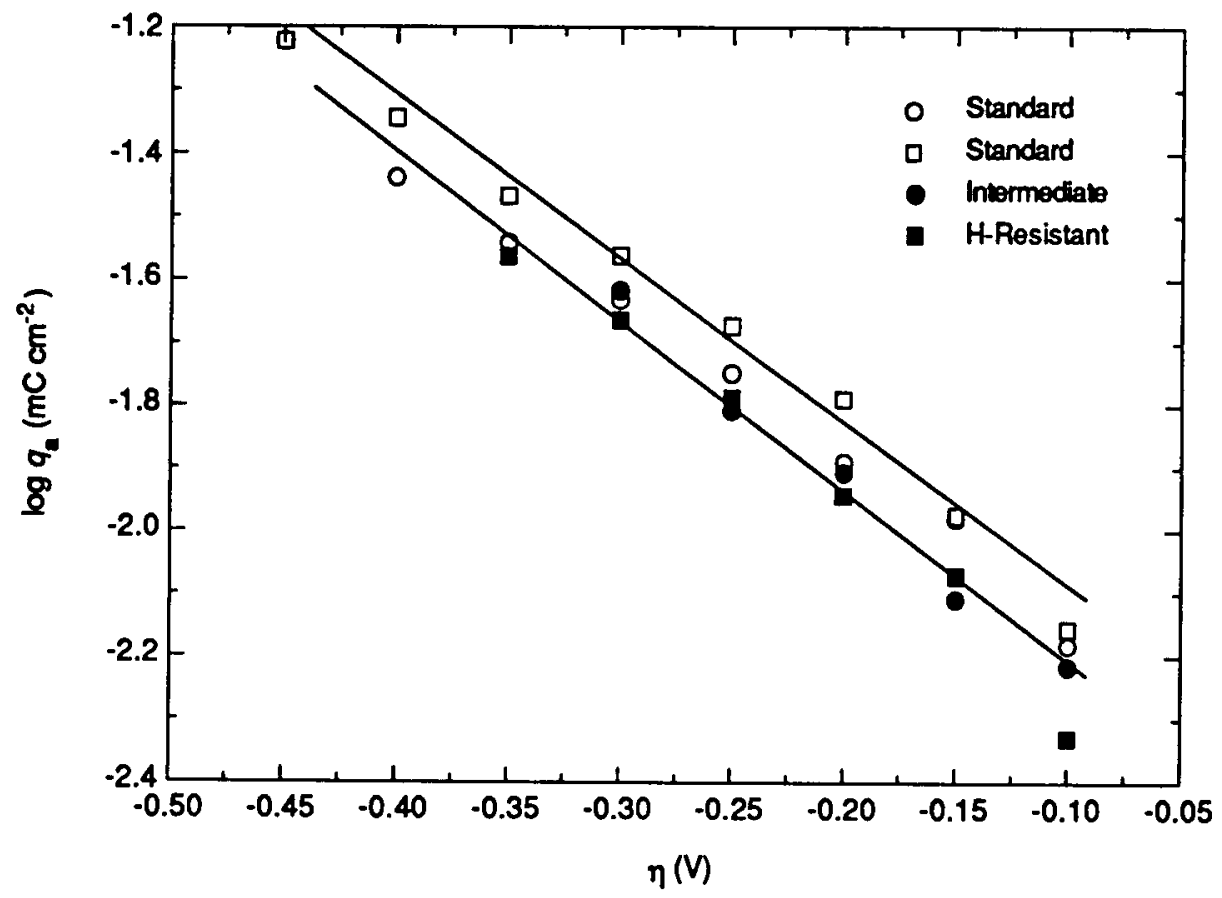

Figure 3-1. Dependence of $\log q_{a}$ on overpotential for the three grades of the UNS S44660 alloy. The two sets of data shown for the standard grade were obtained from identical tests. 
most effective way of rendering the UNS $\$ 44660$ alloy more resistant to HE is to reduce the intrinsic susceptibility by controlling the number and type of carbide particles, as has apparently been done for the hydrogen-resistant grade. It may be possible to determine the trapping constants of the three grades of the UNS $\$ 44660$ alloy by coating the surface with palladium to enhance hydrogen entry at cathodic potentials where the oxide would be stable.

\section{SUMMARY}

- The surface oxides on the three grades of the UNS S44660 alloy were effective barriers to hydrogen entry. Hence, these alloys should be resistant to $\mathrm{HE}$ in mildly acidic or near-neutral solutions at potentials in the range of oxide stability.

- The propensity of superferritics to undergo HE in seawater when they are cathodically polarized to potentials in excess of $-0.9 \mathrm{~V}$ (SCE) can be attributed to the relatively unrestricted entry of hydrogen into the alloy, as a result of the absence of a surface oxide.

- The resistance to HE of the UNS $\$ 44660$ alloy is most effectively improved by reducing the intrinsic susceptibility in terms of carbide particles, since changes to the surface oxide and hence the rate of hydrogen entry would be of no consequence at highly cathodic potentials.

\section{ACKNOWLEDGEMENTS}

Financial support of this work by the U.S. Office of Naval Research under Contract N00014-91-C-0263 is gratefully acknowledged. The author is also grateful to Mr. J. Eckenrod of Crucible Research for supplying samples of the three grades of the UNS S44660 alloy.

\section{REFERENCES}

1. J. F. Grubb and J. R. Maurer, "Use of Cathodic Protection with Superferritic Stainless Steels," Paper No. 28, CORROSION/84 (National Association of Corrosion Engineers, Houston, TX, 1984).

2. Crucible Materials Corporation, U.S. Patent No. 4942922; Sea-Cure Hy-Resist (UNS S44660), Data Sheet, Trent Tube (East Troy, WI).

3. I. M. Bernstein and G. M. Pressouyre, in Hydrogen Degradation of Ferrous Alloys, R. A. Oriani, J. P. Hirth, and M. Smialowski, Eds. (Noyes Publications, Park Ridge, NJ, 1985), p. 641. 
4. B. G. Pound, in Proceedings of the Fifth International Conference on Hydrogen Effects on Material Behavior, N. R. Moody and A. W. Thompson, Eds. (The Minerals, Metals \& Materials Society, Warrendale, PA, 1994), in press.

5. B. G. Pound, Corrosion 45, 18 (1989).

6. R. McKibbin, D. A. Harrington, B. G. Pound, R. M. Sharp, and G. A. Wright, Acta Metall. 35, 253 (1987). 
Table 3-1

COMPOSITION (wt\%) AND THICKNESS OF THE UNS $\mathbf{5 4 4 6 6 0}$ ALLOY AND MODIFIED GRADES

\begin{tabular}{lccc}
\hline Element & Standard & Intermediate & H-Resistant \\
\hline $\mathrm{Al}$ & & 0.058 & 0.09 \\
$\mathrm{C}$ & 0.018 & 0.027 & 0.006 \\
$\mathrm{Cr}$ & 27.00 & 27.18 & 26.90 \\
$\mathrm{Cu}$ & & 0.11 & 0.06 \\
$\mathrm{Fe}$ & 66.45 & 65.66 & 66.53 \\
$\mathrm{Mn}$ & 0.26 & 0.38 & 0.36 \\
$\mathrm{Mo}$ & 3.40 & 3.26 & 3.51 \\
$\mathrm{Nb}+\mathrm{Ta}$ & & 0.37 & 0.26 \\
$\mathrm{~N}$ & 0.025 & 0.025 & 0.006 \\
$\mathrm{Ni}$ & 1.99 & 1.96 & 1.92 \\
$\mathrm{P}$ & 0.021 & 0.029 & 0.025 \\
$\mathrm{~S}$ & 0.001 & 0.001 & 0.001 \\
$\mathrm{Si}$ & 0.40 & 0.66 & 0.33 \\
$\mathrm{Ti}$ & 0.44 & 0.28 & \\
Thickness $(\mathrm{mm})$ & 2.3 & 2.1 & 2.6 \\
\hline
\end{tabular}




\title{
Section 4
}

\section{THE RESISTANCE OF HIGH-STRENGTH ALLOYS TO HYDROGEN EMBRITTLEMENT*}

\begin{abstract}
The resistance of an alloy to hydrogen embrittlement $(H E)$ is strongly influenced by the presence of microstructural heterogeneities, which can provide sites to trap hydrogen. The entry and trapping of hydrogen in a range of high-strength alloys have been investigated with a technique referred to as hydrogen ingress analysis by potentiostatic pulsing (HIAPP). Data were analyzed by using a diffusion/trapping model to determine entry and trapping parameters for high-strength steels, precipitation-hardened and work-hardened nickel-base alloys, and titanium alloys. For most of the alloys studied, the observed resistance to $H E$ appeared to be determined primarily by the alloy's intrinsic susceptibility as defined by the trapping characteristics; that is, the $H$ entry flux generally has only a secondary effect on the resistance to $H E$. However, in one case, the HE resistance was attributable to a low entry flux. This type of case highlights the need for characterizing alloys in terms of both trapping capability and rate of $H$ entry to account for differences observed in their $H E$ resistance.
\end{abstract}

\section{INTRODUCTION}

Microstructural heterogeneities in alloys provide potential trapping sites for hydrogen and so can play a crucial role in determining an alloy's resistance to hydrogen embrittlement (HE). This role originates in the fact that the interaction of these heterogeneities with hydrogen can strongly influence the series of events leading to failure. ${ }^{1}$ The accumulation of hydrogen at second-phase particles and precipitates, for example, is generally considered to promote microvoid initiation via the fracture of particles or the weakening of particle-matrix interfaces. Traps with a large saturability and a high binding energy for hydrogen are highly conducive to $\mathrm{HE}, 2,3$ whereas alloys containing a high density of well-distributed irreversible (high binding energy) traps that have a low saturability should be less susceptible. Thus, the intrinsic susceptibility of an alloy to HE is highly dependent on the type of microstructural defect, with large irreversible traps typically imparting a high susceptibility.

\footnotetext{
* In Proceedings of the Tri-Service Conference on Corrosion (Wright-Patterson Air Force Base, Dayton, OH, 1994), in press.
} 
The basic concept of trap theory is that the local concentration of hydrogen trapped at a defect must reach some critical value $\left(C_{k}\right)$ for cracks to be initiated.1,3 It should be recognized, however, that the mechanism by which such an accumulation triggers $\mathrm{HE}$ is not addressed. The value of $\mathrm{C}_{\mathrm{k}}$, and therefore the intrinsic susceptibility of an alloy, is determined by the type of trap, its size, concentration (density), and other parameters. A decrease in $C_{k}$ will render the alloy more susceptible. However, whether embrittlement will actually occur is also affected by the amount of trapped $H$, which depends on factors such as the entry kinetics, exposure time, and transport mode. In some cases, an alloy may prove resistant during exposure because the amount of $\mathrm{H}$ that enters is small enough that the critical concentration at the traps is not exceeded. Likewise, when alloys have a similar intrinsic susceptibility in terms of their trapping characteristics, the difference in their actual resistance to $\mathrm{HE}$ is likely to be determined by the amount of $\mathrm{H}$ absorbed by each alloy.

Over the last few years, the entry and trapping of hydrogen in a wide range of highstrength alloys have been investigated at SRI.4-8 The rates of $\mathrm{H}$ entry and rate constants for irreversible trapping were determined using an electrochemical technique referred to as hydrogen ingress analysis by potentiostatic pulsing (HIAPP). 4,9 The research was aimed in part at characterizing the intrinsic susceptibility of the alloys to $\mathrm{HE}$ in terms of their irreversible trapping constants. The relative intrinsic susceptibilities then could be compared with results for the actual resistance to $\mathrm{HE}$ observed in tests by other workers. In this paper, the irreversible trapping constants and, where necessary, $H$ entry fluxes for the different alloys are compared, with the objective of providing a basis for explaining differences in the resistance of these alloys to HE.

\section{EXPERIMENTAL PROCEDURE}

The alloy of interest is cathodically charged with hydrogen at a constant potential $\mathrm{E}_{\mathrm{c}}$ for a time $t_{c}$, after which the potential is stepped in the positive direction. H diffuses back to the entry surface and is reoxidized, thereby generating an anodic current transient. Data are obtained over a range of charging times, typically from 5 to $60 \mathrm{~s}$, at different overpotentials $\left(\eta=E_{c}-E_{o c}\right)$ relative to the open-circuit potential $\left(\mathrm{E}_{\alpha c}\right)$, which is measured immediately before each charging time. $\mathrm{E}_{\alpha c}$ is also used to monitor the stability of the alloy surface, since any oxides present should not be reduced during charging.

The pulse technique was applied to high-strength steels, 4,5 precipitation-hardened and work-hardened nickel-base alloys, ${ }^{5,6}$ and titanium. ${ }^{7}$ The composition of each alloy is given in Table 4-1. Table 4-2 shows the yield strength of the alloys and the thermomechanical treatment used in each case. 
Table 4-1

Alloy Composition (wt\%)

\begin{tabular}{lllllllll}
\hline & 4340 & $18 \mathrm{Ni}$ & 718 & 925 & $\mathrm{C}-276$ & 625 & 716 & TiGr2 \\
\hline $\mathrm{Al}$ & 0.031 & 0.13 & 0.60 & 0.30 & & 0.18 & 0.22 & \\
$\mathrm{~B}$ & & 0.003 & 0.003 & & & & & \\
$\mathrm{C}$ & 0.42 & 0.009 & 0.03 & 0.02 & 0.002 & 0.03 & 0.011 & 0.021 \\
$\mathrm{Co}$ & & 9.15 & 0.16 & & 0.83 & & $<0.01$ & \\
$\mathrm{Cr}$ & 0.89 & 0.06 & 18.97 & 22.20 & 15.27 & 22.06 & 20.99 & \\
$\mathrm{Cu}$ & 0.19 & 0.11 & 0.04 & 1.93 & & & & \\
$\mathrm{Fe}$ & $\mathrm{bal}$ & $\mathrm{bal}$ & 16.25 & 28.96 & 5.84 & 4.37 & 5.32 & 0.17 \\
$\mathrm{Mn}$ & 0.46 & 0.01 & 0.10 & 0.62 & 0.48 & 0.17 & 0.01 & \\
$\mathrm{Mo}$ & 0.21 & 4.82 & 3.04 & 2.74 & 16.04 & 8.70 & 8.10 & \\
$\mathrm{O}$ & 0.001 & & & & & & & 0.16 \\
$\mathrm{Nb}+\mathrm{Ta}$ & & & 5.30 & & & 3.50 & 3.47 & \\
$\mathrm{Ni}$ & 1.74 & 18.42 & 54.41 & 40.95 & 57.5 & 60.33 & 60.5 & \\
$\mathrm{P}$ & 0.009 & 0.004 & 0.009 & & $<0.005$ & 0.012 & 0.004 & \\
$\mathrm{~S}$ & 0.001 & 0.001 & 0.002 & 0.001 & $<0.002$ & 0.001 & 0.001 & \\
$\mathrm{Si}$ & 0.28 & 0.04 & 0.11 & 0.17 & $<0.02$ & 0.38 & 0.02 & \\
$\mathrm{Ti}$ & & 0.65 & 0.98 & 2.11 & & 0.27 & 1.35 & bal \\
W & & 0.01 & & & 3.90 & & & \\
Other & $0.005 \mathrm{~N}$ & $0.05 \mathrm{Ca}$ & & & $0.12 \mathrm{~V}$ & & & $<0.005 \mathrm{H}$ \\
& & $0.02 \mathrm{Zr}$ & & & & & & $0.007 \mathrm{~N}$ \\
\hline
\end{tabular}

Test electrodes of each alloy were fabricated from a length $(1.3-3.8 \mathrm{~cm})$ of rod press-fitted into a Teflon sheath so that only the planar end surface was exposed to the electrolyte. The surface was polished before each experiment with $\mathrm{SiC}$ paper followed by $0.05-\mu \mathrm{m}$ alumina powder.

Table 4-2

Thermomechanical Treatment of Alloys

\begin{tabular}{lllr}
\hline Alloy & Heat Treatmenta & Test Condition & Yield Strength (MPa) \\
\hline 4340 & Annealed & HRC 41 & 1206 \\
& & HRC 53 & 1792 \\
$18 \mathrm{Ni}$ & Aged $\left(482^{\circ} \mathrm{C}, 4 \mathrm{~h}\right)$ & As received & 1954 \\
$\mathrm{~K}-500$ & Cold drawn, unaged & As received & 758 \\
& & Aged $\left(600^{\circ} \mathrm{C}, 8 \mathrm{~h}\right)$ & 1096 \\
$35 \mathrm{~N}$ & Cold drawn and aged & As received & 1854 \\
718 & Hot fin., solution treated & As received & 1238 \\
925 & Hot fin., annealed, aged & As received & 758 \\
$\mathrm{C}-276$ & Hot rolled & $27 \%$ cold work & 1237 \\
625 & Hot fin., annealed & $17 \%$ cold work & 1195 \\
716 & Annealed, aged & $4 \%$ cold work & 1186 \\
TiGr2 & Annealed $\left(620^{\circ} \mathrm{C}, 1 \mathrm{~h}\right)$ & As received & 380 \\
\hline
\end{tabular}

a Provided by producer. 
Details of the electrochemical cell and instrumentation have been given elsewhere. ${ }^{4}$ The alloys were exposed in a deaerated solution containing $1 \mathrm{~mol} \mathrm{~L}^{-1}$ acetic acid and $1 \mathrm{~mol} \mathrm{~L}^{-1}$ sodium acetate with $15 \mathrm{ppm} \mathrm{As}_{2} \mathrm{O}_{3}$ added to promote $\mathrm{H}$ entry. The potentials were measured with respect to a saturated calomel electrode (SCE). All tests were performed at $22 \pm 2^{\circ} \mathrm{C}$.

\section{ANALYSIS}

Although permeation methods have been used extensively, they suffer from several disadvantages, as discussed elsewhere. 10 The main theoretical limitation is that most, if not all, diffusion/trapping models for these methods are based on an input boundary condition of constant concentration. Hence, these models are strictly applicable only for charging conditions without any entry limitation.

In the case of HIAPP, a model has been developed to allow for the effect of trapping on diffusion for cases involving either a constant concentration or a constant flux at the input surface. 4,9 The constant flux model was found to apply to all alloys studied to date. In this model, the rate of hydrogen ingress is controlled by diffusion but the entry flux of hydrogen is restricted, which results in interface-limited diffusion control. Solution of the diffusion equation for a constant flux condition gives the following expression for the total anodic charge $\left(\mathrm{C} \mathrm{m}^{-2}\right)$ :

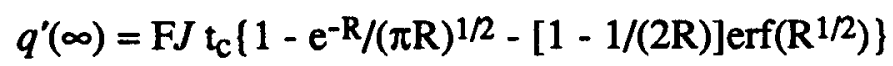

where $\mathrm{F}$ is the Faraday constant, $J$ is the ingress flux in mol m $\mathrm{m}^{-2} \mathrm{~s}^{-1}$, and $\mathrm{R}=k_{\mathrm{a}} \mathrm{t}_{\mathrm{c}}$. The charge $q^{\prime}(\infty)$ is equated to the charge $\left(q_{\mathrm{a}}\right)$ associated with the experimental anodic transients. $q_{\mathrm{a}}$ can be associated entirely with absorbed $\mathrm{H}$, since the adsorbed charge is almost invariably negligible.

$k_{\mathrm{a}}$ is an apparent trapping constant measured for irreversible traps in the presence of reversible traps. It is related to the irreversible trapping constant $(k)$ by $k \mathrm{D}_{\mathrm{a}} / \mathrm{D}_{\mathrm{L}}$ where $\mathrm{D}_{\mathrm{a}}$ is the apparent diffusivity and $\mathrm{D}_{\mathrm{L}}$ is the lattice diffusivity of $\mathrm{H}$. The magnitude of $k$ depends on the density of particles or defects $\left(\mathrm{N}_{\mathrm{i}}\right)$ providing irreversible traps, the radius $(d)$ of the trap defects, and the diameter $(a)$ of the metal atom ${ }^{11}$ :

$$
k=\frac{4 \pi d^{2} \mathrm{~N}_{\mathrm{i}} \mathrm{D}_{\mathrm{L}}}{a}
$$

The term $d^{2} \mathrm{~N}_{\mathrm{i}}$ represents the trapping capability and underlies the use of $k$ as an index of an alloy's intrinsic susceptibility to HE. 
For the constant flux model to be applicable, it must be possible to determine a trapping constant for which $J$ is independent of charging time. Data for $q_{\mathrm{a}}$ could in fact be fitted to Eq. (41) to obtain values of $k_{\mathrm{a}}$ and $J$ that satisfied this requirement at each potential. Experimental and fitted values of $q_{\mathrm{a}}$ for various charging times are compared in Fig. 4-1, which illustrates the level of agreement obtained for the alloys in this work.

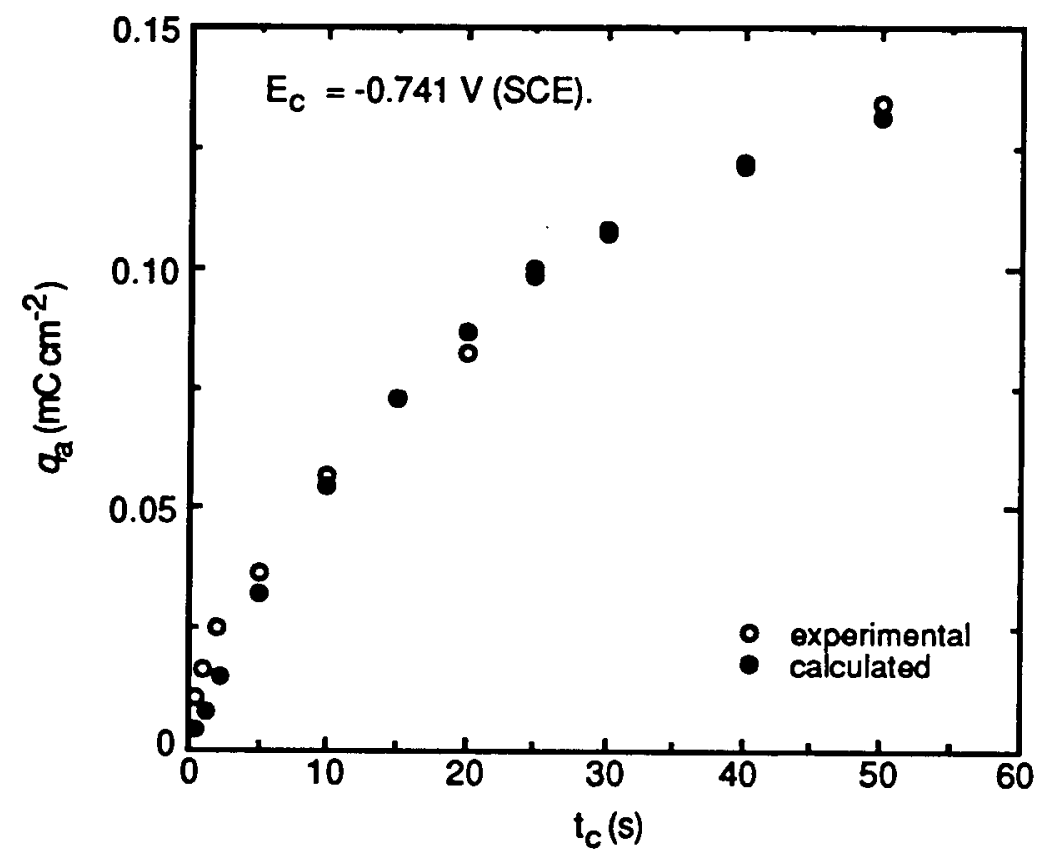

Figure 4-1. Dependence of anodic charge on charging time for Ti grade 2.

\section{RESULTS}

The alloys were studied as a series of groups, which were then merged to provide an overall comparison of the irreversible trapping constants. The values of $k_{\mathrm{a}}$ and $k$ for each group are summarized in Table 4-3. The first group consisted of a high-strength steel (AISI 4340) and two nickel-containing alloys (K-500 and 35N). ${ }^{4}$ The aim was to determine whether the irreversible trapping constants might assist in explaining differences observed in HE resistance between high-strength steels and nickel-base alloys. The values of both $k$ and $J$ for the steel were higher than those for alloys K-500 and 35N. Hence, both the irreversible trapping characteristics and the amount of $\mathrm{H}$ entering could account for the steel being less resistant to $\mathrm{HE}$ than the two nickel-containing alloys.

Two further groups of alloys were then studied: precipitation-hardened alloys $(718,925$, and $18 \mathrm{Ni}$ maraging steel $)^{5}$ and work-hardened alloys (625 and C-276). ${ }^{6}$ Alloys 625,718 , and 
Table 4-3

Trapping Parameters

\begin{tabular}{|c|c|c|c|}
\hline Alloy & $k_{\mathrm{a}}\left(\mathrm{s}^{-1}\right)$ & $D_{L} / D_{a}$ & $k\left(\mathrm{~s}^{-1}\right)$ \\
\hline $\begin{array}{l}4340 \text { Steel } \\
\text { K-500 Unaged } \\
\text { Aged } \\
35 \mathrm{~N}\end{array}$ & $\begin{array}{l}0.008 \pm 0.001 \\
0.017 \pm 0.003 \\
0.021 \pm 0.003 \\
0.026 \pm 0.002\end{array}$ & $\begin{array}{c}500 \\
2.0 \\
2.0 \\
1\end{array}$ & $\begin{array}{c}4.0 \pm 0.5 \\
0.034 \pm 0.006 \\
0.042 \pm 0.006 \\
0.026 \pm 0.002\end{array}$ \\
\hline $\begin{array}{l}718 \\
925 \\
18 \mathrm{Ni} \text { Steel }\end{array}$ & $\begin{array}{l}0.031 \pm 0.002 \\
0.006 \pm 0.003 \\
0.005 \pm 0.002 \\
0.010 \pm 0.005^{a}\end{array}$ & $\begin{array}{l}4.0 \pm 0.5 \\
5.6 \pm 0.6 \\
300 \pm 90 \\
300 \pm 90\end{array}$ & $\begin{array}{c}0.124 \pm 0.024 \\
0.034 \pm 0.004 \\
1.50 \pm 1.05 \\
3.00 \pm 2.40\end{array}$ \\
\hline $\begin{array}{l}\text { C-276 } \\
625 \\
716\end{array}$ & $\begin{array}{l}0.025 \pm 0.003 \\
0.019 \pm 0.010^{\mathrm{a}} \\
0.004 \pm 0.002 \\
0.054 \pm 0.004\end{array}$ & $\begin{array}{l}3.6 \pm 0.8 \\
3.6 \pm 0.8 \\
3.6 \pm 0.8 \\
3.8 \pm 0.8\end{array}$ & $\begin{array}{c}0.090 \pm 0.030 \\
0.068 \pm 0.051 \\
0.014 \pm 0.010 \\
0.20 \pm 0.06\end{array}$ \\
\hline Ti grade 2 & $\begin{array}{l}0.028 \pm 0.002 \\
0.012 \pm 0.006^{b}\end{array}$ & $\begin{array}{l}1 \\
1\end{array}$ & $\begin{array}{l}0.028 \pm 0.002 \\
0.012 \pm 0.006\end{array}$ \\
\hline
\end{tabular}

a Quasi-irreversible trapping. ${ }^{b}$ Hydride formation.

925 were each characterized by a single type of irreversible trap, whereas alloy C-276 and $18 \mathrm{Ni}$ maraging steel were characterized by both an irreversible trap and a quasi-irreversible trap. In irreversible trapping, the rate constant for release is assumed to be zero, whereas for the quasiirreversible case, the release constant is not zero but is too small to achieve local equilibrium between the lattice and trapped H. ${ }^{5}$ The maraging steel had the highest value of $k$, followed by alloys $718, \mathrm{C}-276,925$, and 625 . It is apparent from its value of $k$ that the maraging steel is intrinsically somewhat less susceptible than $\mathbf{4 3 4 0}$ steel. Test results have in fact shown that 18 $\mathrm{Ni}(250)$ maraging steel is more resistant to cracking than $4340 \mathrm{steel}^{12}$ so the differing susceptibility of the two steels was matched by their actual resistances to $\mathrm{HE}$.

A similar parallel was found to exist for the $18 \mathrm{Ni}$ steel and alloy 718 . Stress-rupture tests during electrolytic charging have shown that $18 \mathrm{Ni}$ (1723 MPa) maraging steel undergoes severe $\mathrm{HE}$, whereas alloy 718 exhibits negligible embrittlement. ${ }^{13}$ Likewise, gas-phase charging tests showed from the reduction in strength that the maraging steel was less resistant than alloy 718 , although the embrittlement in both cases was characterized as extreme. ${ }^{13}$

No Ni-base alloys in the 900 series were included in the electrolytic embrittlement tests. However, gas-phase studies on alloy 903 have shown that short exposure to high-pressure hydrogen is not detrimental, though prolonged exposure, particularly at higher temperatures, can reduce ductility. ${ }^{14}$ In contrast, alloy 718 undergoes extreme embrittlement under gas-phase charging, as noted above. These results suggest that alloy 903 and, by implication, alloy 925 are 
less sensitive than alloy 718 to HE. Hence, the irreversible trapping constants of the three precipitation-hardened alloys are consistent with their relative resistances to HE observed in failure tests.

A similar comparison of the resistances of alloys C-276 and 625 is complicated by their sensitivity to cold work. However, the ranking of these alloys can be assessed indirectly from results for alloys C-276 and G. ${ }^{15}$ Time-to-failure and crack propagation data showed that alloy C276 has a greater tendency to $\mathrm{HE}$ than alloy $\mathrm{G}$ cold-worked to an equivalent degree. Alloys $\mathrm{G}$ and 625 are comparable in their levels of $\mathrm{Cr}, \mathrm{Mo}$, and $\mathrm{Nb}+\mathrm{Ta}$, so they might be expected to be similar in their resistance to HE. For the degree of cold work involved, alloy C-276 should therefore be less resistant to HE than alloy 625,6 which coincides with the order of their trapping constants.

A lack of relevant data in the literature makes it difficult to determine whether the two coldworked alloys fit in with the other alloys on the basis of their $k$ values. The difficulty in evaluating the position of the cold-worked alloys is compounded by some uncertainty in these values.

Nevertheless, the trapping constants for alloys 625 and 718 show a significant difference, and the sequence of values is consistent with results from $\mathrm{C}$-ring and $\mathrm{U}$-bend exposure tests that indicated alloy 625 is more resistant to cracking than alloy 718.16

If allowance is made for the uncertainty in $k$, the position of alloy 625 is comparable to that of alloy $35 \mathrm{~N}$. Tests using C-ring specimens of these alloys showed that the time-to-failure of unaged alloy 625 with $59 \%$ cold reduction is intermediate between those for $35 \%$ and $51 \%$ cold reduced alloy $35 \mathrm{~N}$ in the aged condition. ${ }^{17}$ Alloy 625 with $17 \%$ cold work, as was used in the present study, should withstand a longer exposure time than the same alloy with $59 \%$ cold work and therefore should be at least as resistant to $\mathrm{HE}$ as alloy $35 \mathrm{~N}$ in the condition of interest (40-50\% cold reduced and aged). In fact, the 625 specimen may be more resistant than the $35 \mathrm{~N}$ alloy, as implied by their values of $k$. Thus, the order of the trapping constants parallels the relative resistance of these alloys to $\mathrm{HE}$.

Ti grade 2 was also examined. ${ }^{6}$ It exhibited two values of $k$, depending on the overpotential (Fig. 4-2) and therefore on the level of $\mathrm{H}$ in the alloy. Hydride precipitates have been observed in Ti grade 2 at $\mathrm{H}$ levels above $\sim 100 \mathrm{ppm}$, but gross embrittlement does not result until much higher levels. ${ }^{18}$ Thus, the similarity observed in the values of $k$ for low-H Ti grade 2 and alloy 925 fits their relative resistance to HE in that both alloys must be exposed for long times to cause degradation of their mechanical properties. ${ }^{14,18}$ Furthermore, the higher value of $k$ for $\mathrm{Ti}$ grade 2 coincides with its decreased resistance to embrittlement at high enough $\mathrm{H}$ concentrations.

An exception to these trends was observed with alloy 716, which is an age-hardenable alternative to alloy $625 .{ }^{16}$ Alloy 716 had a $k$ of 0.2 , which is the highest value among those for 
the nickel-base alloys and indicates that this alloy is intrinsically the most susceptible to HE. However, tests with C-ring and U-bend specimens have shown that it is comparable to alloy 625 of similar yield strength in being able to withstand exposure in aggressive environments. ${ }^{16} \mathrm{~A}$ likely explanation is that, although alloy 716 has a high intrinsic susceptibility, the $\mathrm{H}$ concentration at the dominant traps remains below the critical level required to initiate cracking. The entry flux was found to be low in the acetate buffer and could well have been low enough in the cracking test environments to delay failure in most cases (up to $1000 \mathrm{~h}$ ). Thus, the resistance to cracking observed for alloy 716 was believed to be associated with the low entry flux of hydrogen.

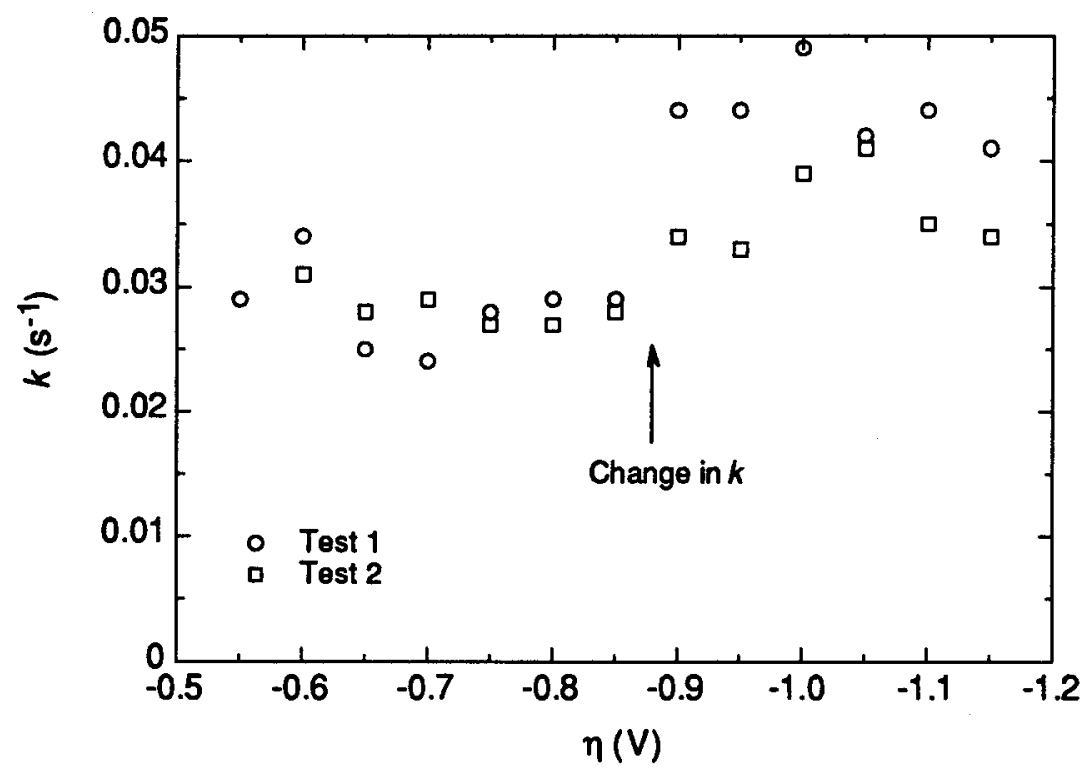

Figure 4-2. Variation in $k$ with overpotential for Ti grade 2 in identical tests.

\section{DISCUSSION}

The alloys studied were generally characterized by a single type of irreversible trap, but in some alloys the principal irreversible type of trap was supplemented by other traps of either a quasi-irreversible type or another irreversible type. Values of $k$ associated with the principal irreversible traps are listed in Table 4-4 for all the alloys except 716. They are also presented graphically in Fig. 4-3 to highlight differences between them.

The steels, particularly 4340, exhibit high values of $k$ that are indicative of a high intrinsic susceptibility to HE, whereas the nickel-base alloys are characterized by lower values of $k$ and are therefore intrinsically less susceptible. Differences in the susceptibility of the nickel-base alloys are smaller than those for the steels but are clearly discernible. In particular, the trapping constants for 
alloys within groups defined by thermomechanical treatment (precipitation- and work-hardening) indicate that the susceptibilities can vary significantly.

Table 4-4

Irreversible Trapping Constants

\begin{tabular}{lc}
\hline Alloy & $k\left(\mathrm{~s}^{-1}\right)$ \\
\hline 4340 steel & $4.0 \pm 0.5$ \\
$18 \mathrm{Ni}(300)$ steel & $1.50 \pm 1.05$ \\
718 & $0.124 \pm 0.024$ \\
C-276 (27\% cold work) & $0.090 \pm 0.030$ \\
K-500 & $0.042 \pm 0.006$ \\
Ti grade 2 (high H) & $0.040 \pm 0.008$ \\
925 & $0.034 \pm 0.004$ \\
Ti grade 2 (low H) & $0.028 \pm 0.002$ \\
$35 \mathrm{~N}$ & $0.026 \pm 0.002$ \\
625 (17\% cold work) & $0.014 \pm 0.010$
\end{tabular}

For most alloys, there appears to be a correlation between the intrinsic susceptibility, as represented by $k$, and the actual resistance to HE observed in failure tests. This correlation suggests that the observed resistance to $\mathrm{HE}$ is determined primarily by the alloy's intrinsic susceptibility - that is, by the irreversible trapping characteristics. Thus, the entry flux generally has only a secondary effect on the HE resistance.

Exceptions to this correlation can be expected in cases where the ingress flux for an alloy is low enough that the alloy is relatively resistant to cracking even though it might have a high

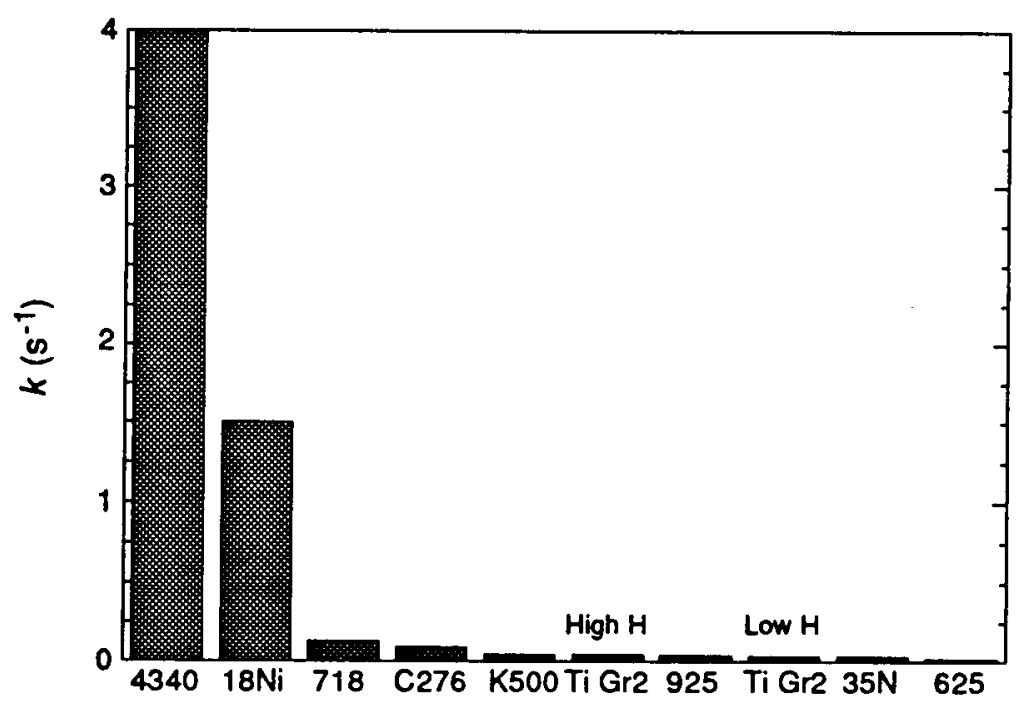

Figure 4-3. Variation in $k$ for the different alloys. 
intrinsic susceptibility. Such an exception was observed with alloy 716 . The intrinsic susceptibility of this alloy was shown to be high $(k=0.2)$, yet the entry flux was apparently low enough that the alloy generally did not undergo cracking during exposure in aggressive environments for periods up to $1000 \mathrm{~h}$.

The use of $k$ to provide an index of HE susceptibility can be justified on the basis of Eq. (4-2), but there remains the question of why such a relatively simple parameter has the apparent ability in most cases to indicate the relative resistance actually observed to HE. Some insight may be gained by considering $k$, which encompasses the trapping capability $\left(d^{2} \mathrm{~N}_{\mathrm{i}}\right)$ as well as the alloyspecific characteristics of metal atom size and lattice diffusivity. The trapping capability has a strong influence on the critical concentration $\left(C_{k}\right)$ required to initiate cracking at traps, while the diffusivity reflects the ease of $\mathrm{H}$ transport to different sites, including traps. Since the likelihood of crack initiation is highly dependent on both $\mathrm{C}_{\mathrm{k}}$ and $\mathrm{H}$ accumulation, it is perhaps not surprising that $k$ is effective as an index of susceptibility in being able to indicate the actual resistance of most alloys to HE. Underlying this rationale is the implication that, despite differences between alloys, the $\mathrm{H}$ entry flux is generally not low enough to become the controlling factor.

Finally, it should be noted that the density of particles or defects providing irreversible traps can be calculated from $k$, or $k_{\mathrm{a}}$, by using Eq. (4-2). The trap radius $(d)$ is estimated from the dimensions of heterogeneities that are potential irreversible traps, and trap densities are then calculated for the different values of $d$. In this way, the dominant irreversible trap can be identified by comparing the values of $\mathrm{N}_{\mathrm{i}}$ with the actual concentrations of specific heterogeneities.

Identification of the primary irreversible traps in the various alloys is described elsewhere. ${ }^{4-8}$

\section{SUMMARY}

For a wide range of alloys, a correlation exists between the intrinsic susceptibility, as defined by the irreversible trapping constant, and the observed resistance to HE. Thus, the HE resistance appears to be determined primarily by the alloy's intrinsic susceptibility. This relationship implies that generally the $H$ entry flux has only a secondary effect on the $H E$ resistance, suggesting that it is not low enough to become the controlling factor for most alloys. However, in one case (alloy 716), the resistance to HE can be attributed to a low entry flux.

The irreversible trapping constant, by virtue of the observed correlation, appears to be an indicator of the relative resistance to $\mathrm{HE}$ for most alloys, and as such, it can be used to predict the relative resistance of alloys in a particular environment. However, the predicted relative resistance may not be reliable in cases where $\mathrm{H}$ entry is severely restricted. The ability of $k$ to provide an indication of the relative resistance to $\mathrm{HE}$ seems to be attributable to its dependence on both the 
trapping capability and the diffusivity. The combination of these two characteristics is crucial for crack initiation and therefore provides a rationale for the correlation observed between $k$ and the actual resistance to $\mathrm{HE}$.

\section{ACKNOWLEDGMENT}

Financial support of this work by the Office of Naval Research under Contract N00014-86C-0233 is gratefully acknowledged.

\section{REFERENCES}

1. I. M. Bernstein and G. M. Pressouyre, in Hydrogen Degradation of Ferrous Alloys, R. A. Oriani, J. P. Hirth, and M. Smialowski, Eds. (Noyes Publications, Park Ridge, NJ, 1985), p. 641.

2. G. M. Pressouyre and I. M. Bernstein, Metall. Trans. 9A, 1571 (1978).

3. G. M. Pressouyre and I. M. Bernstein, Acta Metall. 27, 89 (1979).

4. B. G. Pound, Corrosion 45, 18 (1989); 50, 301 (1994).

5. B. G. Pound, Acta Metall. 38, 2373 (1990).

6. B. G. Pound, Acta Metall. 39, 2099 (1991).

7. B. G. Pound, Corrosion 47, 99 (1991).

8. B. G. Pound, Scripta Metall. 29, 1433 (1993).

9. R. McKibbin, D. A. Harrington, B. G. Pound, R. M. Sharp, and G. A. Wright, Acta Metall., 35, 253 (1987).

10. B. G. Pound, in Modern Aspects of Electrochemistry, J. O'M. Bockris, B. E. Conway, and R. E. White, Eds. (Plenum, New York, 1993), No. 25, p. 63.

11. B. G. Pound, R. M. Sharp, and G. A. Wright, Acta Metall. 35, 263 (1987).

12. T. P. Groeneveld, E. E. Fletcher, and A. R. Elsea, "A Study of Hydrogen Embrittlement of Various Alloys," Tech. Support Package to Tech. Brief No. 67-10141, (Washington D.C.: NASA, 1967), p. 135.

13. R. J. Walter, R. P. Jewett, and W. T. Chandler, Mater. Sci. Eng. 5, 98 (1969/70).

14. C. G. Rhodes and A. W. Thompson, Metall. Trans., 8A, 949 (1977).

15. D. A. Mezzanotte, J. A. Kargol, and N. F. Fiore, Metall. Trans., 13A, 1181 (1982).

16. R. B. Frank and T. A. DeBold, Properties of an Age-Hardenable, Corrosion-Resistant Nickel-Base Alloy, Corrosion 88, Paper No. 75, National Association of Corrosion Engineers, Houston, TX (1988).

17. R. D. Kane, M. Watkins, D. F. Jacobs, and G. L. Hancock, Corrosion, 33, 309 (1977).

18. R. W. Schutz and D. E. Thomas, in Metals Handbook, 9 th ed., Vol. 13 (American Society for Metals, Metals Park, OH, 1987), p. 669. 


\title{
Section 5 \\ THE ROLE OF TRAPS IN DETERMINING \\ THE RESISTANCE TO HYDROGEN EMBRITTLEMENT*
}

\begin{abstract}
$\underline{\text { Abstract }}$
The ability of microstructural heterogeneities to act as hydrogen traps can critically affect the resistance of an alloy to hydrogen embrittlement (HE), so a knowledge of the alloy's trapping characteristics is crucial in accounting for the role of these heterogeneities. The entry and trapping of hydrogen in a range of high-strength alloys have been investigated using a technique referred to as hydrogen ingress analysis by potentiostatic pulsing (HIAPP) to determine the entry flux and the rate constant ( $(\mathrm{k})$ for irreversible trapping. For most of the alloys, the observed resistance to $H E$ appears to be determined primarily by the alloy's intrinsic susceptibility defined by $\mathbf{k}$; that is, the entry flux generally has only a secondary effect on the resistance to $H E$. Analysis of the trapping constants allowed identification of various microstructural heterogeneities as the principal irreversible traps, either singly or in combination. The size and density of the irreversible traps were primary factors underlying the intrinsic susceptibility to $H E$. For example, alloys such as 718 and 4340 steel that contained large particles as the primary irreversible traps were found to have high intrinsic susceptibilities (high values of $\mathrm{k}$ ). Thus, it was shown that microstructural heterogeneities, such as precipitates and grain boundary segregants, impart an intrinsic susceptibility to the alloy through their capacity for trapping hydrogen and, as a result, generally play a key role in determining the HE resistance observed in practice.
\end{abstract}

\footnotetext{
* In Proceedings of the Fifth International Conference on Hydrogen Effects on Material Behavior, N. R. Moody and A. W. Thompson, Eds. (The Minerals, Metals \& Materials Society, Warrendale, PA, 1994), in press.
} 


\section{Introduction}

The interaction of hydrogen with microstructural heterogeneities in alloys can play a crucial role in determining an alloy's resistance to hydrogen embrittlement (HE). These heterogeneities provide potential trapping sites for hydrogen and so can strongly influence the series of events leading to failure (1). The accumulation of hydrogen at second-phase particles and precipitates, for example, is generally considered to induce particle fracture or weakening of particle-matrix interfaces, thereby promoting microvoid initiation. Large incoherent precipitates tend to be particularly conducive to $\mathrm{HE}$. In general, traps with a large saturability and a high binding energy for hydrogen are conducive to $\mathrm{HE}$, whereas alloys containing a high density of well-distributed irreversible (high binding energy) traps that have a low saturability are considered to be less susceptible $(2,3)$. Thus, the intrinsic susceptibility of an alloy to HE is highly dependent on the type of microstructural defect, with large irreversible traps typically imparting a high susceptibility.

The basic concept of trap theory is that the local concentration of hydrogen trapped at a defect must reach some critical value $\left(C_{k}\right)$ for cracks to be initiated $(1,3)$. It should be recognized, however, that the mechanism by which such an accumulation triggers $\mathrm{HE}$ is not addressed. The value of $\mathrm{C}_{k}$ at a potential crack site is determined by the type of trap, its size, concentration (density), and other parameters. A decrease in $C_{k}$ will render the alloy more susceptible. However, whether embrittlement will actually occur is also affected by the amount of trapped $\mathrm{H}$, which depends on factors such as the entry kinetics, exposure time, and transport mode. In some cases, an alloy may prove resistant during exposure because the amount of $\mathrm{H}$ entering the alloy is small enough that the critical concentration at a particular trap is not exceeded. Likewise, when alloys have a similar intrinsic susceptibility in terms of their trapping characteristics, the difference in their actual resistance to $\mathrm{HE}$ is likely to be determined by the amount of $\mathrm{H}$ absorbed by each alloy.

Over the last few years, the entry and trapping of hydrogen in a wide range of high-strength alloys have been investigated at SRI (4-9). The rates of $\mathrm{H}$ entry and rate constants for irreversible trapping were determined using an electrochemical technique referred to as hydrogen ingress analysis by potentiostatic pulsing (HIAPP) $(4,10)$. The research was aimed in part at characterizing the intrinsic susceptibility of the alloys to $\mathrm{HE}$ in terms of their irreversible trapping constants. The relative intrinsic susceptibilities then could be compared with results for the actual resistance to HE observed in tests by other workers. A further goal was to determine the trap density where possible and thereby identify the principal irreversible trap in each alloy. In this paper, the irreversible trapping constants and principal irreversible traps for particular groups of alloys are compared, with the objective of rationalizing the role of traps in determining the resistance of these alloys to $\mathrm{HE}$.

\section{Experimental Procedure}

In the pulse technique, the alloy of interest is cathodically charged with hydrogen at a constant potential $E_{c}$ for a time $t_{c}$, after which the potential is stepped in the positive direction. $H$ diffuses back to the entry surface and is reoxidized, thereby generating an anodic current transient. Data are obtained over a range of charging times, typically from 5 to $60 \mathrm{~s}$, at different overpotentials $\left(\eta=E_{c}\right.$ - $E_{o c}$ ) relative to the open-circuit potential $\left(E_{o c}\right)$, which is measured immediately before each charging time. $E_{o c}$ is also used to monitor the stability of the alloy surface, since any oxides present must not be reduced during charging.

The pulse technique was applied to high-strength steels $(4,5)$, precipitation-hardened and workhardened nickel-base alloys (4-8), and titanium grade 2 (9). The composition of each alloy is given in Table 5-I. Table 5-II shows the yield strength of the alloys and the thermomechanical treatment used in each case. A number of the alloys contained micrometer-size particles such as carbides or, in the case of 4340 steel, sulfide inclusions.

Test electrodes of each alloy were fabricated from a length $(1.3-3.8 \mathrm{~cm})$ of rod press-fitted into a 
Table 5-I. Alloy Composition (wt\%)

\begin{tabular}{lllllllllll}
\hline & 4340 & $18 \mathrm{Ni}$ & 718 & 925 & $\mathrm{C}-276$ & 625 & 716 & K-500 & $35 \mathrm{~N}$ & Ti Gr2 \\
\hline $\mathrm{Al}$ & 0.031 & 0.13 & 0.60 & 0.30 & & 0.18 & 0.22 & 2.92 & & \\
$\mathrm{~B}$ & & 0.003 & 0.003 & & & & & & & \\
$\mathrm{C}$ & 0.42 & 0.009 & 0.03 & 0.02 & 0.002 & 0.03 & 0.011 & 0.16 & 0.003 & 0.021 \\
$\mathrm{Co}$ & & 9.15 & 0.16 & & 0.83 & & $<0.01$ & & bal & \\
$\mathrm{Cr}$ & 0.89 & 0.06 & 18.97 & 22.20 & 15.27 & 22.06 & 20.99 & & 20.19 & \\
$\mathrm{Cu}$ & $\mathbf{0 . 1 9}$ & 0.11 & 0.04 & 1.93 & & & & 29.99 & & \\
$\mathrm{Fe}$ & $\mathrm{bal}$ & $\mathrm{bal}$ & 16.25 & 28.96 & 5.84 & 4.37 & 5.32 & 0.64 & 0.34 & 0.17 \\
$\mathrm{Mn}$ & $\mathbf{0 . 4 6}$ & 0.01 & 0.10 & 0.62 & 0.48 & 0.17 & 0.01 & 0.72 & $<0.01$ & \\
$\mathrm{Mo}$ & 0.21 & 4.82 & 3.04 & 2.74 & 16.04 & 8.70 & 8.10 & & 9.55 & \\
$\mathrm{O}$ & 0.001 & & & & & & & & & 0.16 \\
$\mathrm{Nb}+\mathrm{Ta}$ & & & 5.30 & & & 3.50 & 3.47 & & & \\
$\mathrm{Ni}$ & 1.74 & 18.42 & 54.41 & 40.95 & 57.5 & 60.33 & 60.5 & 64.96 & 35.88 & \\
$\mathrm{P}$ & 0.009 & 0.004 & 0.009 & & $<0.005$ & 0.012 & 0.004 & & 0.003 & \\
$\mathrm{~S}$ & 0.001 & 0.001 & 0.002 & 0.001 & $<0.002$ & 0.001 & 0.001 & 0.001 & 0.002 & \\
$\mathrm{Si}$ & 0.28 & 0.04 & 0.11 & 0.17 & $<0.02$ & 0.38 & 0.02 & 0.15 & 0.02 & \\
$\mathrm{Ti}$ & & 0.65 & 0.98 & 2.11 & & 0.27 & 1.35 & 0.46 & 0.85 & bal \\
W & & 0.01 & & & 3.90 & & & & & $<0.005 \mathrm{H}$ \\
Other & $0.005 \mathrm{~N}$ & $0.05 \mathrm{Ca}$ & & & $0.12 \mathrm{~V}$ & & & & & $0.007 \mathrm{~N}$ \\
& & $0.02 \mathrm{Zr}$ & & & & & & & & \\
\hline
\end{tabular}

Teflon sheath so that only the planar end surface was exposed to the electrolyte. The surface was polished before each experiment with $\mathrm{SiC}$ paper followed by $0.05-\mu \mathrm{m}$ alumina powder. Details of the electrochemical cell and instrumentation have been given elsewhere (4). The alloys were exposed in a deaerated solution containing $1 \mathrm{~mol} \mathrm{~L}^{-1}$ acetic acid and $1 \mathrm{~mol} \mathrm{~L}^{-1}$ sodium acetate with $15 \mathrm{ppm} \mathrm{As}_{2} \mathrm{O}_{3}$ added to promote $\mathrm{H}$ entry. The potentials were measured with respect to a saturated calomel electrode (SCE). All tests were performed at $22 \pm 2^{\circ} \mathrm{C}$.

Table 5-II. Thermomechanical Treatment of Alloys

\begin{tabular}{lllc}
\hline Alloy & Heat Treatment & Test Condition & Yield Strength (MPa) \\
\hline 4340 & Annealed & HRC 41 & 1206 \\
& & HRC 53 & 1792 \\
$18 \mathrm{Ni}$ & Aged $\left(482^{\circ} \mathrm{C}, 4 \mathrm{~h}\right)$ & As received & 1954 \\
718 & Hot fin., solution treated & As received & 1238 \\
925 & Hot fin., annealed, aged & As received & 758 \\
C-276 & Hot rolled & $27 \%$ cold work & 1237 \\
625 & Hot fin., annealed & $17 \%$ cold work & 1195 \\
716 & Annealed, aged & $4 \%$ cold work & 1186 \\
K-500 & Cold drawn, unaged & As received & 758 \\
$35 \mathrm{~N}$ & Cold drawn and aged & Aged (600 & As, $8 \mathrm{~h})$ \\
Ti Gr 2 & Annealed $\left(620^{\circ} \mathrm{C}, 1 \mathrm{~h}\right)$ & As received & 1096 \\
& & & 1854 \\
\hline
\end{tabular}

a Provided by producer. ${ }^{\mathrm{b}}$ Rockwell $\mathrm{C}$ hardness 


\section{Analysis}

Although permeation methods have been used extensively, they suffer from several disadvantages, as discussed elsewhere (11). The main theoretical limitation is that most, if not all, diffusion/trapping models for these methods are based on an input boundary condition of constant concentration. Hence, these models are strictly applicable only for charging conditions without any entry limitation.

In the case of HIAPP, a model has been developed to allow for the effect of trapping on diffusion for cases involving either a constant concentration or a constant flux at the input surface $(4,10)$. The constant flux model was found to apply to all alloys studied to date. In this model, the rate of hydrogen ingress is controlled by diffusion but the entry flux of hydrogen is restricted, which results in interface-limited diffusion control. Solution of the diffusion equation for a constant flux condition gives the following expression for the total anodic charge $\left(\mathrm{C} \mathrm{m}^{-2}\right)$ :

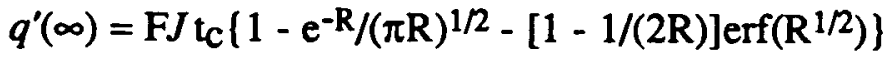

where $\mathrm{F}$ is the Faraday constant, $J$ is the entry flux in mol m $\mathrm{m}^{-2} \mathrm{~s}^{-1}$, and $\mathrm{R}=k_{\mathrm{a}} \mathrm{t}_{\mathrm{c}}$. The charge $q^{\prime}(\infty)$ is equated to the charge $\left(q_{\mathrm{a}}\right)$ passed during the experimental anodic transients. $q_{\mathrm{a}}$ can be associated entirely with absorbed $\mathrm{H}$, since the adsorbed charge is almost invariably negligible.

$k_{\mathrm{a}}$ is an apparent trapping constant measured for irreversible traps in the presence of reversible traps. It is related to the irreversible trapping constant $(k)$ by $k \mathrm{D}_{\mathrm{a}} / \mathrm{D}_{\mathrm{L}}$ where $\mathrm{D}_{\mathrm{a}}$ is the apparent diffusivity and $D_{L}$ is the lattice diffusivity of $H$. The magnitude of $k$ depends on the density of particles or defects $\left(\mathrm{N}_{\mathrm{i}}\right)$ providing irreversible traps, the radius $(d)$ of the trap defects, the diameter (a) of the metal atom, and $\mathrm{D}_{\mathrm{L}}(12)$ :

$$
k=4 \pi d^{2} \mathrm{~N}_{\mathrm{i}} \mathrm{D}_{\mathrm{L}} / a
$$

The term $d^{2} \mathrm{~N}_{\mathrm{i}}$ represents the trapping capability and underlies the use of $k$ as an index for characterizing an alloy's intrinsic susceptibility to $\mathrm{HE}$.

For the constant flux model to be applicable, it must be possible to determine a trapping constant for which $J$ is independent of charging time. Eq. [5-1] could in fact be fitted to the experimental data for $q_{\mathrm{a}}$ to obtain values of $k_{\mathrm{a}}$ and $J$ that satisfy this requirement at each potential.

The trap density $\left(\mathrm{N}_{\mathrm{i}}\right)$ can be obtained from $k$ or directly from $k_{\mathrm{a}}$, according to Eq. [5-3]:

$$
\mathrm{N}_{\mathrm{i}}=k_{\mathrm{a}} a /\left(4 \pi d^{2} \mathrm{D}_{\mathrm{a}}\right)
$$

The value of $a$ for an alloy is taken as the mean of the atomic diameters weighted in accordance with the atomic fraction of each element. The trap radius is estimated from the dimensions of heterogeneities that are potential irreversible traps, and trap densities are then calculated for the different values of $d$. In this way, the dominant irreversible trap can be identified by comparing the values of $\mathrm{N}_{\mathrm{i}}$ with the actual concentrations of specific heterogeneities. 


\section{Susceptibility to HE}

The values of $k_{\mathrm{a}}$ and $k$ for the various alloys are given in Table 5-III. Most of the alloys were characterized by a single type of irreversible trap, but alloy C-276 and the $18 \mathrm{Ni}$ steel were characterized by both a quasi-irreversible trap and an irreversible trap. In quasi-irreversible trapping, the release constant is not zero but is far too small to achieve local equilibrium between the lattice and trapped $H(5)$.

Among the alloys studied, 4340 steel (HRC 53) has the highest value of $k$ and so can be classified as having the highest intrinsic susceptibility to $\mathrm{HE}$. The $18 \mathrm{Ni}$ maraging steel has the next highest $k$ value, followed by various Ni-base alloys, with alloy 625 having the lowest value. Failure tests during cathodic charging have shown that $18 \mathrm{Ni}(1723 \mathrm{MPa})$ steel is more resistant to cracking than 4340 steel (13) but that the $18 \mathrm{Ni}$ steel in turn will undergo severe $\mathrm{HE}$, whereas alloy 718 exhibits negligible embrittlement (14). Furthermore, ductility losses $(14,15)$ under gas-phase charging suggest that alloy 903 and, by implication, alloy 925 are less sensitive than alloy 718 to HE. Hence, the irreversible trapping constants of the precipitation-hardened alloys, $18 \mathrm{Ni}, 718$, and 925, are consistent with their relative resistances to HE observed in tests.

A similar comparison of the resistances of the work-hardened alloys, C-276 and 625, is complicated by their sensitivity to cold work. However, failure tests have shown that alloy C-276 has a greater tendency to $\mathrm{HE}$ than alloy $\mathrm{G}$ cold-worked to an equivalent degree (16). Alloys $\mathrm{G}$ and 625 are comparable in their levels of $\mathrm{Cr}, \mathrm{Mo}$, and - more important - $\mathrm{Nb}+\mathrm{Ta}$, so they are likely to be similar in their resistance to HE. Hence, for the degree of cold work involved, alloy C-276 should be less resistant to HE than alloy $625(6)$, which matches the order of their trapping constants.

Table 5-III. Trapping Parameters

\begin{tabular}{lccc}
\hline \multicolumn{1}{c}{ Alloy } & $k_{\mathrm{a}}\left(\mathrm{s}^{-1}\right)$ & $\mathrm{D}_{\mathrm{L}} / \mathrm{D}_{\mathrm{a}}$ & $k\left(\mathrm{~s}^{-1}\right)$ \\
\hline 4340 steel (HRC 53) & $0.008 \pm 0.001$ & 500 & $4.0 \pm 0.5$ \\
$18 \mathrm{Ni}(1954 \mathrm{MPa})$ steel & $0.005 \pm 0.002$ & $300 \pm 90$ & $1.50 \pm 1.05$ \\
& $0.010 \pm 0.005^{\mathrm{b}}$ & $300 \pm 90$ & $3.00 \pm 2.40$ \\
$716(4 \%$ cold work) & $0.054 \pm 0.004$ & $3.8 \pm 0.8$ & $0.20 \pm 0.06$ \\
718 & $0.031 \pm 0.002$ & $4.0 \pm 0.5$ & $0.124 \pm 0.024$ \\
925 & $0.006 \pm 0.003$ & $5.6 \pm 0.6$ & $0.034 \pm 0.004$ \\
C-276 (27\% cold work) & $0.025 \pm 0.003$ & $3.6 \pm 0.8$ & $0.090 \pm 0.030$ \\
625 (17\% cold work) & $0.019 \pm 0.010 \mathrm{~b}$ & $3.6 \pm 0.8$ & $0.068 \pm 0.051$ \\
K-500 Unaged & $0.004 \pm 0.002$ & $3.6 \pm 0.8$ & $0.014 \pm 0.010$ \\
$\quad$ Aged & $0.017 \pm 0.003$ & 2.0 & $0.034 \pm 0.006$ \\
$35 \mathrm{~N} \quad 0.021 \pm 0.003$ & 2.0 & $0.042 \pm 0.006$ \\
Ti grade 2 (low H) & $0.028 \pm 0.002$ & 1 & $0.026 \pm 0.002$ \\
$\quad$ (high H) & $0.040 \pm 0.008$ & 1 & $0.028 \pm 0.002$ \\
& & & \\
\hline
\end{tabular}

a $\mathrm{HRC} 41$ had the same value of $k_{\mathrm{a}}{ }^{\mathrm{b}}$ Quasi-irreversible trapping.

Evaluating the positions of the cold-worked alloys relative to the other alloys is more difficult because of some uncertainty in their values of $k$. Nevertheless, the trapping constants for alloys 
625 and 718 show a significant difference, and the sequence of values is consistent with results from exposure tests that indicated alloy 625 is more resistant to cracking than alloy 718 (17).

If allowance is made for the uncertainty in $k$, the position of alloy 625 is comparable to that of alloy $35 N$. Failure tests (18) have indicated that alloy 625 with $17 \%$ cold work should be at least as resistant to $\mathrm{HE}$ as alloy $35 \mathrm{~N}$ in the condition of interest (40-50\% cold reduced and aged). In fact, the 625 specimen may be more resistant than the $35 \mathrm{~N}$ alloy, as implied by their $k$ values. Thus, the order of the trapping constants parallels the relative resistance of these alloys to HE.

Ti grade 2 exhibited two values of $k$ (Fig. 5-1), depending on the overpotential and therefore on the level of $\mathrm{H}$ in the alloy (9). The similarity in the values of $k$ for low-H Ti grade 2 and alloy 925 fits the relative resistance of these two alloys to $\mathrm{HE}$ in that both require long exposure times for their mechanical properties to be degraded $(15,19)$. The higher value of $k$ for Ti grade 2 coincides with its decreased resistance to embrittlement at sufficiently high levels of $H(19)$.

An exception to the above trends was observed with alloy 716 , which is an age-hardenable alternative to alloy 625 (17). Alloy 716 had the highest value of $k$ among those for the nickel-base alloys, yet mechanical tests have shown that it is comparable to alloy 625 of similar yield strength

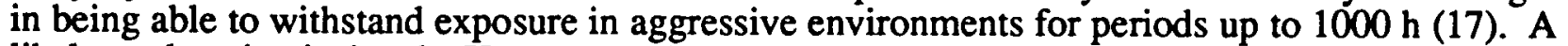
likely explanation is that the $\mathrm{H}$ concentration at the dominant traps remains below the critical level required to initiate cracking. In fact, the entry flux of $\mathrm{H}$ was low in the acetate buffer and could well have been low enough in the cracking test environments to delay failure (8). Thus, the resistance to cracking observed for alloy 716 was attributed to a low entry flux.

\section{Identification of Traps}

The intrinsic susceptibility of an alloy, as noted above, is strongly influenced by the characteristics of its irreversible traps. Identification of the traps on the basis of density and size can be expected to assist in explaining differences in the intrinsic susceptibility of the alloys. Hence, for each alloy, the density of irreversible trap defects calculated from $k_{\mathrm{a}}$ (Eq. [5-3]) was compared with the actual concentration of defects that were assumed to provide the principal traps, as shown in Table 5-IV.

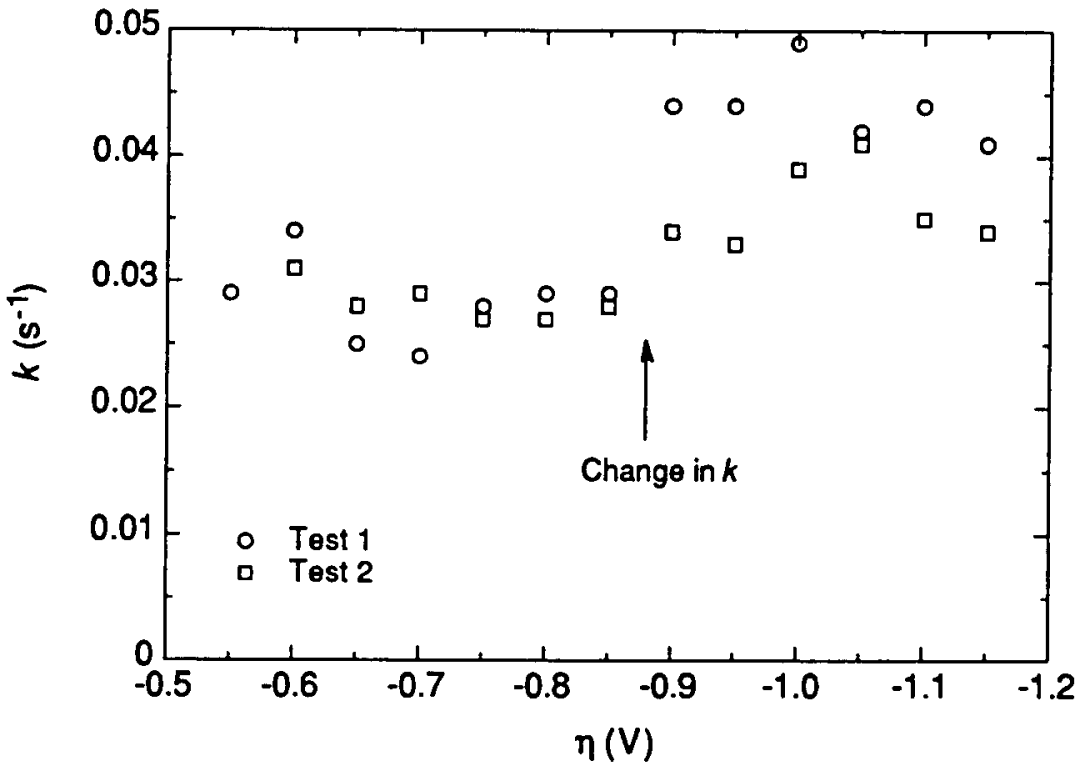

Figure 5-1. Variation in $k$ with overpotential for Ti grade 2 in identical tests. 


\section{Precipitates/Inclusions}

The Ni-base alloys, $718,925,716$, and 625 , contained carbide or carbonitride particles, which are known to provide irreversible traps in steels (1). The density of irreversible trap defects was therefore calculated on the basis of these particles and was generally found to be in close agreement with the actual concentration of particles, despite some uncertainty in the value of $\mathrm{D}_{\mathrm{a}}$, particularly for alloys 625 and 716. The level of agreement is remarkable, since both the traps and carbides were treated as spherical in calculating the trap density and particle concentration, respectively. However, it indicates clearly that large traps with both a high surface area and a high binding energy can overwhelmingly dominate the irreversible trapping behavior of an alloy.

Table 5-IV. Comparison of Irreversible Trap Densities with Defect Concentrations

\begin{tabular}{llcc}
\hline Alloy & Defect & Concentration $\left(\mathrm{m}^{-3}\right)$ & $\mathrm{Ni}_{\mathrm{i}}\left(\mathrm{m}^{-3}\right)$ \\
\hline 718 & NbTi(CN) & $2.2 \times 10^{13}$ & $2.0 \times 10^{13}$ \\
925 & $\mathrm{TiC}$ & $4.6 \times 10^{13}$ & $4.1 \times 10^{13}$ \\
625 & $\mathrm{NbTi}(\mathrm{C})$ & $7.4 \times 10^{13}$ & $2.5 \times 10^{13}$ \\
716 & $\mathrm{TiC}$ & $1.4 \times 10^{15}$ & $1.4 \times 10^{15}$ \\
$18 \mathrm{Ni}$ & $\mathrm{TiC} / \mathrm{Ti}(\mathrm{CN})$ & $1.1 \times 10^{13}$ & $3.4 \times 10^{11}$ \\
4340 & $\mathrm{MnS}$ & $2 \times 10^{9}$ & $2 \times 10^{8}$ \\
$\mathrm{C}-276$ & $\mathrm{P}(\mathrm{seg})$ & $9 \times 10^{21}$ & $1.9 \times 10^{22}$ \\
$35 \mathrm{~N}$ & $\mathrm{~S}, \mathrm{P}(\mathrm{seg})$ & $8 \times 10^{21}$ & $8.2 \times 10^{21}$ \\
K-500 (Aged) & $\mathrm{S}(\mathrm{seg})$ & Not available & $2.7 \times 10^{21}$ \\
\hline
\end{tabular}

The $18 \mathrm{Ni}$ steel contained $\mathrm{TiC} / \mathrm{Ti}(\mathrm{CN})$ particles, which have been shown to act as strong traps in this type of steel (20). Hence, the irreversible trap density was calculated assuming that these particles acted as the principal traps. The values of $\mathrm{N}_{\mathrm{i}}$ and the particle concentration differed by a factor of $\sim 30$ but were considered to correlate moderately well, since the difference can be attributed largely to uncertainties in the particle concentration and the value of $D_{a}$ used for the steel.

The 4340 steel had MnS inclusions, which are prominent irreversible traps in steels (1). The calculated trap density was considered to be in reasonable agreement with the actual concentration of inclusions, since both the inclusions and the traps were assumed to be spherical. Also, $\mathrm{N}_{\mathrm{i}}$ did not change significantly with heat treatment, and this lack of change was further evidence that the irreversible traps were associated with the sulfide inclusions.

\section{Segregants}

The HE resistance of alloys $\mathrm{C}-276$ and $35 \mathrm{~N}$ has been correlated with the concentration of $\mathrm{S}$ and $\mathrm{P}$ segregated at grain boundaries $(21,22)$. Hydrogen segregates to the grain boundaries in $\mathrm{Ni}(23)$ and presumably does so in Ni-base alloys, so grain boundary $\mathrm{S}$ and $\mathrm{P}$ were assumed to provide the irreversible traps predominantly encountered by $\mathrm{H}$ in alloys C-276 and 35N. In the case of alloy C-276, it has been suggested that a higher level of grain boundary P may reduce the critical concentration of $\mathrm{H}$ required for fracture (21).

In unaged alloy C-276, $\mathrm{P}$ is enriched from a bulk concentration of $0.006-0.008$ at.\% (0.003$0.004 \mathrm{wt. \% )}$ to 0.3 at.\% at grain boundaries (21). Using the grain boundary concentration, the amount of grain boundary $P$ distributed per unit volume $\left(\mathrm{C}_{\mathrm{gb}}\right)$ of the alloy was estimated in terms of a simple microstructural model based on cubic grains of length $b(6)$. For alloy C-276 in the 
condition of interest, $b=10 \mu \mathrm{m}$ and $\mathrm{C}_{\mathrm{gb}}$ was calculated to be $9 \times 10^{16} / \mathrm{b}$, or $9 \times 10^{21} \mathrm{P}$ atoms m $\mathrm{m}^{-3}$. The trap density of $1.9 \times 10^{22} \mathrm{~m}^{-3}$ calculated on the basis of atomic $\mathrm{P}$ was close to the grain boundary concentration, whereas the total P content (taken as 0.004 wt.\%) of the alloy corresponded to a much higher concentration, $8.6 \times 10^{24}$ atoms $\mathrm{m}^{-3}$.

For alloy $35 \mathrm{~N}$ in the same cold-worked and aged condition used in this study, the level of $\mathrm{S}$ and $\mathrm{P}$ at grain boundaries has been found to reach 1.6 at.\%, compared with a bulk concentration of 0.01 at.\% $\left(0.005\right.$ wt. \%) (22). $C_{g b}$ for segregated $S$ and $P$ in alloy $35 \mathrm{~N}$ is given by $4.8 \times 10^{17} / b$ atoms $\mathrm{m}^{-3}$. The grains in $59 \%$ cold reduced and aged $\left(593^{\circ} \mathrm{C} / 4 \mathrm{~h}\right)$ alloy have an average dimension of $60 \mu \mathrm{m}$, and using this value gave a $\mathrm{C}_{\mathrm{gb}}$ of $\sim 8 \times 10^{21}$ atoms $\mathrm{m}^{-3}$. The trap density calculated in terms of $S$ and $P$ was $8.2 \times 10^{21}$ atoms $\mathrm{m}^{-3}$, which closely matched the value of $C_{g b}$ but was 3 orders of magnitude less than the total concentration of $S$ and $P\left(0.005 \mathrm{wt} . \%\right.$, or $8.1 \times 10^{24}$ atoms $\mathrm{m}^{-3}$ ) in the alloy. The large differences between $\mathrm{N}_{\mathrm{i}}$ and the S-P content in alloys C-276 and 35N indicated that the primary irreversible traps were not associated with matrix $S$ and $P$. In contrast, the close agreement between the values of $\mathrm{C}_{\mathrm{gb}}$ and $\mathrm{N}_{\mathrm{i}}$, though somewhat fortuitous, was strong evidence that the primary traps were grain boundary $S$ and $P$.

$\mathrm{Ni}-\mathrm{Cu}$ base alloys also undergo $\mathrm{HE}$ that is assisted by $\mathrm{S}$ segregated at grain boundaries (24), so the irreversible trap density for alloy K-500 was calculated on the basis of atomic S. However, the absence of data for $\mathbf{S}$ segregation in this alloy meant that the identity of the principal irreversible traps could not be verified by comparing $\mathrm{N}_{\mathrm{i}}$ with the grain boundary concentration. On the other hand, it was apparent that the principal traps were not associated with matrix $S$, since $\mathrm{N}_{\mathrm{i}}$ was about 3 orders of magnitude less than the $S$ content $\left(1.6 \times 10^{24}\right.$ atoms $\left.\mathrm{m}^{-3}\right)$ of the alloy. TiN particles present in alloy K-500 were likewise ruled out as the principal traps because of a large ( 2 orders of magnitude) difference between the corresponding value of $\mathrm{N}_{\mathrm{i}}$ and the particle concentration. In contrast, the results for alloys C-276 and 35N lent some support to the case for considering a grain boundary segregant (in this case, S) as the principal trap in alloy K-500. Further support was provided by recent results for a $77 \% \mathrm{Cu}-15 \% \mathrm{Ni}$ alloy, which was found to have a higher trap density than that for the $65 \mathrm{Ni}-30 \mathrm{Cu}$ alloy $\mathrm{K}-500$ (7). Even allowing for some difference in the degree of segregation between the two alloys, the higher trap density was consistent with a higher level of grain boundary segregants, based on the higher S-P content $(0.015 \mathrm{wt} . \%)$ of the $77 \mathrm{Cu}$ $15 \mathrm{Ni}$ alloy.

\section{Interstitials}

The density of traps detected in Ti grade 2 at low $\mathrm{H}$ levels was calculated in terms of the minor elements ( $\mathrm{C}, \mathrm{N}, \mathrm{O}$, and $\mathrm{Fe}$ ). All of the elements except $\mathrm{N}$ could be discounted as the principal irreversible trap because of large differences between the values of $\mathrm{N}_{\mathrm{i}}$ and the atomic concentrations. Interestingly, among the interstitials, $\mathrm{N}$ is particularly effective in reducing the ductility of $\mathrm{Ti}$ (25), which coincides with its apparent role as the principal trap. Hence, $\mathrm{N}$ may affect the $\mathrm{HE}$ resistance of Ti grade 2 through its influence on both brittleness and $\mathrm{H}$ trapping.

\section{Hydrides}

Evidence of trapping by way of hydride formation was observed in Ti grade 2 and alloy C-276. The increase in $k$ for Ti grade 2 at sufficiently negative potentials $\left(\mathrm{E}_{\mathrm{c}}<-0.93 \mathrm{~V}\right)$ can be ascribed to an additional irreversible trap that participates concurrently with the $\mathrm{N}$ traps. The additional trapping appeared to be associated with accelerated hydride formation that occurs at potentials more negative than $-1.0 \mathrm{~V}(26)$. The $\mathrm{H}$ entry efficiency, which can be calculated from $k_{\mathrm{a}}$ and $J$, was found to decrease in this region; the decrease was attributed to $\mathrm{H}$ entry being partially blocked by a hydride layer (9).

For alloy C-276, the quasi-irreversible trapping was consistent with the formation of an unstable hydride, as found by other workers (27). The quasi-irreversible traps in $18 \mathrm{Ni}$ steel, however, were thought to be martensite boundaries, which are moderately strong traps in this type of steel 
(20). A trap density of $9 \times 10^{17} \mathrm{~m}^{-3}$ was calculated in terms of the martensite boundaries, which, like grain boundaries (28), were assumed to have an influence diameter of $3 \mathrm{~nm}$.

\section{Discussion}

The alloys in this work were typically characterized by a single irreversible trap, but in some alloys the principal trap was supplemented by another irreversible trap or a quasi-irreversible trap. Values of $k$ associated with the principal irreversible traps are presented in Fig. 5-2 for all the alloys except 716. The steels, particularly 4340, exhibited high values of $k$ that were indicative of a high intrinsic susceptibility to $\mathrm{HE}$, whereas the nickel-base alloys were characterized by lower values of $k$ and therefore were intrinsically less susceptible. Differences in the susceptibility of the nickelbase alloys were smaller than those for the steels but were clearly discernible, as shown in Table
III.

Most of the alloys appear to show a correlation between the intrinsic susceptibility, as represented by $k$, and the actual resistance to HE observed in mechanical tests. This correlation suggests that, for these alloys, the observed resistance to $\mathrm{HE}$ was determined primarily by the alloy's intrinsic susceptibility - that is, by the irreversible trapping characteristics. Thus, while factors such as the entry flux and stress level may be important, they seem to have had only a secondary effect on the HE resistance in most cases. Exceptions to this correlation can occur in cases such as alloy 716, where the entry flux is low enough that the alloy is relatively resistant to cracking, even though it might have a high intrinsic susceptibility.

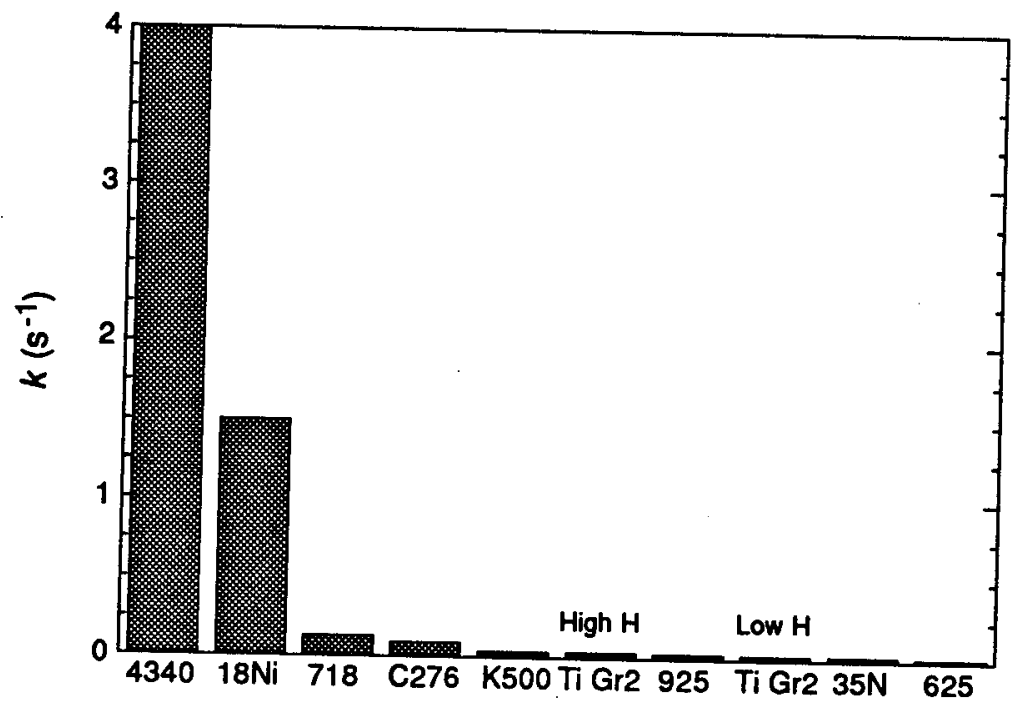

Figure 5-2. Variation in $k$ for the different alloys.

The use of $k$ to provide an index of HE susceptibility can be justified on the basis of Eq. [5-2], but there remains the question of why such a relatively simple parameter has the apparent ability in most cases to indicate the relative resistance observed to HE. Some insight may be gained by considering $k$, which encompasses the trapping capability $\left(d^{2} \mathrm{~N}_{\mathrm{i}}\right)$ as well as the alloy-specific characteristics of metal atom size and lattice diffusivity. For simplicity, the defects providing the principal traps are assumed to be similar in size $(d)$, with the critical concentration $\left(\mathbf{C}_{k}\right)$ at each of these defects having roughly the same value. The trap defect size has a strong influence on $\mathrm{C}_{k}$ and is incorporated as an area term in the trapping capability together with the density of potential crack 
sites possessing this $C_{k}$, while the diffusivity reflects the ease of $H$ transport to different sites, including traps. Since the likelihood of crack initiation is highly dependent on both $\mathrm{C}_{\mathrm{k}}$ and $\mathrm{H}$ accumulation as well as the availability of sufficiently large defects, it is perhaps not surprising that $k$ is effective as an index of susceptibility in being able to indicate the actual resistance of most of the alloys to HE. Underlying this rationale is the implication that, despite differences in the $\mathrm{H}$ entry flux between the alloys, the flux was generally not low enough to become the controlling factor.

The nature of the irreversible trap defects appears to play a significant but not exclusive role in determining the intrinsic susceptibility of an alloy. Alloys such as 718 and 4340 steel, in which the principal traps are large second-phase particles, typically exhibited a high intrinsic susceptibility ( $k$ $>0.1 \mathrm{~s}^{-1}$ ), whereas other alloys do not show a relationship between the susceptibility and the type of irreversible trap, whether it be particles, segregants, or interstitials. However, the microstructural features that provided the principal traps in the different alloys had a wide range of sizes and concentrations, and for alloys with comparable $\mathrm{H}$ diffusivities, the resulting diversity in trapping capabilities produces considerable differences in the intrinsic susceptibilities to HE. In cases where the values of $D_{L}$ are similar, $k$ is predicted to increase linearly with $N_{i} d^{2}$ (Eq. [5-2]). Fig. 5-3 shows the dependence of $k$ on $C_{p}\left(d_{p} / 2\right)^{2}$ for the four alloys $(625,716,925$, and 718) containing carbides or carbonitrides, where $C_{p}$ and $d_{p}$ are the concentration and characteristic dimension, respectively, of the particles. Although the amount of data is limited and the value of $\mathrm{D}_{\mathrm{a}}$ for alloy 625 is uncertain, a linear relationship seems to exist, which underscores the fact that the carbide/carbonitride particles appear to be primarily responsible for irreversible trapping in these alloys.

\section{Summary}

For a wide range of alloys, a correlation exists between the intrinsic susceptibility, as defined by the irreversible trapping constant, and the observed resistance to $\mathrm{HE}$. Thus, the HE resistance appears to be determined primarily by the alloy's intrinsic susceptibility. This relationship implies that the $\mathrm{H}$ entry flux generally has only a secondary effect on the HE resistance for most of the alloys, which suggests that the flux is usually not low enough to become the controlling factor.

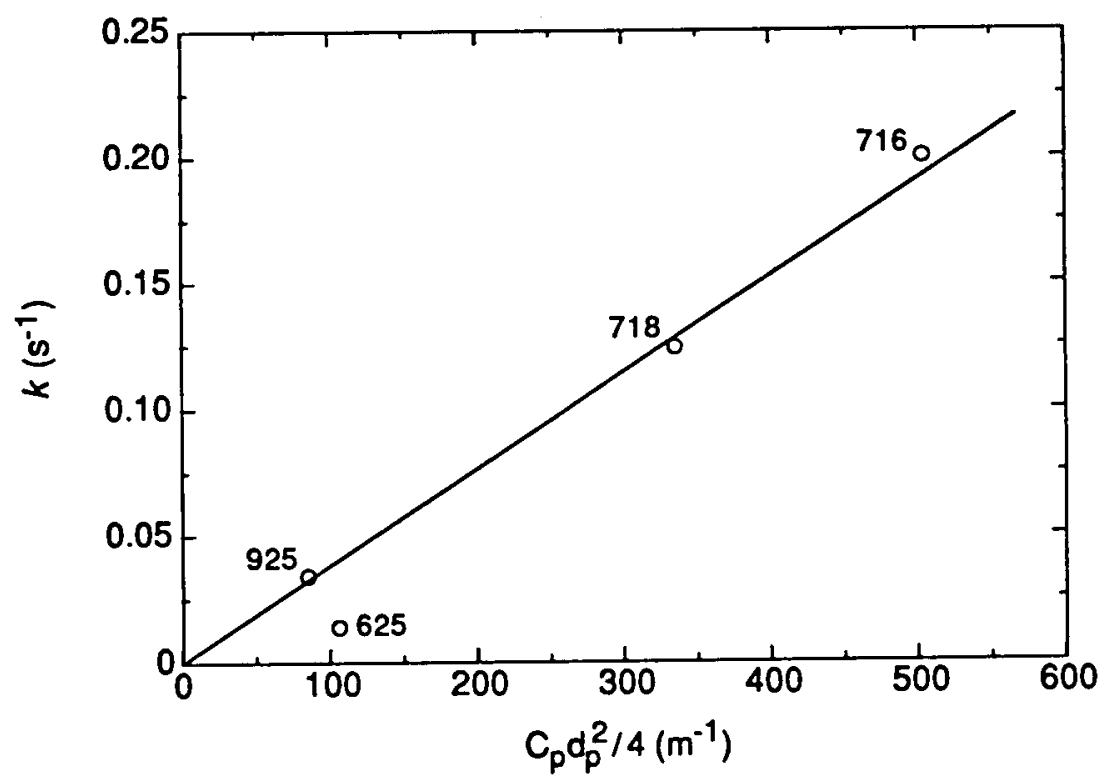

Figure 5-3. Dependence of $k$ on $\mathrm{C}_{\mathrm{p}}\left(\mathrm{d}_{\mathrm{p}} / 2\right)^{2}$ for Ni-base alloys containing particles. 
However, in one case (alloy 716), the resistance to HE can be attributed to a low entry flux. The irreversible trapping constant, by virtue of the observed correlation, appears able to indicate the relative resistance to $\mathrm{HE}$ for all the alloys except 716. This ability of $k$ seems to be attributable to its dependence on both the trapping capability and the diffusivity. The combination of these two characteristics is crucial for crack initiation and therefore provides a rationale for the correlation observed between $k$ and the resistance to HE. Various microstructural features can be identified as the principal irreversible traps, either singly or in the presence of multiple principal traps. Although $k$ is affected by the diffusivity, the variation in intrinsic susceptibility of the different Nicontaining alloys generally seemed to result from differences in the trapping capability caused by the diversity of sizes and concentrations of the microstructural defects.

\section{Acknowledgment}

Financial support of this work by the Office of Naval Research under Contract N00014-86-C-0233 is gratefully acknowledged.

\section{References}

1. I. M. Bernstein and G. M. Pressouyre: in Hydrogen Degradation of Ferrous Alloys, R. A. Oriani, J. P. Hirth, and M. Smialowski, eds., Noyes Publications, Park Ridge, NJ, 1985, pp. 641-85.

2. G. M. Pressouyre and I. M. Bernstein: Metall. Trans., 1978, vol. 9A, pp. 1571-80.

3. G. M. Pressouyre and I. M. Bernstein: Acta Metall., 1979, vol. 27, pp. 89-100.

4. B. G. Pound: Corrosion, 1989, vol. 45, pp. 18-25.

5. B. G. Pound: Acta Metall., 1990, vol. 38, pp. 2373-81.

6. B. G. Pound: Acta Metall., 1991, vol. 39, pp. 2099-105.

7. B. G. Pound: Corrosion, 1994, vol. 50, pp. 301-7.

8. B. G. Pound: Scripta Metall., 1993, vol. 29, pp. 1433-38.

9. B. G. Pound: Corrosion, 1991, vol. 47, pp. 99-104.

10. R. McKibbin, D. A. Harrington, B. G. Pound, R. M. Sharp, and G. A. Wright: Acta Metall., 1987, vol. 35, pp. 253-62.

11. B. G. Pound: in Modern Aspects of Electrochemistry, J. O'M. Bockris, B. E. Conway, and R. E. White, eds., Plenum Press, New York, NY, 1993, No. 25, pp. 63-133.

12. B. G. Pound, R. M. Sharp, and G. A. Wright: Acta Metall., 1987, vol. 35, pp. 263-70.

13. T. P. Groeneveld, E. E. Fletcher, and A. R. Elsea: "A Study of Hydrogen Embrittlement of Various Alloys," Tech. Support Package to Tech. Brief No. 67-10141, NASA, 1967.

14. R. J. Walter, R. P. Jewett, and W. T. Chandler: Mater. Sci. Eng., 1969/70, vol. 5, pp. 98 110.

15. C. G. Rhodes and A. W. Thompson: Metall. Trans., 1977, vol. 8A, pp. 949-54.

16. D. A. Mezzanotte, J. A. Kargol, and N. F. Fiore: Metall. Trans., 1982, vol. 13A, pp. 118186.

17. R. B. Frank and T. A. DeBold: "Properties of an Age-Hardenable, Corrosion-Resistant Nickel-Base Alloy," Corrosion 88, NACE, Houston, TX, 1988, Paper No. 75.

18. R. D. Kane, M. Watkins, D. F. Jacobs, and G. L. Hancock: Corrosion, 1977, vol. 33, pp. 309-20.

19. R. W. Schutz and D. E. Thomas: in Metals Handbook, ASM, Metals Park, OH, 1987, vol. 13, pp. 669-97.

20. M. Aucouturier, G. Lapasset, and T. Asaoka: Metallography, 1978, vol. 11, pp. 5-21.

21. B. J. Berkowitz and R. D. Kane: Corrosion, 1980, vol. 36, pp. 24-29.

22. R. D. Kane and B. J. Berkowitz: Corrosion, 1980, vol. 36, pp. 29-36.

23. D. H. Lassila and H. K. Birnbaum: Acta Metall., 1987, vol. 35, pp. 1815-22.

24. J. D. Frandsen and H. L. Marcus: in Effect of Hydrogen on the Behavior of Materials, I. M. Bernstein and A. W. Thompson, eds., TMS, Warrendale, PA, 1976, pp. 233-48.

25. A. E. Jenkins and H. W. Worner: J. Inst. Metal., 1951/52, vol. 80, p. 157. 
26. H. Sato, T. Fukuzuka, K. Shimogori, and H. Tanabe: "Hydrogen Pickup by Titanium Held Cathodic in Seawater," 2nd International Congress on Hydrogen in Metals, Paris, 1977.

27. E. Lunarska-Borowiecka and N. F. Fiore: Metall. Trans., 1981, vol. 12A, pp. 101-7.

28. G. M. Pressouyre: Metall. Trans., 1979, vol. 10A, pp. 1571-73.

\section{Addendum}

The concepts explored in the review above attempt to bring together the various aspects of hydrogen embrittlement ranging from hydrogen entry through trapping to cracking. These concepts could not be adequately discussed in the review and are therefore considered in more detail below.

\section{Intrinsic Susceptibility to HE}

The intrinsic susceptibility to HE is affected by a range of factors, but some of them would be expected to exert a greater influence than others and so be primarily responsible for determining the susceptibility. The irreversible trapping constant $(k)$ that was used as an index of the intrinsic susceptibility incorporates several key parameters: trap size, trap density, lattice diffusivity, and metal atom size. The local mechanical conditions are addressed to some extent through the trap size in the case of particles because of the strong influence that trap size has on the critical concentration $\left(C_{k}\right)$. $C_{k}$ is the concentration of $H$ required to cause enough of an increase in the induced and applied stresses and/or the hydrogen pressure to overcome the cohesive strength, which itself may be decreased (1). Since larger particles lead to higher local stress concentrations, the trap size affects $C_{k}$ (in part) by affecting the difference between the local stresses and cohesive strength. Hence, $k$, in allowing for trap size, implicitly contains some allowance for the effect of the local stress/cohesive strength conditions on $\mathrm{C}_{\mathbf{k}}$.

The correlation between $k$ and the observed resistance to HE suggests that $k$ contains enough key parameters to be effective as an index of susceptibility for the alloys studied at their respective yield strengths. The correlation for the high-strength steels is supported by recent trapping data for the aged martensitic steel, AerMet 100 (yield strength $=1834 \mathrm{MPa}$ ) (2). The order of the irreversible trapping constants for 4340 steel, $18 \mathrm{Ni}$ steel, and AerMet $100\left(k=0.41 \mathrm{~s}^{-1}\right)$ is consistent with their threshold stress intensities for stress corrosion cracking. Thus, it seems increasingly unlikely that the correlation for the high-strength steels is fortuitous. However, it is possible that factors other than those above could assume a greater role at low yield strengths, such that $k$ becomes inadequate as an index of susceptibility.

At high yield strengths, $k$ must decrease with decreasing yield strength of these steels, if it is to be consistent with the reported increase in $\operatorname{KISCC}_{\mathrm{ISC}}(3,4)$. The lattice diffusivity $\left(\mathrm{D}_{\mathrm{L}}\right)$ and therefore $k$ could be affected by the microstructural changes that occur as the tempering temperature is increased (yield strength decreased). However, it can be difficult to find appropriate values for $D_{L}$ because the measured diffusivities are usually affected by trapping. For the 4340 and $18 \mathrm{Ni}$ steels, $D_{L}$ was taken to be the diffusivity for $\alpha-\mathrm{Fe}$ and $\mathrm{Fe}-18 \mathrm{Ni}$, respectively, but it would have been more appropriate to use the diffusivity, if it were available, for the corresponding tempered martensitic lattice. It has been shown for a high-strength martensitic steel containing $0.4 \mathrm{C}-0.6 \mathrm{Mn}$ $0.3 \mathrm{Ni}$ (compared with $0.42 \mathrm{C}-0.46 \mathrm{Mn}-1.74 \mathrm{Ni}$ in the 4340 steel) that the diffusivity decreases as the tempering temperature is increased above the point where $\varepsilon$-carbide precipitation is essentially complete and quenched-in lattice defects have largely been relieved (5). Thus, although part of this decrease probably resulted from reversible trapping, it seems that a decrease in $D_{L}$ is quite plausible in the case of 4340 steel.

The value of $k$ for 4340 steel could also change because of a change in the type of principal irreversible trap and therefore in $\mathrm{N}_{\mathrm{i}} d^{2}$. Sulfide inclusions are important irreversible traps in 4340 
steel, as shown by thermal desorption results (6) and by differences in $\mathrm{H}$ absorption and outgassing between different grades of 4340 steel (7). However, incoherent $\mathrm{Fe}_{3} \mathrm{C}$ and high angle grain boundaries can also act as irreversible traps, though their presence in 4340 steel depends on the tempering conditions (8). It has been found that $\mathrm{MnS}$ inclusions act as traps in a low alloy steel $(0.34 \mathrm{C}-1 \mathrm{Cr})$ tempered at $300^{\circ} \mathrm{C}$, and precipitates come into play in specimens tempered at $600^{\circ} \mathrm{C}$ (9). Hence, it is possible that sulfide inclusions provide the predominant irreversible traps in 4340 steel at very high yield strengths (low tempering temperatures) where there is negligible $\mathrm{Fe}_{3} \mathrm{C}$ and another defect becomes the principal trap as the yield strength is decreased.

The cracking behavior of 4340 steel is strongly influenced by the relative importance of the different irreversible traps (8). Prominent particle-type traps such as large (even round) inclusions have a high probability of cutting or lying along grain boundaries, and cracks initiated at the inclusions are then likely to follow the relatively susceptible grain boundary (10). The importance of each trap depends on its density and size, so cracking can be affected by the grade of 4340 steel and its yield strength (heat treatment) as well as by the level of elements such as $\mathrm{Mn}$ (11)-Mn, for example, is detrimental (12) when segregated to grain boundaries in high strength steels. It is therefore important that the interpretation of cracking behavior in terms of trapping be made on the basis of comparable specimens for the respective tests.

The possibility also exists that some type of defect other than sulfide inclusions provides the principal irreversible trap in 4340 steel, even at high yield strengths. The trap density calculated on the basis of sulfide inclusions differed from the actual concentration of inclusions by a factor of 10 , which was regarded as being reasonably close. (It was also reported that $\mathrm{N}_{\mathbf{i}}$ did not change significantly with heat treatment, but this conclusion was based on the rough approximation that $\mathrm{D}_{a}$ did not vary significantly with heat treatment.) However, this difference may imply that the sulfide inclusions were not the principal traps. If incoherent $\mathrm{Fe}_{3} \mathrm{C}$ or high angle grain boundaries were the principal traps, $\mathrm{N}_{\mathrm{i}} d^{2}$ and therefore $k$ for 4340 steel would be expected to change with heat treatment.

In maraging steels, the resistance to $\mathrm{H}$-assisted cracking (generally intergranular) is thought to be lowered by $\mathrm{Ti}(\mathrm{CN})$ particles (4). Autoradiography has shown that hydrogen trapping occurs at the carbonitride interfaces in maraging steels, and this trapping is reported to be strong enough to explain crack initiation; the interface between the carbonitride particle and its matrix appears to be weakened by trapped hydrogen (13). The trap density and concentration of $\operatorname{TiC} / \mathrm{Ti}(\mathrm{CN})$ particles in the $18 \mathrm{Ni}$ steel used in the present work differed by a factor of $\sim 30$ but were considered to be moderately close, for reasons given in the paper. As with 4340 steel, this difference may in fact indicate that these particles were not the principal traps. Still, the carbides/carbonitrides were $>1$ $\mu \mathrm{m}$ in size, which puts them in the category of detrimental-rather than beneficial-traps, as designated by Bernstein and Pressouyre (14). In the case of the Ni-base alloys, carbides and carbonitrides were generally identified as the principal traps, and various studies have shown that fracture is typically initiated by void formation at matrix carbides (15).

1. G. M. Pressouyre and I. M. Bernstein: Metall. Trans., 1981, vol. 12A, pp. 835-44.

2. B. G. Pound: "The Characterization of Hydrogen Ingress in High-Strength Alloys by a Potentiostatic Pulse Technique," Annual Report to the Office of Naval Research, Contract No. N00014-91-C-0263, 1994.

3. G. Sandoz: Metall. Trans, 1972, vol. 3, pp. 1169-76.

4. D. P. Dautovich and S. Floreen: in Proceedings of the Conference on Stress Corrosion Cracking and Hydrogen Embrittlement of Iron-Base Alloys, R. W. Staehle, J. Hochman, R. D. McCright, and J. E. Slater, eds., NACE, Houston, TX, 1977, p. 798-815.

5. T. P. Radhakrishnan and L. L. Shreir: Electrochim. Acta, 1967, vol. 12, pp. 889-903. 
6. J. Y. Lee, J. L. Lee, and W. Y. Choo: in Proceedings of 1st International Conference on Current Solutions to Hydrogen Problems, C. G. Interrante and G. M. Pressouyre, eds., ASM, Metals Park, OH, 1982, pp. 423-27.

7. J. A. Kargol and L. D. Paul: in Proceedings of 1st International Conference on Current Solutions to Hydrogen Problems, C. G. Interrante and G. M. Pressouyre, eds., ASM, Metals Park, OH, 1982, pp. 91-97.

8. R. Gibala and D. S. DeMiglio: in Proceedings of 3rd International Conference on Effect of Hydrogen on Behavior of Materials, I. M. Bernstein and A. W. Thompson, eds., TMS, Warrendale, PA, 1980, pp. 113-22.

9. T. Asaoka: in Proceedings of JIMIS-2, "Hydrogen in Metals," Minakami, Jpn. Inst. Met., 1980, p. 161.

10. I. M. Bernstein and G. M. Pressouyre: in Hydrogen Degradation of Ferrous Alloys, R. A. Oriani, J. P. Hirth, and M. Smialowski, eds., Noyes Publications, Park Ridge, NJ, 1985, pp. 641-85.

11. G. Sandoz: Metall. Trans., 1971, vol. 2, pp. 1055-63.

12. C. J. McMahon, Jr., J. Kameda, and N. Bandyopadhyay: 2nd Japanese Institute of Metals Symposium on Hydrogen in Metals, Tokyo, 1979; cited by J. P. Hirth: Metall. Trans., 1980, vol. 11A, pp. 861-90.

13. M. Aucouturier, G. Lapasset, and T. Asaoka: Metallography, 1978, vol. 11, pp. 5-21.

14. G. M. Pressouyre and I. M. Bernstein: Acta Metall., 1979, vol. 27, pp. 89-100.

15. N. R. Moody, M. W. Perra, and S. L. Robinson: in Proceedings of the 4th International Conference on Hydrogen Effects on Material Behavior, N. R. Moody and A. W. Thompson, eds., TMS, Warrendale, PA, 1990, pp. 625-35.

\section{Verification of Diffusion/Trapping Model}

Both a constant concentration and a constant flux have been assumed as the input boundary condition in models for hydrogen diffusion in metals; however, models that allow for trapping in the conventional permeation methods deal only with the constant concentration case. Limitations in the use of a constant concentration boundary condition have been discussed elsewhere (1). In our work, the constant flux model was found to apply to all the alloys studied under the charging conditions imposed by the pulse technique. As noted in the paper, it was possible to determine a trapping constant for which the entry flux was independent of charging time at each potential. This condition had to be satisfied for the model to be applicable. Also, the trapping constant was independent of charging potential (except when a change in trapping behavior occurred), as is required for the model to be valid, since the trapping characteristics at low occupancy should be unaffected by electrochemical conditions at the metal surface. Any attempts to apply the constant concentration form of the diffusion/trapping model to these alloys have been unsuccessful.

1. B. G. Pound: in Modern Aspects of Electrochemistry, J. O'M. Bockris, B. E. Conway, and R. E. White, eds., Plenum Press, New York, NY, 1993, No. 25, pp. 63-133.

\section{Effect of Different Irreversible Traps}

It must be emphasized that the observed correlation between the intrinsic susceptibility, as defined by $k$, and the observed resistance to $\mathrm{HE}$ applies to the specific alloys studied in their particular thermomechanical conditions. This correlation may not extend to these alloys at lower yield strengths or to other alloys. As noted in the paper, exceptions to the correlation can occur when the entry flux is so low, as with alloy 716 , that it becomes the primary factor in determining the resistance to $\mathrm{HE}$. 
Defect size can also be an important factor. Your work (1) has shown that homogeneously distributed, small particles $(\ll<1 \mu \mathrm{m}$ for $\alpha-\mathrm{Fe})$ that are irreversible traps can be beneficial. Thus, the addition of small particles imparting high values of $C_{k}$ to a metal that is otherwise free of irreversible traps would not be expected to reduce the resistance to $\mathrm{HE}$. On the other hand, these particles are supposedly small enough that the concentration of trapped $\mathrm{H}\left(\mathrm{C}_{\mathrm{H}}\right)$ cannot reach $\mathrm{C}_{\mathbf{k}}$, so their presence will not increase the intrinsic susceptibility. Accordingly, $k$ should not be used as an index of susceptibility in this case; the relationship between $k$ and $\mathrm{N}_{\mathrm{j}} d^{2}$ (Eq. [5-2] in the review) implicitly applies to particles that are large enough for $\mathrm{C}_{\mathrm{H}}$ to be able to reach $\mathrm{C}_{\mathbf{k}}$. If detrimental traps are present in an alloy, the addition of small particles will increase the HE resistance by delaying the accumulation of $\mathrm{H}$ at the detrimental traps. In this sense, small particles can have the same effect as a decrease in the entry flux.

In practice, most irreversible traps are characterized by large specific saturabilities, as noted by Gibala and DeMiglio (2). The majority of the engineering alloys in our work contained carbides, carbonitrides, or sulfides that were in the form of large particles ( $>1 \mu \mathrm{m}$ and typically several micrometers) and, as might be expected, it was these particles that provided the principal irreversible traps. Such particles are known to be conducive to HE, particularly if they are distributed heterogeneously (1). Thus, the addition of large traps, unlike small traps, increases the intrinsic susceptibility (higher $k$ ) and is expected to result in a corresponding decrease in the actual resistance to $\mathrm{HE}$, which fits with the observed correlation.

1. G. M. Pressouyre and I. M. Bernstein: Acta Metall., 1979, vol. 27, pp. 89-100.

2. R. Gibala and D. S. DeMiglio: in Proceedings of 3rd International Conference on Effect of Hydrogen on Behavior of Materials, I. M. Bernstein and A. W. Thompson, eds., TMS, Warrendale, PA, 1980, pp. 113-22. 